\title{
The transmission and segregation of mitochondrial DNA mutations
}

Citation for published version (APA):

Jacobs, L. J. A. M. (2007). The transmission and segregation of mitochondrial DNA mutations. [Doctoral Thesis, Maastricht University]. Maastricht University. https://doi.org/10.26481/dis.20071213lj

Document status and date:

Published: 01/01/2007

DOI:

10.26481/dis.20071213lj

Document Version:

Publisher's PDF, also known as Version of record

\section{Please check the document version of this publication:}

- A submitted manuscript is the version of the article upon submission and before peer-review. There can be important differences between the submitted version and the official published version of record.

People interested in the research are advised to contact the author for the final version of the publication, or visit the DOI to the publisher's website.

- The final author version and the galley proof are versions of the publication after peer review.

- The final published version features the final layout of the paper including the volume, issue and page numbers.

Link to publication

\footnotetext{
General rights rights.

- You may freely distribute the URL identifying the publication in the public portal. please follow below link for the End User Agreement:

www.umlib.nl/taverne-license

Take down policy

If you believe that this document breaches copyright please contact us at:

repository@maastrichtuniversity.nl

providing details and we will investigate your claim.
}

Copyright and moral rights for the publications made accessible in the public portal are retained by the authors and/or other copyright owners and it is a condition of accessing publications that users recognise and abide by the legal requirements associated with these

- Users may download and print one copy of any publication from the public portal for the purpose of private study or research.

- You may not further distribute the material or use it for any profit-making activity or commercial gain

If the publication is distributed under the terms of Article $25 \mathrm{fa}$ of the Dutch Copyright Act, indicated by the "Taverne" license above, 
The transmission and segregation of mitochondrial DNA mutations 
(C)Lorraine J.A.M Jacobs, Someren 2007 ISBN 978-90-8891-022-7

Cover design

Lorraine Jacobs

Printed by proefschriftmaken.nl 


\section{Transmission and segregation of Mitochondrial DNA mutations}

\section{Proefschrift}

ter verkrijging van de graad van doctor

Aan de universiteit van Maastricht,

op gezag van de Rector Magnificus,

Prof. Mr. G.P.M.F. Mols

volgens het besluit van het college van Decanen,

in het openbaar te verdedigen,

Op Donderdag 13 December om 12.00 uur

Door

Lorraine Johanna Arnolda Maria Jacobs

Geboren te Bakel op 26 mei 1975 


\title{
Promotor
}

Prof.dr. J.P.M. Geraedts

\author{
Co-promotor \\ Dr. H.J.M. Smeets
}

Dr. I.F.M. de Coo

Beoordelingscommissie

Prof.dr. J.L.H. Evers (voorzitter)

Prof.dr. P.F. Chinnery (University of Newcastle upon Tyne, UK)

Dr. C.E.M. de Die-Smulders

Prof.dr. I. Liebaers (University Hospital Vrije Universiteit Brussel, België)

Prof.dr. J.S.H. Vles

Studies described in this thesis were performed at the department of Genetics and Cell Biology, Research institute GROW (Growth and development), Maastricht University, The Netherlands.

Financial support for the publication of this thesis was granted by Eurofins Medinet B.V., Greiner Bio-one B.V. and Affymetrix. 


\section{Contents}

Chapter 1 Introduction

Aims and outline of this thesis

Chapter 2 The transmission of OXPHOS disease and methods to prevent this

Chapter 3 Pearson syndrome and the role of deletion dimers and duplications in the mtDNA

Chapter 4 Transmission and prenatal diagnosis of the T9176C mitochondrial DNA mutation

Chapter 5 Skewed heteroplasmy levels in single fibroblasts and lymphocytes of carriers of the Leigh syndrome m.9176T $>$ C mutation

Chapter 6 MtDNA point mutations are present at various levels of heteroplasmy in human oocytes

Chapter 7 General discussion

Summary

Samenvatting

Dankwoord

Curriculum Vitae

Publications and Abstracts 
Het wonder van een nieuw leven blijft ons verstand te boven gaan 
Chapter

Introduction 


\section{Introduction}

Mitochondrial encephalomyopathies are disorders associated with abnormalities of the terminal component of mitochondrial energy metabolism, i.e. oxidative phosphorylation (OXPHOS). Recent epidemiological studies have shown that $\sim 1$ in 8000 of the general population have an OXPHOS disorder (Chinnery, 2004). OXPHOS related diseases therefore cause significant morbidity and mortality. OXPHOS defects have a broad impact on public health, as they have been encountered in age-related neurodegenerative diseases, cardiovascular disease, diabetes, and cancer (Zeviani and Di Donato, 2004; Ritz and Berrut, 2005; Baysal, 2006). OXPHOS is carried out in the inner mitochondrial membrane by the four enzymatic complexes of the respiratory chain (complexes I-IV), plus the ATP-synthase complex (complex V) (Hatefi, 1985; Saraste, 1999). OXPHOS disease can be due to mutations in mitochondrial DNA (mtDNA) or nuclcar DNA genes. This implicates a dual genetic control and intergenomic interactions. The nuclear component includes more than 70 genes encoding protein subunits of the OXPHOS complexes and hundreds of genes encoding factors controlling their expression, assembly, function and turnover (Thorburn et al., 2004). An impressive and ever expanding number of pathogenic mutations in the mtDNA have been found in association with a wide spectrum of clinical presentations (Zeviani and Di Donato, 2004). Mutations in mtDNA include either large-scale rearrangements, which are in general sporadic, or point mutations, which are usually transmitted through the maternal lineage. While large-scale rearrangements are invariably heteroplasmic, point mutations may be either heteroplasmic or homoplasmic, and can affect structural genes or genes encoding the RNA apparatus (22 tRNA- and 2 rRNA-genes are encoded by the mtDNA) involved in mtDNA translation (Chinnery and Turnbull, 1999).

One of the intriguing features of OXPHOS disease is the extremely variable clinical presentation. It has been described that OXPHOS disease might affect any tissue and disease can manifest itself at any age. This truism is held up in clinical practice and patients may present in their first few hours after birth or in their 70's and 80's. Another important clinical issue relates to the potential involvement of a variety of different tissues. Thus, a patient with OXPHOS disease might present neurological features and subsequently develop diabetes or cardiomyopathy. These other clinical features may well be those, which are most lifethreatening and important with regard to treatment. As far as heteroplasmic mtDNA mutations are concerned, some correlation between mutation load and clinical or biochemical manifestations has been established for few of them. However, the basis of the wide variability of clinical and biochemical features observed in OXPHOS disease remains largely unknown. Likewise, little is known about the mechanisms underlying the tissue specificity consistently reported for some mutations or, on the contrary, the widespread involvement of multiple organs, observed in other mutations, and the variations in the clinical presentations observed in different individuals carrying the same mutation. The extreme clinical, biochemical and genetic variability that characterises OXPHOS disorders creates major difficulties in clinical practice and laboratory diagnosis. This is of particular concern as 
treatment is limited for patients with OXPHOS disease and common genetic approaches to prevent the transmission of OXPHOS disease are not applicable for the majority of patients with mtDNA defects. The unpredictable transmission of heteroplasmic mtDNA mutations, due to the genetic bottleneck [a restriction in the number of mtDNA molecules to be transmitted followed by an amplification of these founder molecules (Howell et al., 1992)], the somatic variability in heteroplasmy levels between tissues and in time and the poor predictive value of heteroplasmy levels preclude conventional prenatal diagnosis as a reliable option for most carriers.

\section{Aims and outline of thesis}

The main topic of this thesis is to define the somatic segregation and familial transmission and, as well, the origin of hetcroplasmic mtDNA mutations. This is related to their clinical expression and possible modifying factors. Our aims are:

- to develop reliable tools that can predict and/or prevent the transmission of mitDNA mutations, like prenatal diagnosis or preimplantation genetic diagnosis, in order to prevent the transmission of OXPHOS disease;

- to identify factors that influence the severity and nature of the phenotypic manifestations or distribution of the mtDNA load, in order to predict the effect of transmission of mtDNA mutations more accurately;

- to determine the presence and impact of de novo mtDNA mutations in oocytes

Chapter 2 is an introduction on the transmission of OXPHOS disease and methods to prevent this. The OXPHOS system is under dual genetic control, and mutations in both nuclear and mitochondrial genes can cause OXPHOS diseases. The expression and segregation of mitochondrial DNA (mtDNA) mutations is different from nuclear gene defects. The mtDNA mutations can be either homoplasmic or heteroplasmic and in the latter case disease becomes manifest when the mutation exceeds a tissue-specific threshold. This mutation load can vary between tissues and often an exact correlation between mutation load and phenotypic expression is lacking. The transmission of mtDNA mutations is exclusively maternal, but the mutation load between embryos can vary tremendously because of a segregational bottleneck. Diseases by nuclear gene mutations show a normal Mendelian inheritance pattern and often have a more constant clinical manifestation. Given the prevalence and severity of OXPHOS disorders and the lack of adequate therapy, existing and new methods for the prevention of transmission of OXPHOS disorders, like prenatal diagnosis (PND), preimplantation genetic diagnosis (PGD), cytoplasmic transfer (CT) and nuclear transfer (NT), are technically and ethically evaluated.

In chapter 3 and 4 we describe patients with rearrangements or a point mutation in the mtDNA, the former to identify clues to improve the predictive power of the genetic analysis and the latter to evaluate the possibility PND or PGD for this mutation. In chapter 3 we compare in detail the genetic defects and clinical outcome in 2 patients with Pearson 
syndrome, an often fatal multisystem disease associated with mitochondrial DNA rearrangements, to identify factors, which might be involved in and can predict the severity of the disorder. Chapter 4 describes a family with three affected children with Leigh syndrome, a progressive neurodegenerative disorder. Mutation analysis revealed the T9176C mutation in the mtDNA ATPase 6 gene. The possibility of prenatal diagnosis was evaluated. The main problem was the lack of data on genotype-phenotype associations for the T9176C mutation and on variation of the mutation percentage in tissues and in time. Eventually, prenatal diagnosis was offered with understanding by the couple that there could be considerable uncertainty in the interpretation of the results. To get a better insight in the distribution of mtDNA mutations among single cells and the potential use for counselling carriers with respect to recurrence risks, we studied single lymphocytes and fibroblasts of several relatives with the m.9176T $>C$ mutation (chapter 5). Possible differences in distribution may also reveal mechanisms involved in the segregation of mtDNA mutations, which could open up the possibility to manipulate variations in heteroplasmy levels. The basic mechanisms concerning the origin of de novo point mutations in the mtDNA were studied in human oocytes (chapter 6). As a large part of patients with OXPHOS defects carry de novo mutations in the mtDNA we determined the load of mutations and polymorphisms in the mitochondrial DNA (mtDNA) of human oocytes and we discussed the time frame in which these mutations can occur and the possible effect these mutations might have during life. Finally, in the general discussion (chapter 7) we evaluate strategies to influence heteroplasmy and to complement the existing genetic defect and we elaborate further on possible approaches to prevent the transmission of mtDNA caused OXPHOS disease, in case PND and PGD is not a reliable alternative.

\section{References}

Baysal BE (2006) Role of mitochondrial mutations in cancer. Endocr Pathol 17,203-212.

Chinnery PF (2004) New approaches to the treatment of mitochondrial disorders. Reprod Biomed Online 8,16-23.

Chinnery PF and Turnbull DM (1999) Mitochondrial DNA and disease. Lancet 354 Suppl 1,SI1 7-21.

Hatefi Y (1985) The mitochondrial electron transport and oxidative phosphorylation system. Annu Rev Biochem 54,1015-1069.

Howell N, Halvorson S, Kubacka I, McCullough DA, Bindoff LA and Tumbull DM (1992)

Mitochondrial gene segregation in mammals; is the bottleneck always narrow? Hum Genet 90,117-120.

Ritz $P$ and Berrut $G$ (2005) Mitochondrial function, energy expenditure, aging and insulin resistance.

Diabetes Metab 31 Spec No 2,5S67-65S73.

Saraste M (1999) Oxidative phosphorylation at the fin de siecle. Science 283,1488-1493.

Thorbum DR, Sugiana C, Salemi R, Kirby DM, Worgan L, Ohtakc A and Ryan MT (2004)

Biochemical and molecular diagnosis of mitochondrial respiratory chain disorders. Biochim Biophys Acta $1659,121-128$.

Zeviani M and Di Donato S (2004) Mitochondrial disorders. Brain 127,2153-2172. 


\section{$\underline{a m} 2$}

The transmission of OXPHOS disease and methods to prevent this

LJAM Jacobs ${ }^{1,2}, G$ de Wert ${ }^{3}$, JPM Geraedts ${ }^{1}$, IFM de Coo ${ }^{4}$, HJM Smeets ${ }^{1}$. ${ }^{1}$ Department of Genetics and Cell Biology, ${ }^{2}$ Research Institute GROW, ${ }^{3}$ Department of Ethics and Philosophy, University Maastricht.

${ }^{4}$ Department of Child Neurology, Erasmus MC-University Medical Center Rotterdam.

Human Reproduction Update, Vol.12, No.2 pp. 119-136, 2006 


\begin{abstract}
Diseases due to defects of oxidative phosphorylation (OXPHOS) affect approximately 1 in 8,000 individuals. Clinical manifestations can be extremely variable and range from single affected tissues to multisystemic syndromes. In general tissues with a high energy demand, like brain, heart and muscle, are affected. The OXPHOS system is under dual genetic control and mutations in both nuclear and mitochondrial genes can cause OXPHOS diseases. The expression and segregation of mitochondrial DNA (mtDNA) mutations is different from nuclear gene defects. The mtDNA mutations can be either homoplasmic or heteroplasmic and in the latter case disease becomes manifest when the mutation exceeds a tissue-specific threshold. This mutation load can vary between tissues and often an exact correlation between mutation load and phenotypic expression is lacking. The transmission of mtDNA mutations is exclusively maternal, but the mutation load between embryos can vary tremendously due to a segregational bottleneck. Diseases by nuclear gene mutations show a normal Mendelian inheritance pattern and often have a more constant clinical manifestation. Given the prevalence and severity of OXPHOS disorders and the lack of adequate therapy, existing and new methods for the prevention of transmission of OXPHOS disorders, like prenatal diagnosis, preimplantation genetic diagnosis, cytoplasmic transfer and nuclear transfer, are technically and ethically evaluated.
\end{abstract}




\section{Mitochondrial disorders}

Mitochondrial disorders are a group of diseases and syndromes commonly defined by lack of energy due to defects in oxidative phosphorylation (OXPHOS) (Zeviani and Di Donato, 2004). They affect at least 1 in 8000 of the general population, making them the most common inherited metabolic diseases (Chinnery, 2004). Energy in the form of ATP is produced by the OXPHOS system, which consists of five multiprotein enzyme complexes that release the energy stored in the form of a proton gradient across the inner mitochondrial membranc (Saraste, 1999). Disease manifestations due to OXPHOS defects usually involve tissues with a high energy demand like brain, heart, liver and the renal and endocrine systems (Wallace, 1999). Clinical manifestations of OXPHOS diseases are extremely variable and range from a single affected tissue, like the loss of vision in Leber's hereditary optic neuropathy (LHON), to multisystemic syndromes like Leigh syndrome (subacute necrotizing encephalomyelopathy, LS), mitochondrial encephalopathy, lactic acidosis and stroke like episodes (MELAS), neuropathy, ataxia and retinitis pigmentosa (NARP) and myoclonic epilepsy with ragged red fibres (MERRF). Table I lists several syndromes and symptoms associated with OXPHOS disease. Involvement of the central nervous system, skeletal muscle or both is seen in many mitochondrial syndromes. A frequent symptom in paediatric patients is developmental delay and failure to thrive. Symptoms can present in just a single tissue or organ, but a multiorgan involvement in a patient or affected relatives is more common. When at least two organ systems unexplained by other diseases are involved in a single person or in affected (maternal) relatives, then an OXPHOS disease should be considered. Clinicians should be aware that apparently unrelated symptoms might have a common genetic cause. 


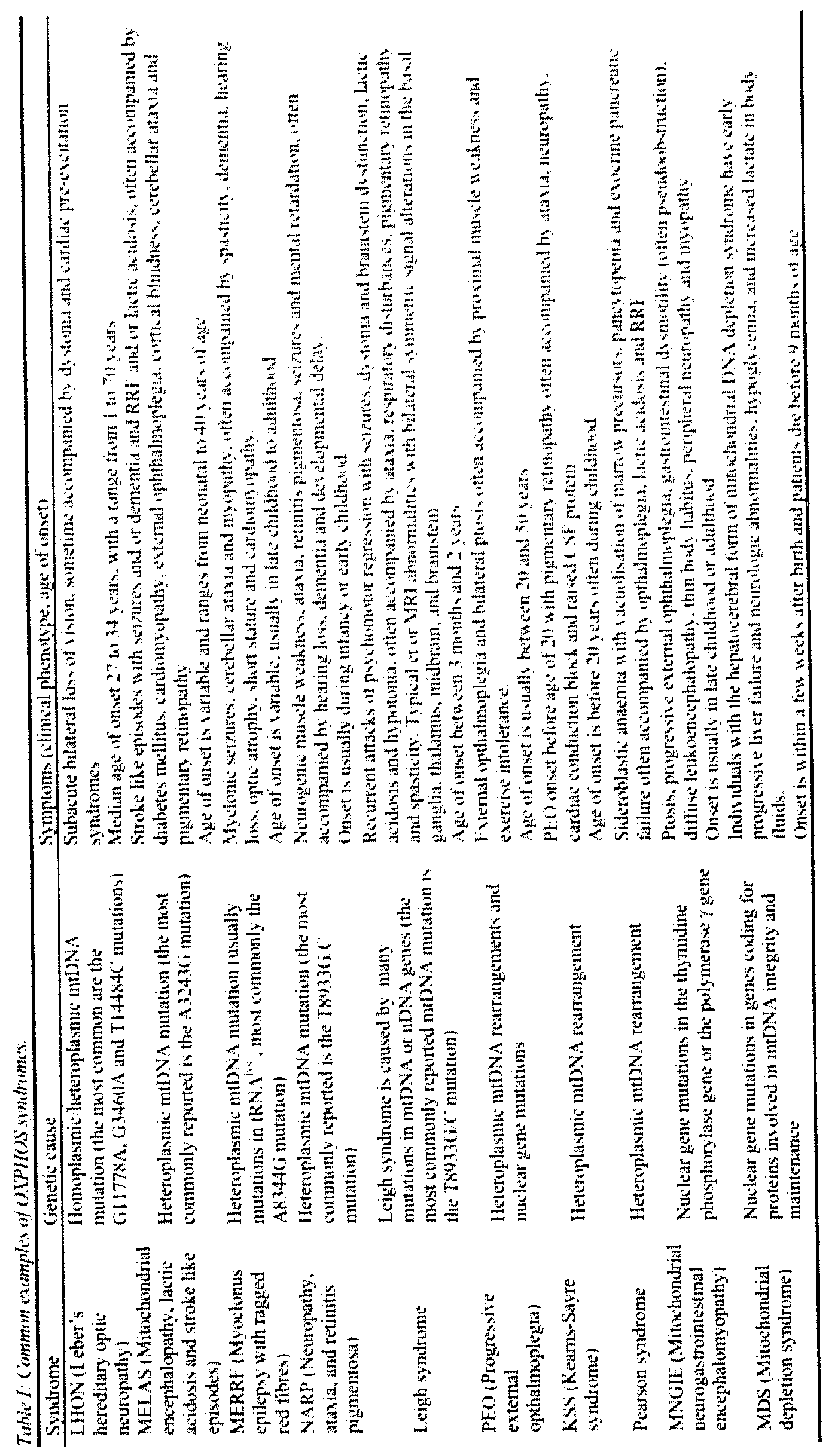




\section{Mitochondrial DNA (mtDNA)}

The first description of a circular DNA structure located in the mitochondria dates from 40 years ago (Nass, 1966). Several unique characteristicsdiscriminate mitochondrial from nuclear DNA:

1. The mtDNA is a multicopy genome. A cell contains hundreds of mitochondria and each mitochondrion contains five to ten copies of mtDNA (Goto, 2001). Dependent on the tissue and energy demand each cell contains between 500-10000 mtDNA molecules, except for mature oocytes which contain between 100000 and 600000 mtDNA molecules (Reynier $e t$ $a l ., 2001)$. Oocytes store mitochondria to deal with the lack of mtDNA replication during the first cleavage stages of the embryo (Schaefer et al., 2001).

2. In a cell all mtDNA molecules can be identical (homoplasmy), or two types of mtDNA molecules, that differ in sequence, in the same cell, tissue or even in the same organelle can coexist (heteroplasmy, (Holt et al., 1988; Lightowlers et cl., 1997).

3. The mtDNA is transmitted entirely through the maternal linc.

4. The mtDNA is a double stranded circle (figure 1) of 16.569 bp with a genetic code different from the nuclear DNA (Fernandez-Silva et al., 2003). The mtDNA encodes 37 genes, of which 13 genes encode OXPHOS subunits (complex I (7), III (1), IV (3) and V (2)) and 22 tRNA- and 2 rRNA-genes, required for mitochondrial translation (Clayton, 1991;

Wallace et al., 1995). Approximately $6 \%$ of the mtDNA is noncoding, located predominantly in the D-loop and involved in the replication and transcription of the mtDNA (Berdanier and Everts, 2001). The mtDNA is compact, it contains no introns, several overlapping genes and incomplete termination codons (Lightowlers et al., 1997).

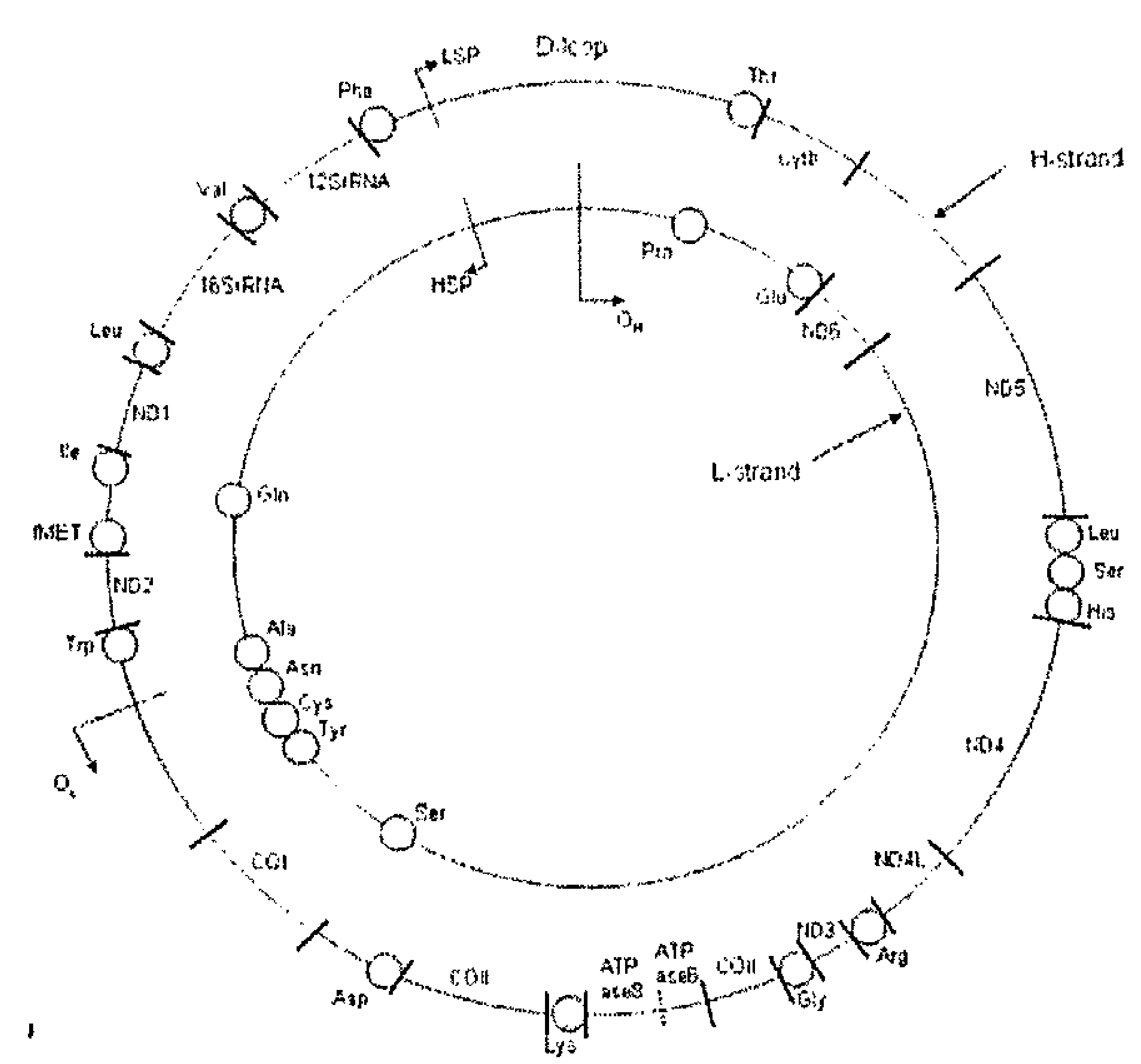

initiated; HSP: H-strand promoter; LSP: L-strand promoter.
Figure I

Map of the human mtDNA presenting the protein coding genes for the seven subunits of complex I (NDI-ND6), the three subunits of cytochrome $c$ oxidase (COI-COIII), cytochrome b (cytb) and the two subunits of ATP synthase (ATPase 6 and 8); the $12 S$ and 165 ribosomal RNAs (rRNAs); and the 22 transfer RNAs ( $t R N A s)$ identified by the three letter code for the corresponding amino acids. Furthermore the location of the origin of replication of both the $H\left(O_{H}\right)$ and $L\left(O_{L}\right)$ strands are indicated as well as the location of the promoter site were transcription is 
MtDNA molecules are packed in somatic cells as nucleoids in which 6 to 10 molecules form a group with several different proteins (Jacobs et al., 2000; Iborra et al., 2004; Legros et al., 2004). These nucleoids are no static entities and mtDNA molecules exchange between nucleoids. The nucleoids are attached to the inner mitochondrial membrane near the OXPHOS system, where reactive oxygen species (ROS) are being produced (Richter et al., 1988). Due to the lack of histones and other protective proteins and an ineffective repair mechanism the mtDNA mutates ten to sixteen times as frequent as the nuclear DNA and duc to the lack of introns the mutations have a high probability of affecting genes and being pathogenic (Larsson and Clayton, 1995; Treem and Sokol, 1998).

\section{Replication, transcription and translation of the mtDNA}

Replication of the mtDNA is called relaxed, because it is not connected to the cell cycle, and there is a constant degradation and production of mtDNA (Chinnery and Samuels, 1999). Replication of mtDNA takes place in post-mitotic terminally differentiated cells. In most cell types two possible mechanisms for the replication of the mtDNA exist (Bowmaker et al., 2003; Holt and Jacobs, 2003; Reyes et al., 2005). The strand displacement mechanism involves unidirectional initiation from the origin of replication of the "heavy" $\mathrm{H}$-strand $\left(\mathrm{O}_{\mathrm{H}}\right)$ located in the D-loop region of the mtDNA molecule (figure 1 ). The replication of this leading strand initiates the synthesis of the lagging-strand from the light $\mathrm{L}$-strand origin of replication $\left(\mathrm{O}_{\mathrm{L}}\right)$ (Shadel and Clayton, 1997; Bogenhagen and Clayton, 2003). Alternatively, strand-coupled replication of the mtDNA implies initiation of lagging strand synthesis at multiple sites probably involving the synthesis of short Okazaki fragments (Holt et al., 2000; Bogenhagen and Clayton, 2003). The original strand displacement mechanism is probably the main replication method in cells which are in a stcady state level whereas the strand coupled model seems to be predominant in cells recovering after depletion and in cells in need of accelerating mtDNA synthesis (Holt et al., 2000; Fish et al., 2004). The mtDNA is synthesized by a mitochondrial specific polymerase, DNA polymerase gamma (POLG), which requires additional factors like Twinkle (a ring helicase, (Spelbrink et al., 2001)) and mitochondrial topoisomerases I and II responsible for respectively the removal and introduction of supercoils in the mtDNA (Kosovsky and Soslau, 1993; Zhang et al., 2001). The mechanism regulating mtDNA replication is still not completely understood. Tfam, a limiting factor, and the size of the nucleoside pool are known to play an important role in the regulation of the mtDNA copy number (Ekstrand et al., 2004; Kanki et al., 2004; Kang and Hamasaki, 2005) but other factors will exist (Kaukonen et al., 2000; Brown and Clayton, 2002).

Transcription of the mtDNA requires mtRNA polymerase, mitochondrial transcription factor A (Tfam) and B1 or B2 (TFB1M or TFB2M) and several other trans-acting factors (Gaspari et al., 2004; Kang and Hamasaki, 2005). L-strand transcription is initiated at the Lstrand promoter (LSP) and results in a single polycistronic precursor RNA. The H-strand is transcribed by two overlapping units starting at two different initiation sites $\mathrm{HSP}_{1}$ and $\mathrm{HSP}_{2}$ 
(Fernandez-Silva et al., 2003). Transcription can be regulated at the level of initiation, termination, by the mitochondrial transcription termination factor (mTERF) (Asin-Cayuela et al., 2005), or both. Autonomous regulation of the mtDNA transcription occurs as in isolated mitochondria the transcription of mtDNA continues for several hours (Enriquez et al., 1996). External signals, which play a role in the transcription regulation are for example ATP levels in the cells and thyroid hormones (Enriquez et al., 1996; Weitzel et al., 2003).

In humans mitochondrial translation occurs at the mitochondrial ribosomes (Sasarman et al., 2002), composed of a small ribosomal subunit (the 12S rRNA subunit encoded by the mtDNA and 29 nuclear encoded proteins) and a large ribosomal subunit (the 16S rRNA subunit encoded by the mtDNA and 48 nuclear encoded proteins) (Koc, E.C. et al., 2001; Koc, E. C. et al., 2001). Additional factors are initiation factors (IF2 and IF3 (Ma and Spremulli, 1996; Koc and Spremulli, 2002)), elongation factors (EFTu (Ling et al., 1997), EFTs (Xin et al., 1995), EFG1 (Gao et al., 2001) and EFG2 (Lochmuller et al., 1999; Hammarsund et al., 2001)) and release factors (RFI (Zhang and Spremulli, 1998)).

\section{Biochemical investigations in OXPHOS disease}

In general lactate (cell redox state, normal $<20$ ) and alanine levels are increased. Histochemical studies of skeletal muscle with accumulation of abnormal mitochondria under the sarcolemmal membrane in muscle fibres [Ragged Red Fibres (RRF)] or cytochrome oxidase (COX) negative fibres confirm mitochondrial dysfunction. Electron microscopy may provide additional information. Biochemical studies carried out in skeletal muscle or cultured skin fibroblasts or in any other (preferably affected) available tissue can determine enzyme deficiencies in one or more of the OXPHOS enzyme complexes (van den Heuvel and Smeitink, 2001). Spectrophotometric methods or Blue Native polyacrylamide gel electrophoresis combined with histochemistry (BN-PAGE) can both be applied to determine the activity of the individual OXPHOS complexes or combinations of complexes (Munnich and Rustin, 2001). (Van Coster et al., 2001). These biochemical measurements are preferably performed in fresh muscle specimens or other fresh tissues clinically expressing the disease, as frozen muscle or cultured fibroblasts do not always present the enzymatic deficiencies. Some difficulties are associated with the biochemical analysis. Normal variation in enzyme activity is high and therefore the frequently detected moderate decreases in activity remain inconclusive. Furthermore, substantial variation exists in normal activity range as determined by different centres, because of the use of different protocols and the lack of widely accepted diagnostic criteria (Thorburn et al., 2004). A classification scheme has been developed by Bernier et al. including clinical features and enzyme activities found in several groups of patients (Bernier et al., 2002).

\section{Genetic causes of OXPHOS disease}

OXPHOS diseases can be caused by mutations in the nuclear and mtDNA. Nuclear OXPHOS mutations can be classified as (i) gene defects altering the stability of mtDNA (ii) gene defects in structural components or assembly factors of the OXPHOS complexes (iii) 
defects in non protein components of the respiratory chain, like CoQ10 or taffazzin and (iv) gene defects in proteins indirectly related to OXPHOS (Chinnery, 2003; Zeviani and Di Donato, 2004). OXPHOS diseases caused by nuclear gene mutations usually follow a Mendelian inheritance pattern. Disease causing mutations in the mtDNA can be either large rearrangements or point mutations or a reduced copy number (mtDNA depletion).

\section{MtDNA rearrangements}

Large-scale rearrangements are usually single deletions. Since 1988 (Holt et al., 1988) over 200 different mtDNA deletions have been reported, associated with several, different OXPHOS diseases. Three main clinical phenotypes are Kearns-Sayre syndrome (KSS), chronic progressive external opthalmoplegia (PEO) and Pearson syndrome (table I). The vast majority of deletions reported are flanked by short repeat sequences ranging from 3-14 bp in length (Mita et al., 1990; Ota et al., 1994). No minimal area of overlap exists between the different deletions, but always at least one tRNA is removed (Tang Y. et al., 2000). The severity of the disease and the age of onset are partly dependent on the amount and tissue distribution of the mtDNA rearrangement and the presence of deletion dimers or partially duplicated mtDNA molecules (Poulton and Holt, 1994; Rotig et al., 1995; Jacobs et al., 2004).

\section{MtDNA point mutations}

Point mutations in the mtDNA can be pathogenic or neutral. Neutral polymorphisms are common and based on a combination of specific polymorphisms the mtDNA can be classified in haplogroups. Over 150 pathogenic point mutations in the mtDNA that affect protein coding genes or RNA genes have been reported since 1988 (Wallace et al., 1988). Most pathogenic point mutations are heteroplasmic, but homoplasmic disease causing point mutations in the mtDNA have been described as well. The clinical phenotype of homoplasmic mutations (table II) is generally restricted to a single tissue. Penetrance is often incomplete and other factors like nuclear encoded proteins, epigenetic factors, environment or lifestyle (tobacco smoking (Tsao et al., 1999)), mtDNA haplogroups (Brown et al., 2002) are likely to be involved (Guan et al., 2001).

Heteroplasmic point mutations in protein encoding and in RNA genes are more often pathogenic (table II). Many mutations are infrequent or even private, presenting in a single family. All mutations display clinical heterogeneity (Sparaco et al., 2003), but this is most evident for the common m.3243A $>\mathrm{G}$ mutation (table II). This variable phenotypic expression can not be explained by the heteroplasmy level only and nuclear genes may be involved (Dunbar et al., 1995; Jacobs and Holt, 2000; Torroni et al., 2003). The threshold at which ATP production decreases is dependent on the tissue and mutation analysed. It appears to be lower in those tissues with a higher energy demand such as brain and muscle (Larsson and Clayton, 1995). The existence of such a threshold implies that in the normal situation there is an overcapacity of the OXPHOS system (Rossignol et al., 2003), required to deal with an 
increased energy demand. This can also be considered a protective mechanism against deleterious mutations, which inevitably will accumulate during life.

Table II: The most common mtDNA point mutations

\begin{tabular}{|c|c|c|c|}
\hline Disease & mtDNA mutation & Homo/heteroplasmy & Reference \\
\hline$\overline{\mathrm{LHON}}$ & $\begin{array}{l}\mathrm{m} .3460 \mathrm{G}>\mathrm{A} \\
\mathrm{m} .11778 \mathrm{G}>\mathrm{A} \\
\mathrm{m} .14484 \mathrm{~T}>\mathrm{C}\end{array}$ & $\begin{array}{l}\text { homoplasmic } \\
\text { homoplasmic } \\
\text { homoplasmic }\end{array}$ & $\begin{array}{l}\text { (Huoponen } \text { et al., 1991) } \\
\text { (Wallace et al., 1988) } \\
\text { (Johns et al., 1992) }\end{array}$ \\
\hline $\begin{array}{l}\text { Hypertrophic } \\
\text { cardiomyopathy }\end{array}$ & $\mathrm{m} .4300 \mathrm{~A}>\mathrm{C}$ & homoplasmic & (Taylor et al., 2003) \\
\hline $\begin{array}{l}\text { Aminoglycoside induced } \\
\text { hearing loss }\end{array}$ & $\mathrm{m} .1555 \mathrm{~A}>\mathrm{G}$ & homoplasmic & (Usami et al., 2000) \\
\hline Leigh syndrome & m. $1624 \mathrm{C}>\mathrm{T}$ & homoplasmic & (McFarland et al., 2004) \\
\hline NARP/Leigh syndrome & $\mathrm{m} .8993 \mathrm{~T}>\mathrm{G} / \mathrm{C}$ & heteroplasmic & (Holt et al., 1990) \\
\hline MERRF & $\mathrm{m} .8344 \mathrm{~A}>\mathrm{G}$ & heteroplasmic & (Shoffner et al., 1990) \\
\hline MELAS & m. $3243 \mathrm{~A}>\mathrm{G}$ & heteroplasmic & (Goto et al., 1990) \\
\hline $\begin{array}{l}\text { Maternally inherited } \\
\text { diabetes and deafness } \\
\text { (MIDD) }\end{array}$ & $\mathrm{m} \cdot 3243 \mathrm{~A}>\mathrm{G}$ & heteroplasmic & $\begin{array}{l}\text { (van den Ouweland et al., } \\
\text { 1995; Akbari et al., 2004; } \\
\text { Maassen et al., 2004) }\end{array}$ \\
\hline $\begin{array}{l}\text { Non-syndromic hearing } \\
\text { loss (NSHL) }\end{array}$ & $\mathrm{m} .3243 \mathrm{~A}>\mathrm{G}$ & heteroplasmic & (Mancuso et al., 2004) \\
\hline KSS and CPEO & $\mathrm{m} .3243 \mathrm{~A}>\mathrm{G}$ & heteroplasmic & (Bosbach et al., 2003) \\
\hline Renal failure & $\mathrm{m} .3243 \mathrm{~A}>\mathrm{G}$ & heteroplasmic & (Jansen et al., 1997) \\
\hline
\end{tabular}

\section{Depletion and multiple mtDNA deletions}

MtDNA depletion is a reduction in copy number of mtDNA molecules, which can be the consequence of a nuclear gene defect. Mitochondrial DNA depletion syndrome (MDS, table I) with or without multiple mtDNA deletions is a severe autosomal recessive genetic disease caused by a mutation in one of the genes involved in mtDNA synthesis or nucleotide metabolism. Other mutations are detected in genes involved in mtDNA replication and the maintenance of the mitochondrial dNTP pool. Defects in comparable genes (ANT1, Twinkle, and POLG1) are involved in multiple mtDNA deletions, which can present with or without depletion. Especially, mutations in the POLG gene have a clinically heterogeneous presentation and both autosomal dominant and autosomal recessive families have been reported.

\section{Acquired mtDNA mutations}

Inherited mtDNA mutations are usually present in all or most of the human tissues, but somatic mutations occur as well. Cytochrome $b$ mutations have been described in muscle of patients only (Andreu et al., 1999). Age-related ROS damage is the most common source of acquired somatic mtDNA mutations. Over 200 different deletions and several point mutations have been found in the mtDNA that accumulate during ageing, especially in ageing muscle (Cottrell and Turnbull, 2000; Wei and Lee, 2002), in humans, but also in other species like monkeys (Lec et al., 1993; Schwarze et al., 1995), mice (Tanhauser and Laipis, 1995; Khaidakov et al., 2003) and nematodes (Melov et al., 1995). The mutant load of these 
individual mutations usually does not exceed $1 \%$, but the total number of mtDNA mutations can be of such that the mitochondrial respiration and OXPHOS is significantly impaired (Hayakawa et al., 1996; Liu et al., 1998). A direct relation between acquired mtDNA mutations and ageing has been shown in a mice-model with a deficient polymerase gamma leading to deletions and point mutations in the mtDNA. These mtDNA-mutator mice show a reduced lifespan and premature onset of ageing problems like hair loss, osteoporosis anaemia and reduced fertility (Trifunovic et al., 2004). Depletion of the mtDNA can also be acquired and for example pharmacologically induced by antiviral nucleoside analogs, as used in HIV therapy (Kakuda, 2000).

\section{Treatment of OXPHOS disease}

Despite extensive studies on use of various pharmacological agents and vitamin supplements there is still no cure for OXPHOS disease. Pharmacological therapy mainly relies on the administration of artificial electron acceptors, metabolites and cofactors or oxygen radical scavengers (Dimauro et al., 2004). The administration of these factors can have a beneficial effect in some cases, but the effect is often transient. Novel strategies are being developed directed at manipulating the level of heteroplasmy in the cell (Chinnery and Turnbull, 2001; Chinnery, 2004). These techniques aim at lowering the level of mutant mtDNA by selectively inhibiting the replication of mutant mtDNA by sequence specific peptide nucleic acids (PNAs) or by the removal of mutated mtDNA by means of restriction enzymes. Alternative strategies attempt to treat the disease at the biochemical level by supplying cells with the normal mitochondrial proteins. Both these strategies encounter problems when executed in isolated organelle models with respect to the specificity and delivery of the product (Taylor et al., 2001). Another novel strategy is to redesign mitochondrial genes for expression from the nucleus and import normal copies of the redesigned gene from the cytosol into the mitochondria. The same can be done with allotopic expression of tRNA's. For the allotropic expression of both mitochondrial proteins and tRNAs the correctly engineered genes must be delivered, recombined into the nucleus and expressed in a large number of cells to be a viable therapeutic approach (Smith et al.,2004).

Physical exercise can also be important to prevent disease manifestations. Most patients with mitochondrial disease are inactive because of exercise intolerance or fear for muscle damage, in spite of the fact that aerobic training increases work and oxidation capacity in these patients (Taivassalo et al., 2001; Taivassalo and Haller, 2004). Questions remain on the (long term) effect of exercise on the mutant load, which may rise during life (Chinnery, 2004). Until a definite cure is developed patients can only be given support and some limited therapy aimed at improving the quality of life. Palliative therapy is directed at preventing, for example, the complications of diabetes mellitus and cardiomyopathy and surgical correction of ptosis and cataracts (Dimauro et al., 2004). 


\section{MtDNA segregation and transmission}

The mtDNA is transmitted through the maternal line via the mitochondria contained in the ooplasm. Maternal transmission is also a hallmark of mtDNA related diseases. Mature human oocytes contain between 100000 and 600000 mitochondria and mtDNA copies (Reynier et al., 2001; Poulton and Marchington, 2002). This is in contrast to sperm cells which have been reported to contain between 10 and 700 copies mtDNA (Hecht et al., 1984; Shitara et al., 2000; Diez-Sanchez et al., 2003; May-Panloup et al., 2003). The mtDNA content of the spermatozoon decreases 5 - to 6 fold during the spermatogenesis, probably because of a down-regulation of the mitochondrial transcription factor A (Tfam) (Larsson et al., 1997; Rantanen and Larsson, 2000; Diez-Sanchez et al., 2003). During spermatid development ubiquitine binds to the mitochondria, which makes the sperm mitochondria prone to proteolysis (Sutovsky, 2003), resulting in the loss of paternal mtDNA molecules (Shitara et al., 1998; Sutovsky et al., 2003). In another study t-tpis, a testis specific translocator, belonging to the translocator of mitochondrial outer membrane (TOM) complex, has been identified as a sperm mitochondria specific factor, which incorporates an elimination factor present in the oocyte. The elimination factor is not yet identified but it probably activates an endonuclease system. The ubiquination proces is thought to follow the selective digestion of sperm mtDNA by endonucleases. Elimination of sperm mitochondria in mouse can be inhibited by treatment with anti-tpis and (Hayashida et al., 2005). Recently, transmission of paternal mtDNA was detected in skeletal muscle of a patient (Schwartz and Vissing, 2002), but this is an infrequent phenomenon (Filosto et al., 2003; Johns, 2003; Schwartz and Vissing, 2003; Taylor et al., 2003; Schwartz and Vissing, 2004). Paternal transmission has also been studied in ICSI and IVF embryos and offspring. In these cases low amounts of paternal mtDNA were detected in 16 of the 32 abnormal polyploid embryos (St John et al., 2000) but not in offspring and normal embryos (Danan et al., 1999; Marchington et al., 2002).

Correct functioning and intactness of the mitochondria is vital for sperm motility. OXPHOS inhibitors decrease sperm motility (Ruiz-Pesini et al., 2000; St John et al., 2005), which suggests that mutations affecting mitochondrial functioning could have an effect on sperm motility. The m.3243A>G mtDNA mutation shows a higher mutation level in semen fraction with a lower motility (Spiropoulos et al., 2002) and analysis of semen from men with lower semen quality revealed a higher incidence of homoplasmic base changes in the mtDNA especially at two locations, nt 9055 and nt 11719 (Holyoake et al., 2001). Kao et al observed a higher incidence of especially the $4977 \mathrm{bp}$ 'common' mtDNA-deletion, in semen with a lower motility (Kao et al., 1998), but this was not confirmed by others (Cummins et al., 1998; St John et al., 2001). Multiple mtDNA deletions have been observed in both normozoospermic and oligozoospermic men but as the semen qualtity diminishes the number of multiple deletions A deviant number of CAG repeats (normally 10) in the polymerase gamma gene has been associated with unexplained male infertility (Rovio et al., 2001; Jensen et al., 2004). This association was not confirmed by others (Krausz et al., 2004; Aknin-Seifer 
et al., 2005). Pathogenic POLG mutations have however been associated with hypofertility in both males and females (Ferrari et al., 2005) and premature menopause has been found in a large number of females suffering from CPEO caused by POLG mutations (Luoma et al., 2004), probably due to a link with steroid hormone genesis (Bose et al., 2002). These data are confirmed by the mutator-mic, carrying a proofreading deficient polymerase gamma, which show reduced fertility of both the male and female mice (Trifunovic et al., 2004).

\section{Mitotic segregation and relaxed replication of mtDNA}

During cell division, mitochondria are randomly divided (Rotig and Munnich, 2003) and in heteroplasmic cells this can lead to a shift in the proportion of mutant mtDNA in the daughter cells. A loss of mutations is observed in fast dividing tissues, probably due to a selection against cells containing high mutation loads. An example is the average decrease of $1 \%$ per year of the m.3243A $>\mathrm{G}$ mutation in blood of patients (Rahman et al., 2001). Increased ROS production is a critical factor triggering mtDNA replication, but also increasing mtDNA damage, eventually leading to apoptosis. In post mitotic tissues accumulation of mtDNA deletions and point mutations has been observed (Larsson $e$ t al., 1990; Weber et al., 1997). This proliferation only takes place in cells containing high amounts of mutant mtDNA and because of this, heteroplasmy percentage in tissues as a whole increases and variation in mutation load between muscle fibres develops (Chinnery et al., 2002). In case of deletions the replicative advantage of the smaller molecule also adds to the accumulation of the mutated mtDNA in tissues and cells (Diaz et al., 2002).

\section{Polymorphism and mutations in oocytes}

Mutations in oocytes have been described as part of the transmission of pathogenic familial mutations and as de novo events. The first group is important for the recurrence risk of mtDNA disease in families and carriers (see next paragraph), the second could potentially explain the occurrence of new discase cases. Deletions in the mtDNA have been reported in $40-60 \%$ of unfertilized oocytes or oocytes that failed to develop into mature metaphase II oocytes, although usually in very low mutation percentages (Chen et al., 1995; Keefe et al., 1995; Brenner et al., 1998; Reynier et al., 1998; Barritt et al., 1999; Hsieh et al., 2002). Since none of the donating couples showed symptoms of mtDNA deletion syndromes these mutations probably arose in the oocyte. Recently, we screened the entire mtDNA in oocytes for predominantly heteroplasmic point mutations and found that over $25 \%$ of the oocytes contained point mutations. The mutation percentages varied from very low levels $(<1 \%)$ to very high levels (>99\%) with most oocytes containing low level mutation percentages $(<30 \%)$ (Jacobs et al in preparation). Therefore, at least $25 \%$ of the unfertilised oocytes contain a mtDNA mutation. Under the assumption that at least $10 \%$ of the point mutations in the mtDNA will be pathogenic this would mean that more than $5 \%$ of the oocytes harbour a possible pathogenic mutation in the mtDNA. Mostly, these mutations are present in very low levels. Some percentages were above the threshold of expression and these de novo mutations can have a direct phenotypic effect (De Coo et al., 1996; Degoul et al., 1997; Maassen et al., 
2002; Thorburn, 2004). The low level mutations can get lost by cell division, but also fixed during life by random genetic drift, which has been observed in rapidly dividing colonic crypt cells (Taylor et al., 2003) and cancer cells (Carew and Huang, 2002). This also means that a very low level of mtDNA mutation in the oocyte can, because of relaxed replication, accumulate during life and might predispose for diseases, like Alzheimer and Parkinson's disease, which are associated with mtDNA mutations (Chinnery et al., 2002; Coskun et al., 2004).

It is unlikely that mutations in the oocyte in general influence the fertilisability as carriers of mtDNA mutation do not present with fertility problems and children with a high mutation load are being born (Moilanen and Majamaa, 2001). However, oocytes can accumulate mutations in an age dependant manner. The $\mathrm{m} .414 \mathrm{~T}>\mathrm{G}$ point mutation is present in $40 \%$ of the oocytes of women aged $\geq 37$ years in contrast to $4 \%$ of the oocytes of women aged $<37$ years. which could be associated with reproductive senescing (Barritt et al., 2000). Reynier et al has shown a lowered number of mitochondria in oocytes from patients with fertilisation failure due to unknown causes (Reynier et al., 2001) and a lower number of mitochondria is found in ageing oocytes (de Bruin et al., 2004). This means that the number of mitochondria in itself is important and not necessarily the ATP production by the OXPHOS system during embryo development. Therefore, acquired mtDNA mutations affecting $m t D N A$ replication might affect the fertility.

\section{Segregation of mtDNA diseases in families}

The segregation of mtDNA disease in families is not straightforward and is highly dependent on the nature and amount of the mtDNA mutation. A woman carrying an mtDNA mutation will transmit a variable amount of this mutation to her offspring. The percentage heteroplasmy of point mutations in the offspring is related to the mutation percentage in the mother (Chinnery et al., 1998) although extreme shifts in mutation percentages occur (White et al., 1999; Carelli et al., 2002). Only a few studies report on the inheritance of heteroplasmic mtDNA mutations (Chinnery et al., 2000; Wong et al., 2002) and it appears that mutations, like the $\mathrm{m} .8363 \mathrm{G}>\mathrm{A}, \mathrm{m} .3460 \mathrm{G}>\mathrm{A}$ and $\mathrm{m} .8993 \mathrm{~T}>\mathrm{C}$, are in general randomly transmitted to offspring although in some cases skewing in favour of the mutation can be observed (Larsson et al., 1992; Chinnery et al., 2000; Hurvitz et al., 2002; Wong et al., 2002). Transmission of the m.8344A $>\mathrm{G}$, the $\mathrm{m} .3243 \mathrm{~A}>\mathrm{G}$ and $\mathrm{m} .8993 \mathrm{~T}>\mathrm{G}$ mutations is possibly not completely random, when comparing blood levels in mother and child (Chinnery et al., 2000). The mutation percentage of the $\mathrm{m} .8344 \mathrm{~A}>\mathrm{G}$ mutation is lower in the offspring and of the m.3243A $>\mathrm{G}$ and $\mathrm{m} .8993 \mathrm{~T}>\mathrm{G}$ mutations higher than expected by random transmission only (White et al., 1999; White et al., 1999; Chinnery et al., 2000; Wong et al., 2002). However, the number of reported transmissions is small, a selection bias is likely, because analysis is performed after discovery of an offspring with clinical symptoms and the age of sampling differs between mother and child.

Analysis of 82 oocytes collected from a woman carrying the m.3243A>G mutation with a mutation load of $18 \%$ in muscle and $7 \%$ in leukocytes, revealed a binominal 
distribution pattern. The mutation percentage in the oocytes ranged from $0 \%$ to $45 \%$ (mean $12.6 \%$ ), which was a random scgregation pattern (Brown et al., 2001). Oocytes from a carrier of the $\mathrm{m} .8993 \mathrm{~T}>\mathrm{G}$ mutation demonstrated an extremely skcwed segregation pattern in seven oocytes of a woman with a mutant load of $50 \%$ in blood. Six of the seven oocytes contained a mutant load $>95 \%$ and the remaining oocyt showed no evidence of the mutation (Blok et al., 1997). It is unclear whether this is a good representation of the entire pool of her oocytes and of other women carrying this mutation.

For most mutations a relation exists between maternal mutation load and the mutation load in offspring and therefore the chance of being affected. This has been extensively studied for the m.8344A $>\mathrm{G}, \mathrm{m} .3243 \mathrm{~A}>\mathrm{G}$ and m.8993T $>\mathrm{G} / \mathrm{C}$ mutation (Chinnery et al., 1998).

Carriers of the m.8344A $>\mathrm{G}$ mutation are at risk of affected offspring if the mutation load in blood is $>40 \%$. This risk ranges from $12 \%$ (mutation load $40-59 \%$ ) to $78 \%$ (mutation load $>80 \%$ ). For the m.3243A $>\mathrm{G}$ mutation the chance of affected offspring ranges from $25 \%$ (mutation load $<20 \%$ in blood) to $57 \%$ (mutation load $40-60 \%$ ). The risk of affected offspring is therefore substantial even at low mutation levels in the acrrier. Finally, for the $\mathrm{m} .8993 \mathrm{~T}>\mathrm{G} / \mathrm{C}$ mutations the risk of affected offspring rises from $0 \%$ (mutation load $<20 \%$ ) to $>75 \%$ (mutation load 61-80\%) (White et al., 1999).

The segregation of large single deletions is different and these deletions are in general de novo. Chinnery et al collected data on 226 families in which a single mtDNA deletion was identified in the proband. Possible other mtDNA rearrangements like mtDNA duplications and deletion dimers, which may affect the transmission (Rotig et al., 1992; Poulton et al., 1993; Ballinger et al., 1994; Shanske et al., 2002), were not taken into account. The overall recurrence risk for disease caused by single mtDNA deletions was estimated at $4.11 \%$ (Chinnery et al., 2004). Transmission of mtDNA deletions in the form of duplications has also been observed in mice strains containing a pathogenic 4696 bp deletion in the mtDNA. After introduction of the deletion, partially duplicated molecules were formed which were transmitted to offspring and caused deletion symptoms (Nakada et al., 2001). MtDNA deletion disorders can also be caused by nuclear gene mutations and usually multiple deletions are observed which are transmitted in a Mendelian way (Kaukonen et al., 2000; Spelbrink et al., 2001; Van Goethem et al., 2001).

\section{Bottleneck location and size}

In the 1980's a study on the segregation of mtDNA in Holstein cows revealed a rapid shift in the mtDNA genotype within two generational transitions (Hauswirth and Laipis, 1982). This shift has been confirmed several times in these cows (Ashley et al., 1989; Koehler et al., 1991), in other species like mice (heteroplasmic New Zealand Black/BINJ progeny (Meirelles and Smith, 1997) and in humans for the homopolymeric tract heteroplasmy located between nt 303 and 315 of the mtDNA (Lutz et al., 2000). This has lead to the identification of the 'mtDNA bottleneck' (figure 2) which is a restriction in the number of mtDNA molecules to be transmitted followed by an amplification of these founder molecules (Howell et al., 1992). The exclusive maternal transmission of mtDNA, the high mutation rate and the 
lack of a good repair mechanism and recombination would lead to decay of the mtDNA (Muller's ratchet (Muller, 1964; Hoekstra, 2000)). The stringent bottleneck has an evolutionary advantage as a sort of reset and acts to maintain a healthy mtDNA by filtering out mutations and minimizing heteroplasmy (Cummins, 1998; Cummins, 2001). Because this filtering happens very early during the development the chance to preserve age-related mutations in the early oocyte is small, although the low amount of mtDNA copies per mitochondria in the early developmental stages of the oocytes renders these oocytes vulnerable for mutational events (Keefe et al., 1995).

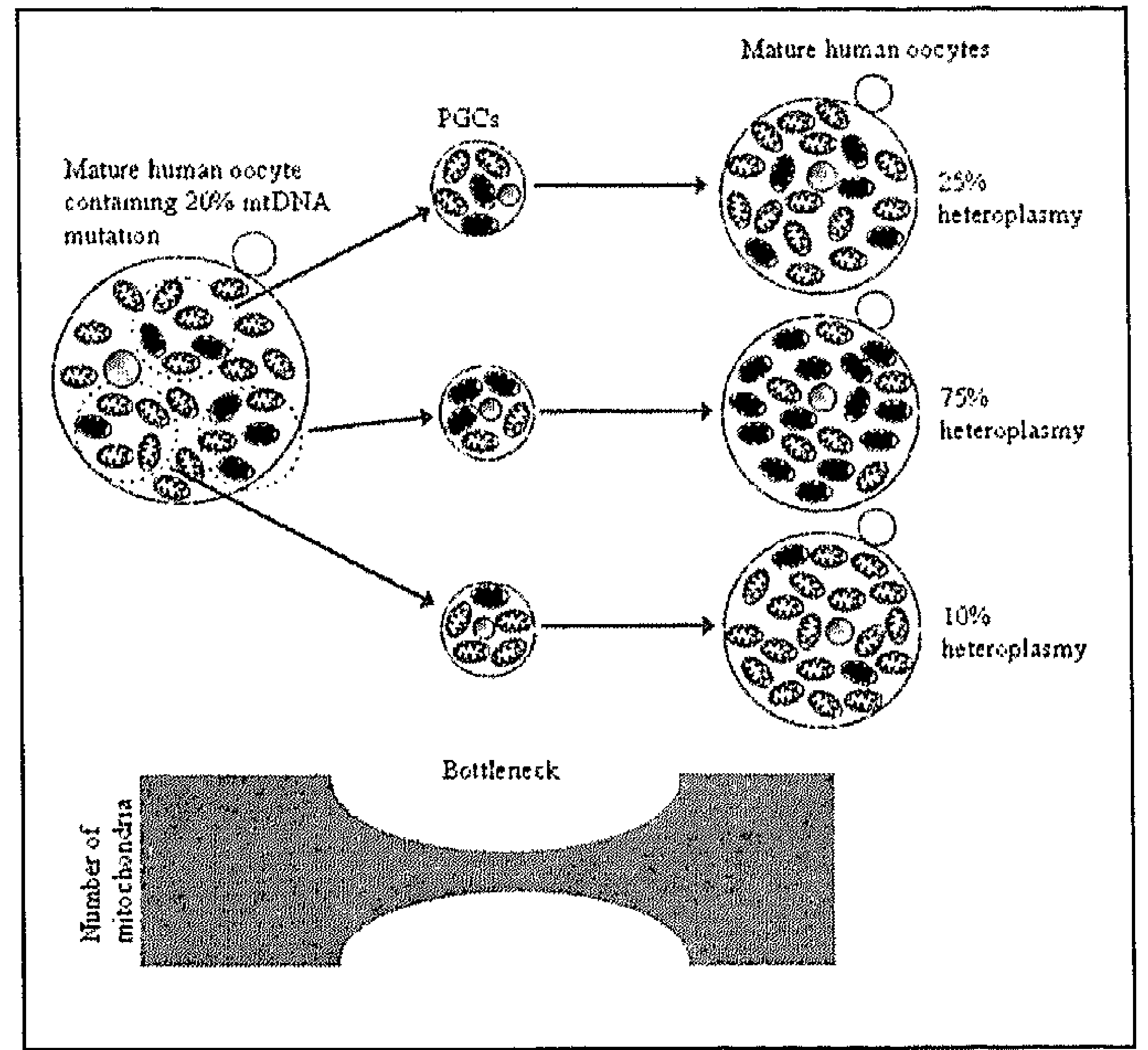

Figure 2

Schematic drawing of the possible location and effect of the bottleneck on the transmission of a miDNA mutation. The green colored mitochondria represent the normal mtDNA and the red colored mitochondria represent the mutated miDNA.

PGC: Primordial germ cell

When the mitochondrial bottleneck exactly occurs during oocyte or embryo development and what the size is, is not yet clear (Poulton et al., 1998). Early during the first developmental stages of oocytes the number of mitochondria and mtDNA molecules is reduced and the lowest number of mitochondria $(<10)$ is found in the early primordial germ cells (PGCs) of a three weeks old embryo. The number of mitochondria is estimated from published electron micrographs of PGCs (Jansen and de Boer, 1998). It can not be excluded that in the embryonic germ cell line a week earlier an even lower number of mitochondria is present (Jansen, 2000). The mtDNA copy number is unknown in PGCs but in oocytes usually only one mtDNA molecule per mitochondrion is observed (Michaels et al., 1982; Chen et al., 1995). In mouse and frog there is no mtDNA synthesis during embryogenesis until the stage of gastrulation (Larsson et al., 1998; Jansen, 2000) exept for a small period of time during the 1 - to 2-cell stage of mouse preimplantation development were there is some mtDNA turnover. The mtDNA content of the embryo does however not increase during this time (McConnell and Petrie, 2004; Thundathil et al., 2005). In humans no mtDNA synthesis, measured by 
BrdU incorporation, is observed until the late morulae and blastocyst stage (McConnell, personal communication). This suggests that in humans most mitochondria remain haploid during the first developmental stages (Jansen and de Boer, 1998). The mean number of mitochondria and mtDNA molecules increases from 10 in the PGC to about 200 in the oogonium and eventually to 100000-600 000 in the mature oocyte (Jansen, 2000). Segregation of the mtDNA during embryogenesis has been studied in mouse models by Jenuth et al. in which BALB/c cytoplasm was introduced in NZB/BINJ oocytes. The mtDNA variants remain evenly distributed in the developing foetal tissues and no evidence is found for an additional bottleneck during embryogenesis (Jenuth et al., 1996; Meirelles and Smith, 1997), although events during embryonal development still can influence the final heteroplasmy percentage (Meirelles et al., 2001). From these studies it appears that the major component of the bottleneck occurs between the primordial germ cell and the primary oocyte stage.

The bottleneck has considerable implications for a carricr of mtDNA mutations and the mutation load can vary largely in both ways among her oocytes. The exact size of the bottleneck is hard to determine and may vary among individuals (Brown, 1997). Several studies have attempted to calculate the number of mtDNA units inherited through the bottleneck in cows, humans and mice (Howell et al., 1992; Bendall et al., 1996; Blok et al., 1997; Jenuth et al., 1997; Marchington et al., 1998; Brown et al., 2001). A repeated selection model, which attempts to take the number of cell divisions of oogenesis into account, and a single selection model which proposes the bottlencck as a one time sampling of mtDNA molecules from a large pool have been applied (Poulton et al., 1998). The repeated selection model appears to represent the physiology more closely but assumes an identical sampling of mtDNA molecules every cell division, approximately 15 , during oogenesis. The single selection model assumes that the bottleneck occurs only once, that replication is equal from all templates and that the levels of heteroplasmy relate to the proportions in oocytes (Bendall et al., 1996). It has become clear that one common bottleneck size does not exist and that it will vary between meioses within and between different women. The bottleneck size using the single selection model is calculated to be $1-30$ segregating units (one unit could represent one mtDNA molecule one nucleoid or one mitochondrion) in contrast to 20-200 units when using a repeated selection model (Bendall et al., 1996; Poulton et al., 1998).

\section{Mouse models for OXPHOS disease}

Animal models are essential for understanding the pathophysiological mechanisms of OXPHOS disease and for testing therapeutic interventions, but only few natural models exist (hearing loss in mice (Johnson et al., 2001)). Over the last decade several mouse models have been developed for OXPHOS disease for both nuclear and mtDNA mutations. Only 2 mice models with mtDNA mutations exist, the CAP-resistant $\left(\mathrm{CAP}^{\mathrm{R}}\right)$ mice with the m.2433T $>\mathrm{C}$ mutation in the 16SrRNA and the mtDNA deletion mice with a 4.696 bp deletion (Sligh et al., 2000; Wallace, 2001). Disease symptoms were related to human OXPHOS disease, but for the mtDNA deletions most mice died of renal failure which is uncommon in human deletion 
patients (Inoue et al., 2000; Sligh et al., 2000; Wallace, 2001). Both these transgenic animal lines demonstrated transmission of the mutated mtDNA to successive generations and can be used to study the inheritance and segregation of pathogenic mtDNA mutations. The CAP mice transmitted the heteroplasmic mtDNA mutation to some of there progeny in homoplasmic or heteroplasmic state. Progeny, born alive, exhibited growth retardation, myopathy and dilated cardiomyopathy. Most animals died either in utero or within the first day after birth, onc animal survived 11 days (Sligh et al., 2000). The mtDNA deletion mice transmitted the rearranged mtDNA through three successive generations with a tendency to increasing heteroplasmy percentage to a maximum of $90 \%$ in muscle of some animals, most likely due to the replication advantage of the smaller mtDNA molecule. A percentage above $90 \%$ has not been found and may be lethality in oocytes or embryos. Severe disease and COX negative fibres were only found in mouse with predominantly $(>60 \%)$ deleted mtDNA (Inoue et al., 2000).

Several mouse models showing an OXPHOS disease phenotype caused by nuclear mutations have been developed (Wallace, 2001; Zeviani, 2001; Biousse et al., 2002). Mutations were introduced in genes associated with the OXPHOS system, like in protein complex genes, radical scavenger genes (Sod2 mutant mouse), transcription factors (Tfamdeficient mouse), adenine nucleotide translocator genes (Antl-deficient mouse) (Li et al., 1995; Lebovitz et al., 1996; Graham et al., 1997; Larsson et al., 1998; Wang et al., 1999). These mouse models show different OXPHOS related symptoms, but fertility is usually normal. This in contrast to the earlier mentioned mutator-mice with a proofreading deficient polymerase gamma. These mice show a premature onset of ageing and a reduced fertility, both males and females. Female reproductivity was nil after the age of 20 weeks and male fertility was severely reduced probably becausc of low sperm count and smaller testes size (Trifunovic et al., 2004). 


\section{How to prevent transmission of mitochondrial disease}

A definitive diagnosis of mitochondrial disease is needed for prognosis and genetic counselling of patients and their family (Thorburn and Dahl, 2001). As these disorders can not be cured, counselling is important to judge the recurrence risk of mitochondrial disease and the options to prevent the transmission of this discase. Refraining from children or adoption is the safest and most reliable method, but this is usually not the first choice. IVF enables prospective parents to opt for using donor oocytes. In some cases prenatal diagnosis (PND) or preimplantation genetic diagnosis (PGD) is possible, but other, more experimentally, methods are being developed as well (figure 3). The ethical aspects concerned with these techniques are discussed separately.

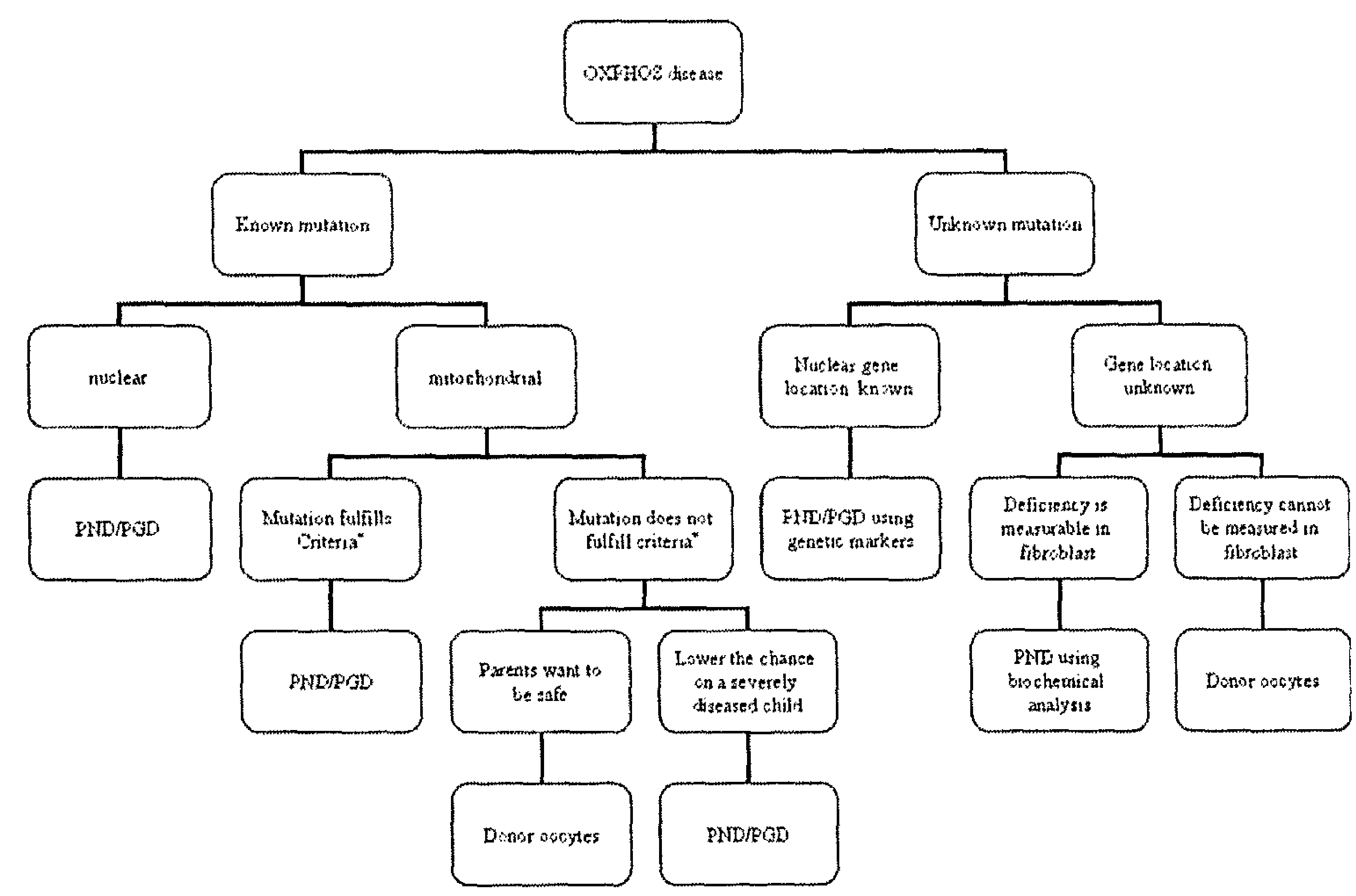

Figure 3

Scheme presenting the possible causes of OXPHOS disease and options for the prevention of transmission of these diseases.

PND: Prenatal diagnosis

$P G D$ : Preimplantation genetic diagnosis

* Criteria developed by the European NeuroMuscular Consortium concerning prenatal options for carriers of mtDNA mutations

\section{Prenatal diagnosis}

Prenatal diagnosis (PND) of OXPHOS disease can be performed at the level of the enzyme or at the level of the DNA. Although the latter is preferable, the genetic defect is often not 
known for patients with OXPHOS disease and the recurrence risk for these patients is hard to determine and based on family information only. If an enzyme deficiency is detectable in fibroblasts, then biochemical analysis of amniocytes might be an option, as fibroblasts, chorionic cells and amniocytes have the same embryonic origin (Graff et al., 2002).

Biochemical analysis of foetal samples is feasible although the methods used must be sufficiently sensitive given the low amount of foetal cells that can be obtained (table III). Another limitation is that only $50 \%$ of the patients express the enzymatic defect in fibroblasts and that knowledge on complex assembly and activity during embryonic development is lacking. OXPHOS diseases caused by nuclear gene mutations show a Mendelian mode of inheritance. For known DNA mutations, PND can be offered by direct mutation analysis of a chorionic villus sample and/or amniotic cells. If only the causing gene and location are known but not the exact mutation, intragenic or closely linked polymorphic markers are being used. DNA-diagnostics is more reliable than enzymatic analysis and should be used whenever possible.

PND for heteroplasmic point mutations in the mtDNA has its own complexity. Genotype-phenotype correlations are less straightforward and (time-dependent) differences may occur between the tested foetal tissue and the actual embryo. For point mutations in the mtDNA three criteria have been proposed to allow reliable PND (Poulton and Marchington, 2000; Poulton and Turnbull, 2000). (I) A close correlation between the mutant load and disease severity. (II) A uniform distribution of mutant $m t D N A$ in all tissues. (III) No change in mutant load over time. Sufficient data are available for only 3 mutations $(\mathrm{m} .8993 \mathrm{~T}>\mathrm{G} / \mathrm{C}$, m. $8344 \mathrm{~A}>\mathrm{G}, \mathrm{m} .3243 \mathrm{~A}>\mathrm{G}$ ) to judge these criteria properly. For the $\mathrm{m} .8993 \mathrm{~T}>\mathrm{G} / \mathrm{C}$ and m. $8344 \mathrm{~A}>\mathrm{G}$ mutation PND can be reliably performed, although for each of these a grey zone of inconclusive results exists. For example a mutant load of $<20 \%$ for the $m .8993 \mathrm{~T}>\mathrm{G}$ would predict healthy offspring, whereas a mutant load of $60 \%$ would give a $25 \%$ chance of disease (White et al. 1990). The number of data used to calculate these risks for the m.8993T $>\mathrm{C}$ mutation are so low that statistically even a mutant load of $0 \%$ does not preserve from a severe outcome. The amount of data required to reduce the confidence intervals of these percentages is for most mutations not available. For private mutations or mutations, which have only been reported a few times, PND should be carefully evaluated, based on genotypephenotype correlations, available number of data and additional experiments (Jacobs et al., 2005). Until now nine prenatal tests were reported, for the m.8993 $>\mathrm{G}$ and $\mathrm{m} .8993 \mathrm{~T}>\mathrm{C}$, the m.3243A $>\mathrm{G}$ and the m.9176T $>\mathrm{C}$ mutation (table III). Also PND for mtDNA rearrangements is becoming an issue, as the recurrence risk for mtDNA deletion disorders appears to be around 5\% (Chinnery et al., 2004) and two PND have been perfomed (table III). MtDNA depletion syndromes are usually caused by nuclear gene defects, but if the causing mutation is not known PND remains a possibility. Amniocytes of children suffering from a mtDNA depletion disorder have been studied and were found to express the mtDNA depletion (Blake et al., 1999).The exact timing of onset of mtDNA depletion during foetal development is still unknown. A second report describes two cases of mtDNA depletion presenting prenatally 
with skin oedema and diminished foetal movements at 36 weeks pregnancy (Arnon et al., 2002).

\section{Preimplantation genetic diagnosis/ polar body analysis}

Preimplantation genetic diagnosis (PGD) is an alternative to PND. Oocytes are fertilized in vitro and cells from the usually 8-cellular embryo are dissected and tested for the presence of a genetic defect. Unaffected embryos are transferred into the uterus(Handyside et al., 1990) PGD avoids the dilemmatic choice of a pregnancy termination, which is an advantagc compared to PND. PGD can be performed by sampling either polar bodies (Rechitsky et al., 1999; Briggs et al., 2000) or blastomeres (Holding and Monk, 1989; Handyside et al., 1990). PGD is an option for mitochondrial disease due to nuclear gene defects, but it may also be a solution for mtDNA disease. The high copy number of mtDNA makes the analysis less prone to artefacts like amplification failure and allelic drop-out (Thorburn, 2004). PGD for mtDNA mutations is, however, not straightforward with respect to the interpretation of the data. In a heteroplasmic mouse model the distribution of both genotypes was identical between the ooplasm and polar body of a mature oocyte and between the blastomeres of 2-, 4-, and 6-8-cell embryos (Molnar and Shoubridge, 1999; Dean et cl., 2003). Both, polar bodies and blastomeres can be analysed, but the efficiency in diagnosing blastomeres is higher (Dean et al., 2003). Analysis of polar bodies might be preferred by consenting couples with a strong reservation against embryo testing but the lower amount of mtDNA molecules in polar bodies may make the analysis susceptible to allelic drop-out and preferential amplification. The criteria for reliable PND also apply for PGD. PGD is especially suited for women with a high mutation load and a high risk of affected offspring (Poulton and Turnbull, 2000). Embryos transferred to the uterus should have a mutant load, which would guarantee a healthy outcome. For some women this could mean that they might need multiple PGD cycles before a suitable embryo can be identified. A disadvantage of PGD is the need of an in vitro fertilisation procedure as only $20 \%-25 \%$ of the IVF cycles results in a pregnancy (Broekmans and Klinkert, 2004). If the IVF/PGD procedure is unsuccessful the analysis of the embryos could still give valuable information for subsequent PGD cycles or other reproductive choices (Thorburn and Dahl, 2001). 


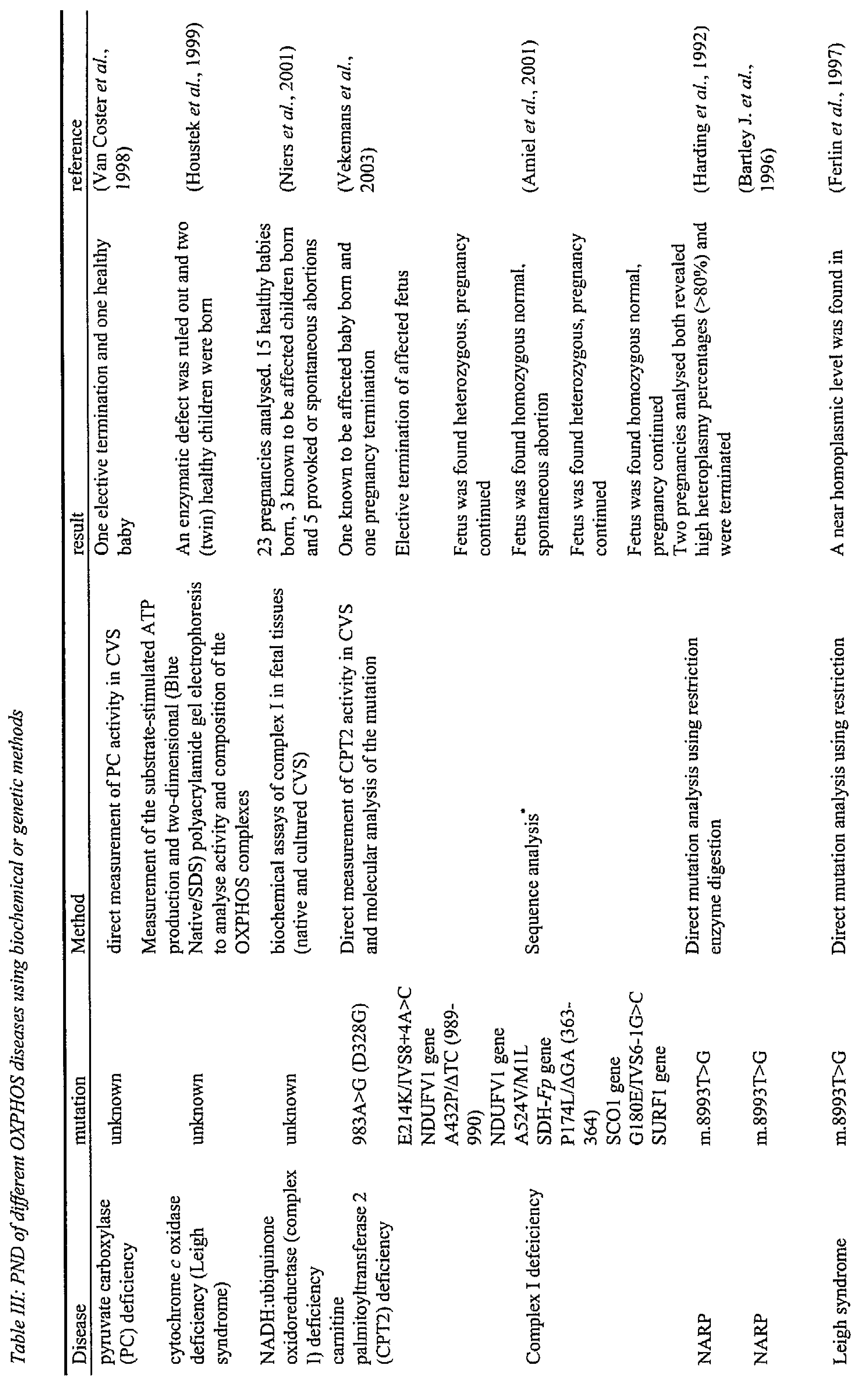




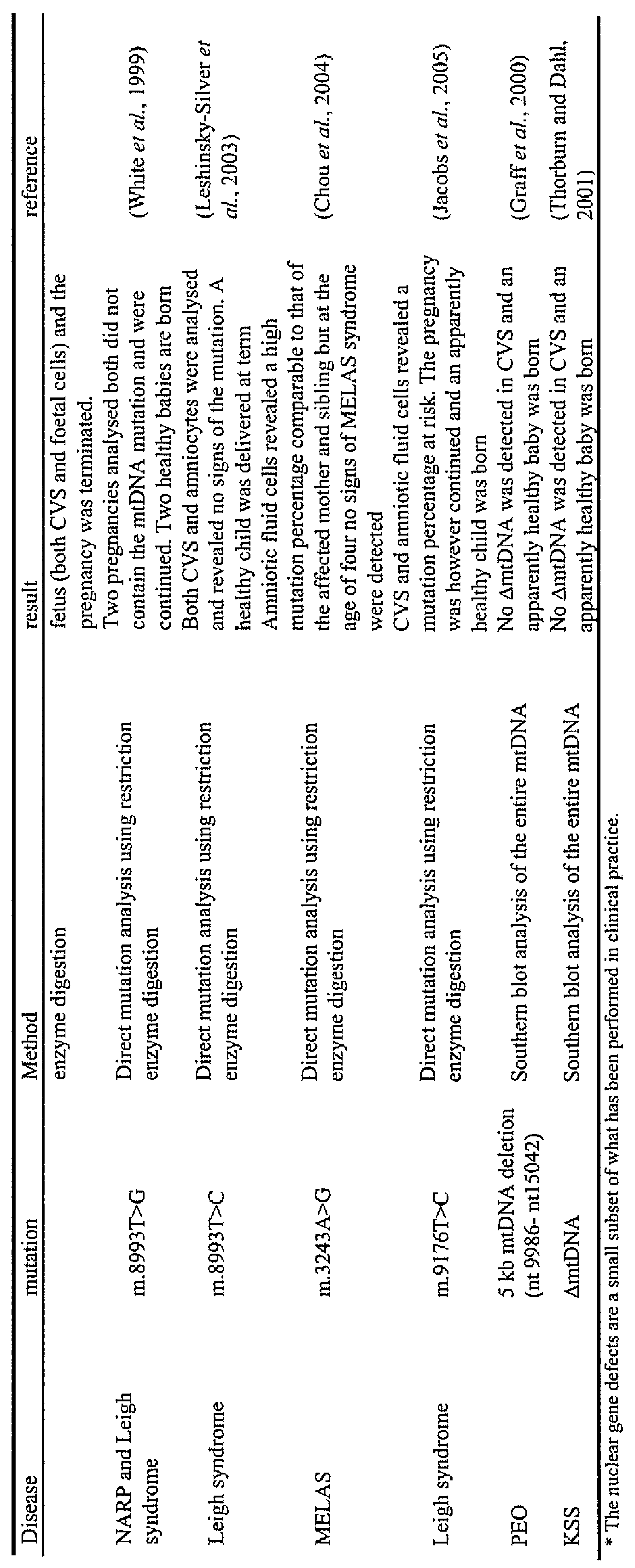




\section{Donor oocytes}

The use of donor oocytes with sperm of the partner is a reliable method to prevent the transmission of OXPHOS disease caused by mtDNA mutations. The use of donor oocytes of maternal relatives is not advisable since these may carry the same mtDNA mutations even though the mutation is undetectable in blood of the possible donor.

\section{Cytoplasmic transfer}

Cytoplasmic transfer (CT), an adaption from the ICSI technique ((Cohen et al., 1997; Cohen et al., 1998), has been tested on women experiencing repeated embryonic development failure, thought to be caused by depleted ATP levels in these oocytes (Van Blerkom et al., 1995; Van Blerkom et al., 2001). This resulted in 13 clinical pregnancies from which one spontaneous abortion and one selective abortion in a twin pair both because of Turner syndrome. With this technique 16 children have been born from which one developed pervasive development syndrome at the age of 18 months (Barritt et al., 2001). This relatively high number of chromosomal abnormalities and birth defects when using CT may be caused by the disruption of the cytoskeleton with the introduction of the ooplasm. CT has been considered to dilute the mtDNA level to below the critical threshold for disease by the transfer of healthy mtDNA (Kagawa and Hayashi, 1997) and reports on the transmission of donor mtDNA in offspring after using CT exist (Brenner et al., 2000; Barritt et al., 2001). In these cases only small amounts (5\%-15\%) of donor cytoplasm were transferred to the recipient's oocyte. Donor mtDNA was demonstrated in about $50 \%$ of the embryos and placentas after $\mathrm{CT}$. When analysing the mtDNA in one year old children born after CT, donor mtDNA is demonstrated in blood of only 2 out of 15 children (Brenner et al., 2000; Barritt et al., 2001). To prevent the transmission of mitochondrial disease a larger amount of donor cytoplasm needs to be used, up to 50\% (Thorburn and Dahl, 2001) or purified mitochondria should be introduced. It still needs to be determined whether it is possible to introduce such a large amount of cytoplasm in the oocyte or to replace a large amount of the oocyte's cytoplasm. These questions make CT for the moment an inappropriate method to prevent the transmission of mitochondrial disease.

\section{Nuclear transfer}

The nuclear transfer (NT) technique involves the fusion of the nucleus of a somatic donor cell with an enucleated recipient oocyte (cloning), which is subsequently activated electrically, or biochemically. NT is being tested in animal models. Offspring is often liable to serious defects (Cibelli et al., 2002) like for example placental oedema, respiratory problems and kidney/brain/liver malformations. In case of mtDNA mutations two strategies could be used. First, the nucleus of the mother's unfertilised oocyte is transferred into an enucleated donor oocyte which subsequently is fertilised using the partner's sperm (Roberts, 1999). Second the nucleus of a blastomere cell is transferred in the enucleated donor oocyte. With both methods a small amount of cytoplasm and mitochondria is transferred with the nucleus, which means that some mutant mtDNA may be present in the embryo. These perinuclear 
mitochondria might have a replicative advantage over mitochondria further from the nucleus (Shadel and Clayton, 1997), although recent studies in mouse oocytes have demonstrated that these karyoplast mitochondria are homogeneously distributed throughout the entire cytoplasm before the oocyte has completed its maturation (Fulka, 2004).

One of the major setbacks with NT is the need for donor oocytes. Also, there are several questions concerning the technique, the compatibility between recipient oocyte and donor nucleus, the reaction of the nucleus and recipient oocyte as a consequence of the transfer, the disruption of the cytoskeleton because of the transfor and the defects seen in animal offspring after using this technique. Another possible problem is associated with possible imprinting problems due to the transfer of an embryo nucleus. This has been proven in animal models after somatic cell nuclear transfer (Jaenisch, 2004) and could affect the embryo cell nuclear transfer although these effects are probably minor since the major part of the imprinting takes place later during embryonic development.

\section{Ethical considerations}

Most of the methods to prevent the transmission of OXPHOS disease are relatively new or in a developmental phase and have considerable ethical implications. PND and PGD are controversial in itself, mainly because of the inherent selection of foetuses/embryos. Ethical questions imply the moral status of the embryo and the so called 'disability rights'. There is a strong consensus that selective abortion and selective transfer can be morally justified to prevent the birth of seriously affected children. This might be at odds with the interests of handicapped people in our society but the use of PND and PGD does not deny the dignity and equal rights of handicapped citizens nor necessarily undermines societal support for handicapped people and their families (Buchanan, 2000). Apart from these general ethical questions, some (more or less) specific moral issues may arise in the context of PND/PGD to prevent the transmission of OXPHOS disorders. A distinction exists between the optimal situation, when the disease is caused by a known nuclear gene mutation and the test result is reliable, and the suboptimal situation, when the causing mutation is unknown or located in the mtDNA and the test result can be somewhat unreliable. The risks of false-negative, false positive and inconclusive results need to be analysed and it should be determined whether or not the prenatal test can be performed accurately. From an ethical (and legal) perspective, it is crucial that prospective parents are adequately informed and counselled on the uncertainties and limitations of the various tests before the analysis is performed, in order to enable them to make a well-considered decision

Most uncertainties are associated with PND and PGD for mtDNA mutations. If the criteria proposed to allow reliable PND are fulfilled, PND and/or PGD of the mtDNA mutation should be possible. For the so-called private mutations (representing in only one family) and mutations which have only been reported a few times, PND and PGD should be carefully evaluated. It is important to determine a safe margin for the mutation load and to discuss this margin and the consequence of an inconclusive mutation percentage or a mutation percentage above the determined threshold for disease with the parents. A question for further 
debate is as to whether the criteria to evaluate the possibility for PND or PGD for mtDNA (Poulton and Turnbull, 2000) mutations are flexible guidelines or strict rules. If a wellinformed couple, with a private or less suitable mutation, after adequate counselling decides to opt for PND or PGD to lower the risk of conceiving a severely affected child, knowing that the technique cannot give an absolute guarantee that the child will be healthy, should this be considered an option? Who determines which mutations are suitable? The possible use of PGD raises some additional issues (de Wert, 2002). There may arise a dilemma between the required mutant load and embryo quality (in terms of viability). Can the transfer of embryos which are more viable, but at higher genetic risk be morally justified? Who makes the final decision in case of conflicts: the reproductive physician or the prospective parents, especially the woman?

Obviously, prospective parents may consider the use of donor oocytes as an alternative option. The ethical concerns associated with the use of donor oocytes in the current context are the same as for the use of donor oocytes for other medical indications (Cohen and National Advisory Board on Ethics in Reproduction, 1996). The donation of oocytes is prohibited in some countries, for instance to prevent misuse of oocytes for women having reached the menopausal age, to protect the child from possible negative influences because of its conception by donor oocytes and because of possible large-scale commercialization of donor oocytes (Robertson, 2004). Relevant ethical concerns are especially related to the welfare of the donor and the offspring. The reproductive physician might be inclined to primarily focus on what is best for the recipient and to overlook the interests and needs of the donor (Kalfoglou and Geller, 2000; Kalfoglou, 2001). Guidelines should protect the autonomy, privacy and health of candidate egg donors. The major controversy with regard to the offspring conceived by use of donor gametes concerns their 'right to know', including both their right to be informed about the way they were conceived and the right to know to whom they are genetically related (ASRM., 2004). A growing number of countries acknowledge the moral and legal right of these children 'to know their origins'. A major practical problem regards the shortage of egg donors. The pros and cons of financial compensation for the donor need further debate (Steinbock, 2004).

Oocyte donation might also be used as a vehicle for other future reproductive options for carriers of mtDNA mutations and unknown OXPHOS disease causing mutations, namely CT and NT. These methods raise additional conceptual and ethical issues. A first conceptual issue, concerning both procedures, is whether or not they constitute a germ-line intervention. The answer probably should be affirmative, insofar as the germ-line of resulting children is modified, as shown for heteroplasmic mouse lines (Meirelles and Smith, 1997). Germ-line interventions are often considered as unjustified and are prohibited. But why should such interventions be categorically wrong if the purpose is therapeutic - and the procedure would be safe? In view of the therapeutic character of these techniques, one could well argue that these protect instead of damage the interests of the offspring (Robertson, 1999). With CT and NT, the genetic change only involves the mitochondrial DNA. Would it, therefore, be justified 
to ethically differentiate this therapy from possible therapeutic germline interventions involving (the insertion or modification of) nuclear genes?

A second conceptual issue, relevant for NT only, is whether this procedure amounts to human cloning. It is important to discern the various possible sources of the nucleus to be transferred (de Wert, 2002). If the nucleus of an unfertilised egg is transferred, the procedure would definitely not involvc cloning. If however the nucleus or nuclei of one or more blastomeres are transferred to an enucleated egg, however, this would involve embryo cloning - even if one would create only one additional embryo. The fact that the newly created embryo would have its own mitochondrial DNA would not make things different, as clones are usually defined as organisms having the same nuclear DNA. The transfer of identical embryos might result in the birth of genetically identical children - and might, therefore, constitute human reproductive embryo cloning. NT using a human embryonic source can be considered unjustified because the rest of the embryo would be destroyed. In fact, however, all available blastomeres of the embryo could be used, thereby avoiding any embryo loss. The question, then, becomes what is to be preferred form an ethical point of view: the loss of (the rest) of an embryo or the avoidance of reproductive embryo cloning?

Another ethical issue (regarding both $\mathrm{CT}$ and NT) concerns the splitting of the female genetic contribution to offspring into two parts, namely the (major) nuclear genetic source and the (minor) mtDNA source (Robertson, 1999). As a result, the child would have two genetic mothers which can be considered unnatural. This could have a socially, psychologically and/or legal effect especially if a major part or all of the oocytes mtDNA is replaced by donor mtDNA. Can we safely assume that the impact will be minimal, as the donor of the mtDNA has only a minimal genetic role, while the major genetic part, the nucleus, is provided by the woman who will be both the gestational and rearing mother? And last, but not least: how to weigh the health risks of these experimental techniques for future children. As a general rule, experimental reproductive technologies should only be introduced in the clinic after adequate preclinical safety studies have been performed. Clearly, the criteria to be used for defining adequate preclinical studies need further debate. No doubt, however, the clinical application of both CT and NT in order to prevent the transmission of OXPHOS disease is, for the time being, premature and, therefore, unjustified. Human embryo research may contribute to the clarification of (some of the) possible risks of these technologies. The ethics of this research is beyond the scope of this article.

In view of the severe impact of mitochondrial disorders, research into the development of new preventive strategies is important. At the same time, this review illustrates that the possible strategies to prevent the transmission of mitochondrial disorders raise lots of ethical issues, general and specific, conceptual and normative, and at the level of both clinical ethics and social ethics. Further proactive ethical analysis and interdisciplinary debate should contribute to the development of adequate guidance. 
In conclusion, transmission of OXPHOS diseases is complex, due to the different and often unknown genetic causes. Reliable prenatal or primplantation genetic diagnosis is largely limited to the group of patients with characterized mutations in nuclear genes, although certain mtDNA mutations are suitable as well. These methods are therefore neither sufficient nor satisfactory for the majority of mtDNA mutations carriers and new approaches are being developed. Mouse models for mtDNA mutation will be very helpful to study the mechanism of the transmission and segregation of mtDNA mutations, and the possibility of paternal mtDNA transmission. These and other animal models can be used to test for safety and consitency of new methods. When safe and ethically acceptable these will provide carriers the choice to prevent the transmission of OXPHOS disease to their children and will reduce the number of people affected by it.

\section{References}

Akbari M, Skjelbred C, Folling I, Sagen J and Krokan HE (2004) A gel electrophoresis method for detection of mitochondrial DNA mutation (3243 tRNA(Leu (UUR))) applied to a Norwegian family with diabetes mellitus and hearing loss. Scand J Clin Lab Invest 64,86-92.

Aknin-Seifer IE, Touraine RL, Lejeune H, Jimenez C, Chouteau J, Siffroi JP, McElreavey K, Bienvenu $T$, Patrat $C$ and Levy $R$ (2005) Is the CAG repeat of mitochondrial DNA polymerase gamma (POLG) associated with male infertility? A multi-centre French study. Hum Reprod 20,736-740.

Amiel J, Gigarel N, Benacki A, Benit P, Valnot I, Parfait B, Von Kleist-Retzow JC, Raclin V, Hadj-

Rabia S, Dumez Y, et al. (2001) Prenatal diagnosis of respiratory chain deficiency by direct mutation screening. Prenat Diagn 21,602-604.

Andreu AL, Hanna MG, Reichmann H, Bruno C, Penn AS, Tanji K, Pallotti F, Iwata S, Bonilla E, Lach B, et al. (1999) Exercise intolerance due to mutations in the cytochrome b gene of mitochondrial DNA. N Engl J Med 341,1037-1044.

Arnon S, Aviram R, Dolfin T, Regev R, Litmanovits I, Tepper R and Elpeleg ON (2002) Mitochondrial DNA depletion presenting prenatally with skin edema and multisystem disease immediately after birth. Prenat Diagn 22,34-37.

Ashley MV, Laipis PJ and Hauswirth WW (1989) Rapid segregation of heteroplasmic bovine mitochondria. Nucleic Acids Res 17,7325-7331.

Asin-Cayuela J, Schwend T, Farge G and Gustafsson CM (2005) The human mitochondrial transcription termination factor (mTERF) is fully active in vitro in the non-phosphorylated form. J Biol Chem 280,25499-25505.

ASRM. EC (2004) Informing offspring of their conception by gamete donation. Fertil Steril $81,527-$ 531.

Ballinger SW, Shoffner JM, Gebhart S, Koontz DA and Wallace DC (1994) Mitochondrial diabetes revisited. Nat Genet 7,458-459.

Barritt JA, Brenner CA, Cohen J and Matt DW (1999) Mitochondrial DNA rearrangements in human oocytes and embryos. Mol Hum Reprod 5,927-933.

Barritt JA, Brenner CA, Malter HE and Cohen J (2001) Mitochondria in human offspring derived from ooplasmic transplantation. Hum Reprod 16,513-516.

Barritt JA, Brenner CA, Malter HE and Cohen J (2001) Rebuttal: interooplasmic transfers in humans. Reprod Biomed Online 3,47-48.

Barritt JA, Cohen J and Brenner CA (2000) Mitochondrial DNA point mutation in human oocytes is associated with maternal age. Reprod Biomed Online 1,96-100. 
Bartley J., Senadheera D., Park P., Brar H., Abad D. and L-J. W (1996) Prenatal Diagnosis of T8993G mitochondrial DNA point mutation in amniocytes by heteroplasmy detection. American Journal of Human Genetics 59,A316.

Bendall KE, Macaulay VA, Baker JR and Sykes BC (1996) Heteroplasmic point mutations in the human mtDNA control region. Am J Hum Genet 59,1276-1287.

Berdanier CD and Everts HB (2001) Mitochondrial DNA in aging and degenerative disease. Mutat Res $475,169-183$.

Bernier FP, Boneh A, Dennett X, Chow CW, Cleary MA and Thorburn DR (2002) Diagnostic criteria for respiratory chain disorders in adults and children. Neurology 59,1406-1411.

Biousse V, Pardue MT, Wallace DC and Newman NJ (2002) The eyes of mito-mouse: mouse models of mitochondrial disease. J Neuroophthalmol 22,279-285.

Blake JC, Taanman JW, Morris AM, Gray RG, Cooper JM, McKiernan PJ, Leonard JV and Schapira AH (1999) Mitochondrial DNA depletion syndrome is expressed in amniotic fluid cell cultures. Am J Pathol 155,67-70.

Blok RB, Gook DA, Thorburn DR and Dahl HH (1997) Skewed segregation of the mtDNA nt 8993 (T-$>$ G) mutation in human oocytes. Am J Hum Genet 60,1495-1501.

Bogenhagen DF and Clayton DA (2003) The mitochondrial DNA replication bubble has not burst. Trends Biochem Sci 28,357-360.

Bosbach S, Komblum C, Schroder R and Wagner M (2003) Executive and visuospatial deficits in patients with chronic progressive external ophthalmoplegia and Kearns-Sayre syndromc. Brain 126,1231-1240.

Bose H, Lingappa VR and Miller WL (2002) Rapid regulation of steroidogenesis by mitochondrial protein import. Nature 417,87-91.

Bowmaker M, Yang MY, Yasukawa T, Reyes A, Jacobs HT, Huberman JA and Holt IJ (2003) Mammalian mitochondrial DNA replicates bidirectionally from an initiation zone. J Biol Chem 278,5096150969.

Brenner CA, Barritt JA, Willadsen S and Cohen J (2000) Mitochondrial DNA heteroplasmy after human ooplasmic transplantation. Fertil Steril 74,573-578.

Brenner CA, Wolny YM, Barritt JA, Matt DW, Munne S and Cohen J (1998) Mitochondrial DNA deletion in human oocytes and embryos. Mol Hum Reprod 4,887-892.

Briggs DA, Power NJ, Lamb V, Rutherford AJ and Gosden RG (2000) Amplification of DNA sequences in polar bodies from human oocytes for diagnosis of mitochondrial disease. Lancet 355,1520-1521. $58,225-234$

Broekmans FJ and Klinkert ER (2004) Female age in ART: when to stop'? Gynecol Obstet Invest

Brown DT, Samuels DC, Michael EM, Turnbull DM and Chinnery PF (2001) Random genetic drift determines the level of mutant mtDNA in human primary oocytes. Am J Hum Genet 68,533-536.

Brown GK (1997) Bottlenecks and beyond: mitochondrial DNA segregation in health and disease. J Inherit Metab Dis 20,2-8.

Brown MD, Starikovskaya E, Derbeneva O, Hosseini S, Allen JC, Miklailovskaya IE, Sukernik RI and Wallace DC (2002) The role of mtDNA background in disease expression: a new primary LHON mutation associated with Western Eurasian haplogroup J. Hum Genet 110,130-138.

Brown TA and Clayton DA (2002) Release of replication termination controls mitochondrial DNA copy number after depletion with 2',3'-dideoxycytidine. Nucleic Acids Res 30,2004-2010. Press.

Buchanan A (2000). From chance to choice : genetics and justice. Cambridge, Cambridge University

Carelli V, Baracca A, Barogi S, Pallotti F, Valentino ML, Montagna P, Zeviani M, Pini A, Lenaz G, Baruzzi A, et al. (2002) Biochemical-clinical correlation in patients with different loads of the mitochondrial DNA T8993G mutation. Arch Neurol 59,264-270.

Carew JS and Huang P (2002) Mitochondrial defects in cancer. Mol Cancer 1,9.

Chen X, Prosser R, Simonetti S, Sadlock J, Jagiello G and Schon EA (1995) Rearranged mitochondrial genomes are present in human oocytes. Am J Hum Genet 57,239-247. 
Chinnery PF (2003) Searching for nuclear-mitochondrial genes. Trends Genet 19,60-62.

Chinnery PF (2004) New approaches to the treatment of mitochondrial disorders. Reprod Biomed Online 8,16-23.

Chinnery PF, DiMauro S, Shanske S, Schon EA, Zeviani M, Mariotti C, Carrara F, Lombes A, Laforet P, Ogier $\mathrm{H}$, et al. (2004) Risk of developing a mitochondrial DNA deletion disorder. Lancet 364,592-596.

Chinnery PF, Howell N, Lightowlers RN and Tumbull DM (1998) MELAS and MERRF. The relationship between maternal mutation load and the frequency of clinically affected offspring. Brain 121 ( $\mathrm{Pt}$ 10),1889-1894.

Chinnery PF and Samuels DC (1999) Relaxed replication of mtDNA: A model with implications for the expression of disease. Am J Hum Genet 64,1158-1165.

Chinnery PF, Samucls DC, Elson J and Turnbull DM (2002) Accumulation of mitochondrial DNA mutations in ageing, cancer, and mitochondrial disease: is there a common mechanism? Lancet 360,1323-1325.

Chinnery PF, Thorburn DR, Samuels DC, White SL, Dahl HM, Turnbull DM, Lightowlers RN and Howell N (2000) The inheritance of mitochondrial DNA heteroplasmy: random drift, selection or both? Trends Genet 16,500-505.

Chinnery PF and Turnbull DM (2001) Epidemiology and treatment of mitochondrial disorders. Am J Med Genet 106,94-101.

Chou YJ, Ou CY, Hsu TY, Liou CW, Lee CF, Tso DJ and Wei YHI (2004) Prenatal diagnosis of a fetus harboring an intermediate load of the $\mathrm{A} 3243 \mathrm{G}$ mtDNA mutation in a maternal carrier diagnosed with MELAS syndrome. Prenat Diagn 24,367-370.

Cibelli JB, Campbell KH, Seidel GE, West MD and Lanza RP (2002) The health profile of cloned animals. Nat Biotechnol 20,13-14.

Clayton DA (1991) Nuclear gadgets in mitochondrial DNA replication and transcription. Trends Biochem Sci 16,107-111.

Cohen CB and National Advisory Board on Ethics in Reproduction, Eds. (1996). New ways of making babies : the case of egg donation. Medical ethics series. Bloomington, Indiana University Press.

Cohen J, Scott R, Alikani M, Schimmel T, Munne S, Levron J, Wu L, Brenner C, Warner C and Willadsen S (1998) Ooplasmic transfer in mature human oocytes. Mol Hum Reprod 4,269-280.

Cohen J, Scott R, Schimmel T, Levron J and Willadsen S (1997) Birth of infant after transfer of anucleate donor oocyte cytoplasm into recipient eggs. Lancet 350,186-187.

Coskun PE, Beal MF and Wallace DC (2004) Alzheimer's brains harbor somatic mtDNA control-region mutations that suppress mitochondrial transcription and replication. Proc Natl Acad Sci U S A 101,10726-10731.

Cottrell DA and Turnbull DM (2000) Mitochondria and ageing. Curr Opin Clin Nutr Metab Care 3,473478.

Cummins J (1998) Mitochondrial DNA in mammalian reproduction. Rev Reprod 3,172-182.

Cummins JM (2001) Mitochondria: potential roles in embryogenesis and nucleocytoplasmic transfer. Hum Reprod Update 7,217-228.

Cummins JM, Jequier AM, Martin R, Mehmet D and Goldblatt J (1998) Semen levels of mitochondrial DNA deletions in men attending an infertility clinic do not correlate with phenotype. Int J Androl 21,47-52.

Danan C, Sternberg D, Van Steirteghem A, Cazeneuve C, Duquesnoy P, Bcsmond C, Goossens M, Lissens W and Amselem S (1999) Evaluation of parental mitochondrial inheritance in neonates born after intracytoplasmic sperm injection. Am J Hum Genet 65,463-473.

de Bruin JP, Dorland M, Spek ER, Posthuma G, van Haaften M, Looman CW and te Velde ER (2004) Age-related changes in the ultrastructure of the resting follicle pool in human ovaries. Biol Reprod 70,419-424.

De Coo IF, Smeets HJ, Gabreels FJ, Arts N and van Oost BA (1996) Isolated case of mental retardation and ataxia due to a de novo mitochondrial T8993G mutation. Am J Hum Genet 58,636-638.

de Wert G (2002). Ethics of assisted reproduction. Reproductive medicine. Molecular, cellular and genetic fundamentals. Parthenon Publishing, 645-665.

Dean NL, Battersby BJ, Ao A, Gosden RG, Tan SL and Shoubridge EA (2003) Prospect of preimplantation genetic diagnosis for heritable mitochondrial DNA diseases. Mol Hum Reprod 9,631-638. 
Degoul F, Francois D, Diry M, Ponsot G, Desguerre I, Heron B, Marsac C and Moutard ML (1997) A near homoplasmic T8993G intDNA mutation in a patient with atypic Leigh syndrome not present in the mother's tissues. J Inherit Metab Dis 20,49-53.

Diaz F, Bayona-Bafaluy MP, Rana M, Mora M, Hao H and Moraes CT (2002) Human mitochondrial DNA with large deletions repopulates organelles faster than full-length genomes under relaxed copy number control. Nucleic Acids Res 30,4626-4633.

Diez-Sanchez C, Ruiz-Pesini E, Lapena AC, Montoya J, Perez-Martos A, Enriquez JA and Lopez-Perez MJ (2003) Mitochondrial DNA content of human spermatozoa. Biol Reprod 68,180-185.

Dimauro S, Mancuso M and Naini A (2004) Mitochondrial encephalomyopathies: therapeutic approach. Ann N Y Acad Sci 1011,232-245.

Dunbar DR, Moonie PA, Jacobs HT and Holt IJ (1995) Different cellular backgrounds confer a marked advantage to either mutant or wild-type mitochondrial genomes. Proc Natl Acad Sci U S A 92,6562-6566.

Ekstrand MI, Falkenberg M, Rantanen A, Park CB, Gaspari M, Hultenby K, Rustin P, Gustafsson CM and Larsson NG (2004) Mitochondrial transcription factor A regulates mtDNA copy number in mammals. Hum Mol Genet 13,935-944.

Enriquez JA, Fernandez-Silva P, Perez-Martos A, Lopez-Perez MJ and Montoya J (1996) The synthesis of mRNA in isolated mitochondria can be maintained for several hours and is inhibited by high levels of ATP. Eur J Biochem 237,601-610.

Ferlin T, Landrieu P, Rambaud C, Fernandez H, Dumoulin R, Rustin P and Mousson B (1997) Segregation of the G8993 mutant mitochondrial DNA through generations and embryonic tissues in a family at risk of Leigh syndrome. J Pediatr 131,447-449.

Fernandez-Silva P, Enriquez JA and Montoya J (2003) Replication and transcription of mammalian mitochondrial DNA. Exp Physiol 88,41-56.

Ferrari G, Lamantea E, Donati A, Filosto M, Briem E, Carrara F, Parini R, Simonati A, Santer R and Zeviani $M(2005)$ Infantile hepatocerebral syndromes associated with mutations in the mitochondrial DNA polymerase-ganmaA. Brain 128,723-731.

Filosto M, Mancuso M, Vives-Bauza C, Vila MR, Shanske S, Hirano M, Andreu AL and DiMauro S (2003) Lack of paternal inheritance of muscle mitochondrial DNA in sporadic mitochondrial myopathies. Ann Neurol 54,524-526.

Fish J, Raule N and Attardi G (2004) Discovery of a major D-loop replication origin reveals two modes of human mtDNA synthesis. Science 306,2098-2101.

Fulka H (2004) Distribution of mitochondria in reconstructed mouse oocytes. Reproduction 127,195200.

Gao J, Yu L, Zhang P, Jiang J, Chen J, Peng J, Wei Y and Zhao S (2001) Cloning and characterization of human and mouse mitochondrial elongation factor G, GFM and Gfm, and mapping of GFM to human chromosome 3q25.1-q26.2. Genomics 74,109-114.

Gaspari M, Larsson NG and Gustafsson CM (2004) The transcription machinery in mammalian mitochondria. Biochim Biophys Acta 1659,148-152.

Goto Y (2001) Clinical and molecular studies of mitochondrial disease. J Inherit Metab Dis 24,181-188.

Goto Y, Nonaka I and Horai S (1990) A mutation in the tRNA(Leu)(UUR) gene associated with the MELAS subgroup of mitochondrial encephalomyopathies. Nature 348,651-653.

Graff C, Bui TH and Larsson NG (2002) Mitochondrial diseases. Best Pract Res Clin Obstet Gynaecol 16,715-728.

Graff C, Wredenberg A, Silva JP, Bui TH, Borg K and Larsson NG (2000) Complex genetic counselling and prenatal analysis in a woman with external ophthalmoplegia and deleted mtDNA. Prenat Diagn $20,426 \cdots 431$.

Graham BH, Waymire KG, Cottrell B, Trounce IA, MacGregor GR and Wallace DC (1997) A mouse model for mitochondrial myopathy and cardiomyopathy resulting from a deficiency in the heart/muscle isoform of the adenine nucleotide translocator. Nat Genet 16,226-234. 
Guan MX, Fischel-Ghodsian N and Attardi G (2001) Nuclear background determines biochemical phenotype in the deafness-associated mitochondrial 12S rRNA mutation. Hum Mol Genet 10,573-580.

Hammarsund M, Wilson W, Corcoran M, Merup M, Einhorn S, Grander D and Sangfelt O (2001) Identification and characterization of two novel human mitochondrial elongation factor genes, $\mathrm{hEFG} 2$ and hEFG1, phylogenetically conserved through evolution. Hum Genet 109,542-550.

Handyside AH, Kontogianni EH, Hardy K and Winston RM (1990) Pregnancies from biopsied human preimplantation embryos sexed by Y-specific DNA amplification. Nature 344,768-770.

Harding AE, Holt IJ, Sweeney MG, Brockington M and Davis MB (1992) Prenatal diagnosis of mitochondrial DNA8993 T----G disease. Am J Hum Genet 50,629-633.

Hauswirth WW and Laipis PJ (1982) Mitochondrial DNA polymorphism in a maternal lineage of Holstein cows. Proc Natl Acad Sci U S A 79,4686-4690.

Hayakawa M, Katsumata K, Yoneda M, Tanaka M, Sugiyama S and Ozawa T (1996) Age-related extensive fragmentation of mitochondrial DNA into minicircles. Biochem Biophys Res Commun 226,369-377.

Hayashida K, Omagari K, Masuda J, Hazama H, Kadokawa Y, Ohba K and Kohno S (2005) The sperm mitochondria-specific translocator has a key role in maternal mitochondrial inheritance. Cell Biol Int 29,472481.

Hecht NB, Liem H, Kleene KC, Distel RJ and Ho SM (1984) Maternal inheritance of the mouse mitochondrial genome is not mediated by a loss or gross alteration of the paternal mitochondrial DNA or by methylation of the oocyte mitochondrial DN $\Lambda$. Dev Biol 102,452-461.

Hoekstra RF (2000) Evolutionary origin and consequences of uniparental mitochondrial inheritance. Hum Reprod 15 Suppl 2,102-111.

Holding $C$ and Monk M (1989) Diagnosis of beta-thalassaemia by DNA amplification in single blastomeres from mouse preimplantation embryos. Lancet 2,532-535.

Holt IJ, Harding AE and Morgan-Hughes JA (1988) Deletions of muscle mitochondrial DNA in patients with mitochondrial myopathies. Nature 331,717-719.

Holt IJ, Harding AE, Petty RK and Morgan-Hughes JA (1990) A new mitochondrial disease associated with mitochondrial DNA heteroplasmy. Am $J$ Hum Genet 46,428-433.

Holt IJ and Jacobs HT (2003) Response: The mitochondrial DNA replication bubble has not burst. Trends Biochem Sci 28,355-356.

Holt IJ, Lorimer HE and Jacobs HT (2000) Coupled leading- and lagging-strand synthesis of mammalian mitochondrial DNA. Cell 100,515-524.

Holyoake AJ, McHugh P, Wu M, O'Carroll S, Benny P, Sin IL and Sin FY (2001) High incidence of single nucleotide substitutions in the mitochondrial genome is associated with poor semen parameters in men. Int J Androl 24,175-182.

Houstek J, Klement P, Hermanska J, Antonicka H, Houstkova H, Stratilova L, Wanders RJ and Zeman $\mathrm{J}$ (1999) Complex approach to prenatal diagnosis of cytochrome $\mathrm{c}$ oxidase deficiencies. Prenat Diagn 19,552558.

Howell N, Halvorson S, Kubacka I, McCullough DA, Bindoff LA and Turnbull DM (1992) Mitochondrial gene segregation in mammals: is the bottleneck always narrow? Hum Genet 90,117-120.

Hsieh RH, Tsai NM, Au HK, Chang SJ, Wei YH and Tzeng CR (2002) Multiple rearrangements of mitochondrial DNA in unfertilized human oocytes. Fertil Steril 77,1012-1017.

Huoponen K, Vilkki J, Aula P, Nikoskelainen EK and Savontaus ML (1991) A new mtDNA mutation associated with Leber hereditary optic neuroretinopathy. Am J Hum Genet 48,1147-1153.

Hurvitz H, Naveh Y, Shoseyov D, Klar A, Shaag A and Elpeleg O (2002) Transmission of the mitochondrial $18993 \mathrm{c}$ mutation in a new family. Am J Med Genet 111,446-447.

Iborra FJ, Kimura $\mathrm{H}$ and Cook PR (2004) The functional organization of mitochondrial genomes in human cells. BMC Biol 2,9.

Inoue K, Nakada K, Ogura A, Isobe K, Goto Y, Nonaka I and Hayashi JI (2000) Generation of mice with mitochondrial dysfunction by introducing mouse mtDNA carrying a deletion into zygotes. Nat Genet $26,176-181$. 
Jacobs HT and Holt IJ (2000) The np 3243 MELAS mutation: damned if you aminoacylate, damned if you don't. Hum Mol Genet 9,463-465.

Jacobs HT, Lehtinen SK and Spelbrink JN (2000) No sex please, we're mitochondria: a hypothesis on the somatic unit of inheritance of mammalian mtDNA. Bioessays 22,564-572.

Jacobs LJ, de Coo IF, Nijland JG, Galjaard RJ, Los FJ, Schoonderwoerd K, Niermeijer MF, Geraedts JP, Scholte HR and Smeets HJ (2005) Transmission and prenatal diagnosis of the T9176C mitochondrial DNA mutation. Mol Hum Reprod.

Jacobs LJ, Jongbloed RJ, Wijburg FA, de Klerk JB, Geraedts JP, Nijland JG, Scholte HR, de Coo IF and Smeets IIJ (2004) Pearson syndrome and the role of deletion dimers and duplications in the mtDNA. J Inherit Metab Dis 27,47-55.

Jaenisch R (2004) Human cloning - the science and ethics of nuclear transplantation. N Engl J Med $351,2787-2791$

Jansen JJ, Maassen JA, van der Woude FJ, Lemmink HA, van den Ouweland JM, t' Hart LM, Smeets HJ, Bruijn JA and Lemkes HH (1997) Mutation in mitochondrial tRNA(Leu(UUR)) gene associated with progressive kidney disease. J Am Soc Nephrol 8,1118-1124.

Jansen RP (2000) Germline passage of mitochondria: quantitative considerations and possible embryological sequelae. Hum Reprod 15 Suppl 2,112*128.

Jansen RP and de Boer K (1998) The bottleneck: mitochondrial imperatives in oogenesis and ovarian follicular fate. Mol Cell Endocrinol 145,81-88.

Jensen M, Leffers H, Petersen JH, Nyboe Andersen A, Jorgensen N, Carlsen E, Jensen TK, Skakkebaek NE and Rajpert-De Meyts E (2004) Frequent polymorphism of the mitochondrial DNA polymerase gamma gene (POLG) in patients with normal spermiograms and unexplained subfertility. Hum Reprod 19,65-70.

Jenuth JP, Peterson AC, Fu K and Shoubridge EA (1996) Random genetic drift in the female germline explains the rapid segregation of mammalian mitochondrial DNA. Nat Genet 14,146-151.

Jenuth JP, Peterson AC and Shoubridge EA (1997) Tissue-specific selection for different mtDNA genotypes in heteroplasmic mice. Nat Genet 16,93-95. $54,422-424$.

Johns D (2003) Paternal transmission of mitochondrial DNA is (fortunately) rare. Annals of Neurology

Johns DR, Neufeld MJ and Park RD (1992) An ND-6 mitochondrial DNA mutation associated with

Leber hereditary optic neuropathy. Biochem Biophys Res Commun 187,1551-1557.

Johnson KR, Zheng QY, Bykhovskaya Y, Spirina O and Fischel-Ghodsian N (2001) A nuclear-

mitochondrial DNA interaction affecting hearing impairment in mice. Nat Genet 27,191-194. Ther 4,6-10.

Kagawa Y and Hayashi JI (1997) Gene therapy of mitochondrial diseases using human cytoplasts. Gene

Kakuda TN (2000) Pharmacology of nucleoside and nucleotide reverse transcriptase inhibitor-induced mitochondrial toxicity. Clin Ther 22,685-708.

Kalfoglou AL (2001) Navigating conflict of interest in oocyte donation. Am J Bioeth 1,WI.

Kalfoglou AL and Geller G (2000) Navigating conflict of interest in oocyte donation: an analysis of donors' experiences. Womens Health Issues 10,226-239.

Kang D and Hamasaki N (2005) Mitochondrial Transcription Factor A in the Maintenance of Mitochondrial DNA: Overview of Its Multiple Roles. Ann N Y Acad Sci 1042,101-108.

Kanki T, Ohgaki K, Gaspari M, Gustafsson CM, Fukuoh A, Sasaki N, Hamasaki N and Kang D (2004) Architectural role of mitochondrial transcription factor $\mathrm{A}$ in maintenance of human mitochondrial DNA. Mol Cell Biol 24,9823-9834.

Kao SH, Chao HT and Wei YH (1998) Multiple deletions of mitochondrial DNA are associated with the decline of motility and fertility of human spermatozoa. Mol Hum Reprod 4,657-666.

Kaukonen J, Juselius JK, Tiranti V, Kyttala A, Zeviani M, Comi GP, Keranen S, Peltonen L and Suomalainen A (2000) Role of adenine nucleotide translocator 1 in mtDNA maintenance. Science 289,782-785. Keefe DL, Niven-Fairchild T, Powell S and Buradagunta S (1995) Mitochondrial deoxyribonucleic acid deletions in oocytes and reproductive aging in women. Fertil Steril 64,577-583. 
Khaidakov M, Heflich RH, Manjanatha MG, Myers MB and Aidoo A (2003) Accumulation of point mutations in mitochondrial DNA of aging mice. Mutat Res 526,1-7.

Koc EC, Burkhart W, Blackburn K, Moseley A and Spremulli LL (2001) The small subunit of the mammalian mitochondrial ribosome. Identification of the full complement of ribosomal proteins present. $J$ Biol Chem 276,19363-19374.

Koc EC, Burkhart W, Blackburn K, Moyer MB, Schlatzer DM, Moseley A and Spremulli LL (2001) The large subunit of the mammalian mitochondrial ribosome. Analysis of the complement of ribosomal proteins present. J Biol Chem 276,43958-43969.

Koc EC and Spremulli LL (2002) Identification of mammalian mitochondrial translational initiation factor 3 and examination of its role in initiation complex formation with natural mRNAs. J Biol Chem 277,35541-35549.

Koehler CM, Lindberg GL, Brown DR, Beitz DC, Freeman AE, Mayfield JE and Myers AM (1991) Replacement of bovine mitochondrial DNA by a sequence variant within one generation. Genetics 129,247-255.

Kosovsky MJ and Soslau G (1993) Immunological identification of human platelet mitochondrial DNA topoisomerase I. Biochim Biophys Acta 1164,101-107.

Krausz C, Guarducci E, Becherini L, Degl'Innocenti S, Gerace L, Balercia G and Forti G (2004) The clinical significance of the POLG gene polymorphism in male infertility. J Clin Endocrinol Metab 89,4292-4297.

Larsson NG and Clayton DA (1995) Molecular genetic aspects of human mitochondrial disorders. Annu Rev Genet 29,151-178.

Larsson NG, Holme E, Kristiansson B, Oldfors A and Tulinius M (1990) Progressive increase of the mutated mitochondrial DNA fraction in Kearns-Sayre syndrome. Pediatr Res 28,131-136.

Larsson NG, Oldfors A, Garman JD, Barsh GS and Clayton DA (1997) Down-regulation of

mitochondrial transcription factor $A$ during spermatogenesis in humans. Hum Mol Genet 6,185-191.

Larsson NG, Tulinius MH, Holme E, Oldfors A, Andersen O, Wahlstrom J and Aasly J (1992)

Segregation and manifestations of the mtDNA tRNA(Lys) A-> $(8344)$ mutation of myoclonus epilepsy and ragged-red fibers (MERRF) syndrome. Am J Hum Genet 51,1201-1212.

Larsson NG, Wang J, Wilhelmsson H, Oldfors A, Rustin P, Lewandoski M, Barsh GS and Clayton DA (1998) Mitochondrial transcription factor $A$ is necessary for mtDNA maintenance and embryogenesis in mice. Nat Genet 18,231-236.

Lebovitz RM, Zhang H, Vogel H, Cartwright J, Jr., Dionne L, Lu N, Huang S and Matzuk MM (1996) Neurodegeneration, myocardial injury, and perinatal death in mitochondrial superoxide dismutase-deficient mice. Proc Natl Acad Sci U S A 93,9782-9787.

Lec CM, Chung SS, Kaczkowski JM, Weindruch R and Aiken JM (1993) Multiple mitochondrial DNA deletions associated with age in skeletal muscle of rhesus monkeys. J Gerontol 48,B201-205.

Legros F, Malka F, Frachon P, Lombes A and Rojo M (2004) Organization and dynamics of human mitochondrial DNA. J Cell Sci 117,2653-2662.

Leshinsky-Silver E, Perach M, Basilevsky E, Hershkovitz E, Yanoov-Sharav M, Lerman-Sagie T and Lev D (2003) Prenatal exclusion of Leigh syndrome due to T8993C mutation in the mitochondrial DNA. Prenat Diagn 23,31-33.

Li Y, Huang TT, Carlson EJ, Melov S, Ursell PC, Olson JL, Noble LJ, Yoshimura MP, Berger C, Chan $\mathrm{PH}$, et al. (1995) Dilated cardiomyopathy and neonatal lethality in mutant mice lacking manganese superoxide dismutase. Nat Genet 11,376-381.

Lightowlers RN, Chinnery PF, Turnbull DM and Howell N (1997) Mammalian mitochondrial genetics: heredity, heteroplasmy and disease. Trends Genet 13,450-455.

Ling M, Merante F, Chen HS, Duff C, Duncan AM and Robinson BH (1997) The human mitochondrial elongation factor tu (EF-Tu) gene: cDNA sequence, genomic localization, genomic structure, and identification of a pseudogene. Gene 197,325-336.

Liu VW, Zhang C and Nagley P (1998) Mutations in mitochondrial DNA accumulate differentially in three different human tissues during ageing. Nucleic Acids Res 26,1268-1275. 
Lochmulter H, Johns T and Shoubridge EA (1999) Expression of the E6 and E7 genes of human papillomavirus (HPV16) extends the life span of human myoblasts. Exp Cell Res 248, 186-193.

Luoma P, Melberg A, Rinne JO, Kaukonen JA, Nupponen NN, Chalmers RM, Oldfors A, Rautakorpi I, Peltonen L, Majamaa K, et al. (2004) Parkinsonism, premature menopause, and mitochondrial DNA polymerase gamma mutations: clinical and molecular genetic study. Lancet 364,875-882.

Lutz S, Weisser HJ, Heizmann J and Pollak S (2000) Mitochondrial heteroplasmy among maternally related individuals. Int J Legal Med 113,155-161.

Ma J and Spremulli LL (1996) Expression, purification, and mechanistic studies of bovine mitochondrial translational initiation factor 2. J Biol Chem 271,5805-5811.

Maassen JA, Biberoglu S, t Hart LM, Bakker E and de Knijff P (2002) A case of a de novo A3243G mutation in mitochondrial DNA in a patient with diabetes and deafness. Arch Physiol Biochem 110,186-188.

Maassen JA, LM TH, Van Essen E, Heine RJ, Nijpels G, Jahangir Tafrechi RS, Raap AK, Janssen GM and Lemkes HH (2004) Mitochondrial diabetes: molecular mechanisms and clinical presentation. Diabetes 53 Suppl 1,S103-109.

Mancuso M, Filosto M, Forli F, Rocchi A, Berrettini S, Siciliano G and Murri L (2004) A nonsyndromic hearing loss caused by very low levels of the mtDNA A3243G mutation. Acta Neurol Scand 110,7274.

Marchington DR, Macaulay V, Hartshorne GM, Barlow D and Poulton J (1998) Evidence from human oocytes for a genetic bottleneck in an mtDNA disease. Am J Hum Genet 63,769-775.

Marchington DR, Scott Brown MS, Lamb VK, van Golde RJ, Kremer JA, Tuerlings JH, Mariman EC, Balen AH and Poulton J (2002) No evidence for paternal mtDNA transmission to offspring or extra-embryonic tissues after ICSI. Mol Hum Reprod 8,1046-1049.

May-Panloup P, Chretien MF, Savagner F, Vasseur C, Jean M, Malthiery Y and Reynier P (2003) Increased sperm mitochondrial DNA content in male infertility. Hum Reprod 18,550-556.

McConnell JM and Petrie L (2004) Mitochondrial DNA turnover occurs during preimplantation development and can be modulated by environmental factors. Reprod Biomed Online 9,418-424.

McFarland R, Schacfer AM, Gardner JL, Lynn S, Hayes CM, Barron MJ, Walker M, Chinnery PF, Taylor RW and Turnbull DM (2004) Familial myopathy: new insights into the T14709C mitochondrial tRNA mutation. Ann Neurol 55,478-484.

Meirelles FV, Bordignon V, Watanabe Y, Watanabe M, Dayan A, Lobo RB, Garcia JM and Smith LC (2001) Complete replacement of the mitochondrial genotype in a Bos indicus calf reconstructed by nuclear transfer to a Bos taurus oocyte. Genetics 158,351-356.

Meirelles FV and Smith LC (1997) Mitochondrial genotype segregation in a mouse heteroplasmic lineage produced by embryonic karyoplast transplantation. Genetics 145,445-451.

Melov S, Lithgow GJ, Fischer DR, Tedesco PM and Johnson TE (1995) Increased frequency of deletions in the mitochondrial genome with age of Caenorhabditis elegans. Nucleic Acids Res 23,1419-1425.

Michaels GS, Hauswirth WW and Laipis PJ (1982) Mitochondrial DNA copy number in bovine oocytes and somatic cells. Dev Biol 94,246-251.

Mita S, Rizzuto R, Moraes CT, Shanske S, Arnaudo E, Fabrizi GM, Koga Y, DiMauro S and Schon EA (1990) Recombination via flanking direct repeats is a major cause of large- scale deletions of human mitochondrial DNA. Nucleic Acids Res 18,561-567.

Moilanen JS and Majamaa K (2001) Relative fitness of carriers of the mitochondrial DNA mutation $3243 \mathrm{~A}>$ G. Eur J Hum Genet 9,59-62.

Molnar MJ and Shoubridge EA (1999) Preimplantation genetic diagnosis for mitochondrial (mt) disorders. Neuromuscul Disord 9,521.

Muller HJ (1964) The relation of recombination to mutational advance. Mutat Res 1,2-9.

Munnich A and Rustin P (2001) Clinical spectrum and diagnosis of mitochondrial disorders. Am J Med Genet 106,4-17.

Nakada K, Inoue K and Hayashi JI (2001) Mito-mice: animal models for mitochondrial DNA-based diseases. Semin Cell Dev Biol 12,459-465. 
Nass MM (1966) The circularity of mitochondrial DNA. Proc Natl Acad Sci U S A 56,1215-1222.

Niers LE, Smeitink JA, Trijbels JM, Sengers RC, Janssen AJ and van den Heuvel LP (2001) Prenatal diagnosis of NADH:ubiquinone oxidoreductase deficiency. Prenat Diagn 21,871-880.

Ota Y, Miyake Y, Awaya S, Kumagai T, Tanaka M and Ozawa T (1994) Early retinal involvement in mitochondrial myopathy with mitochondrial DNA deletion. Retina 14,270-276.

Poulton J, Deadman ME, Bindoff L, Morten K, Land J and Brown G (1993) Families of mtDNA rearrangements can be detected in patients with mtDNA deletions: duplications may be a transient intermediate form. Hum Mol Genet 2,23-30.

Poulton J and Holt IJ (1994) Mitochondrial DNA: does more lead to less? Nat Genet 8,313-315.

Poulton J, Macaulay V and Marchington DR (1998) Mitochondrial genetics '98 is the bottleneck cracked? Am J Hum Genet 62,752-757.

Poulton J and Marchington DR (2000) Progress in genetic counselling and prenatal diagnosis of maternally inherited mtDNA diseases. Ncuromuscul Disord 10,484-487.

Poulton J and Marchington DR (2002) Segregation of mitochondrial DNA (mtDNA) in human oocytes and in animal models of mtDNA disease: clinical implications. Reproduction 123,751-755.

Poulton J and Turnbull DM (2000) 74th ENMC international workshop: mitochondrial diseases 19-20 november 1999, Naarden, the netherlands. Neuromuscul Disord 10,460-462.

Rahman S, Poulton J, Marchington D and Suomalainen A (2001) Decrease of 3243 A $->$ G mtDNA

mutation from blood in MELAS syndrome: a longitudinal study. Am J Hum Genet 68,238-240.

Rantanen A and Larsson NG (2000) Regulation of mitochondrial DNA copy number during

spermatogenesis. Hum Reprod 15 Suppl 2,86-91.

Rechitsky S, Strom C, Verlinsky O, Amet T, Ivakhnenko V, Kukharenko V, Kuliev A and Verlinsky Y (1999) Accuracy of preimplantation diagnosis of single-gene disorders by polar body analysis of oocytes. J Assist Reprod Genet 16,192-198.

Reyes A, Yang MY, Bowmaker M and Holt IJ (2005) Bidirectional replication initiates at sites throughout the mitochondrial genome of birds. J Biol Chem 280,3242-3250.

Reynier P, Chretien MF, Savagner F, Larcher G, Rohmer V, Barriere P and Malthiery Y (1998) Long

PCR analysis of human gamete mtDNA suggests defective mitochondrial maintenance in spermatozoa and supports the bottleneck theory for oocytes. Biochem Biophys Res Commun 252,373-377.

Reynier P, May-Panloup P, Chretien MF, Morgan CJ, Jean M, Savagner F, Barriere P and Malthiery Y

(2001) Mitochondrial DNA content affects the fertilizability of human oocytes. Mol Hum Reprod 7,425-429.

Richter C, Park JW and Ames BN (1988) Normal oxidative damage to mitochondrial and nuclear DNA is extensive. Proc Natl Acad Sci U S A 85,6465-6467.

Roberts RM (1999) Prevention of human mitochondrial (mtDNA) disease by nucleus transplantation into an enucleated donor oocyte. Am J Med Genet 87,265-266.

Robertson JA (1999) Reconstituting eggs: the ethics of cytoplasm donation. Fertil Steril 71,219-221.

Robertson JA (2004) Protecting cmbryos and burdening women: assisted reproduction in Italy. Hum Reprod 19,1693-1696.

Rossignol R, Faustin B, Rocher C, Malgat M, Mazat JP and Letellier T (2003) Mitochondrial threshold effects. Biochem J 370,751-762.

Rotig A, Bessis JL, Romero N, Cormier V, Saudubray JM, Narcy P, Lenoir G, Rustin P and Munnich A (1992) Maternally inherited duplication of the mitochondrial genome in a syndrome of proximal tubulopathy, diabetes mellitus, and cerebellar ataxia. Am J Hum Genet 50,364-370.

Rotig A, Bourgeron T, Chretien D, Rustin P and Munnich A (1995) Spectrum of mitochondrial DNA rearrangements in the Pearson marrow- pancreas syndromc. Hum Mol Genet 4,1327-1330.

Rotig A and Munnich A (2003) Genetic features of mitochondrial respiratory chain disorders. J Am Soc Nephrol 14,2995-3007.

Rovio AT, Marchington DR, Donat S, Schuppe HC, Abel J, Fritsche E, Elliott DJ, Laippala P, Ahola AL, McNay D, et al. (2001) Mutations at the mitochondrial DNA polymerase (POLG) locus associated with male infertility. Nat Genet 29,261-262. 
Ruiz-Pesini E, Lapena $\Lambda$ C, Diez C, Alvarez E, Enriquez JA and Lopez-Perez MJ (2000) Seminal quality correlates with mitochondrial functionality. Clin Chim Acta 300,97-105.

Saraste M (1999) Oxidative phosphorylation at the fin de siecle. Science 283,1488-1493.

Sasarman F, Karpati G and Shoubridge EA (2002) Nuclear genetic control of mitochondrial translation in skeletal muscle revealed in patients with mitochondrial myopathy. Hum Mol Genet 11,1669-1681.

Schaefer AM, Taylor RW and Turnbull DM (2001) The mitochondrial genome and mitochondrial muscle disorders. Current Opninion in Pharmacology 1,288-293.

Schwartz M and Vissing J (2002) Paternal inheritance of mitochondrial DNA. N Engl J Med 347,576580.

Schwartz M and Vissing J (2003) New patterns of inheritance in mitochondrial disease. Biochem Biophys Res Commun 310,247-251.

Schwartz M and Vissing J (2004) No evidence for paternal inheritance of mtDNA in patients with sporadic mtDNA mutations. J Neurol Sci 218,99-101.

Schwarze SR, Lee CM, Chung SS, Roecker EB, Weindruch R and Aiken JM (1995) High levels of mitochondrial DNA deletions in skeletal muscle of old rhesus monkeys. Mech Ageing Dev 83,91-101.

Shadel GS and Clayton DA (1997) Mitochondrial DNA maintenance in vertebrates. Annu Rev Biochem 66,409-435

Shanske S, Tang Y, Hirano M, Nishigaki Y, Tanji K, Bonilla E, Sue C, Krishna S, Carlo JR, Willner J, et al. (2002) Identical mitochondrial DNA deletion in a woman with ocular myopathy and in her son with pearson syndrome. Am J Hum Genet 71,679-683.

Shitara H, Hayashi JI, Takahama S, Kaneda H and Yonekawa H (1998) Maternal inheritance of mouse mtDNA in interspecific hybrids: segregation of the leaked paternal mtDNA followed by the prevention of subsequent paternal leakage. Genetics 148,851-857.

Shitara H, Kaneda H, Sato A, Inoue K, Ogura A, Yonekawa H and Hayashi JI (2000) Selective and continuous elimination of mitochondria microinjected into mouse eggs from spermatids, but not from liver cells, occurs throughout embryogenesis. Genetics 156,1277-1284.

Shoffner JM, Lott MT, Lezza AM, Seibel P, Ballinger SW and Wallace DC (1990) Myoclonic epilepsy and ragged-red fiber disease (MERRF) is associated with a mitochondrial DNA tRNA(Lys) mutation. Cell 61,931-937.

Sligh JE, Levy SE, Waymire KG, Allard P, Dillehay DL, Nusinowitz S, Heckenlively JR, MacGregor GR and Wallace DC (2000) Maternal germ-line transmission of mutant mtDNAs from embryonic stem cellderived chimeric mice. Proc Natl Acad Sci U S A 97,14461-14466.

Smith PM, Ross GF, Taylor RW, Turnbull DM and Lightowlers RN (2004) Strategies for treating disorders of the mitochondrial genome. Biochim Biophys Acta 1659,232-239.

Sparaco M, Simonati A, Cavallaro T, Bartolomei L, Grauso M, Piscioli F, Morelli L and Rizzuto N (2003) MELAS: clinical phenotype and morphological brain abnormalities. Acta Neuropathol (Berl) 106,202212.

Spelbrink JN, Li FY, Tiranti V, Nikali K, Yuan QP, Tariq M, Wanrooij S, Garrido N, Comi G, Morandi L, et al. (2001) Human mitochondrial DNA deletions associated with mutations in the gene encoding Twinkle, a phage T7 gene 4-like protein localized in mitochondria. Nat Genet 28,223-231.

Spiropoulos J, Turnbull DM and Chinnery PF (2002) Can mitochondrial DNA mutations cause sperm dysfunction? Mol Hum Reprod 8,719-721.

St John J, Sakkas D, Dimitriadi K, Barnes A, Maclin V, Ramey J, Barratt C and De Jonge C (2000) Failure of elimination of paternal mitochondrial DNA in abnormal embryos. Lancet 355,200.

St John JC, Jokhi RP and Barratt CL (2001) Men with oligoasthenoteratozoospermia harbour higher numbers of multiple mitochondrial DNA deletions in their spermatozoa, but individual deletions are not indicative of overall aetiology. Mol Hum Reprod 7,103-111.

St John JC, Jokhi RP and Barratt CL (2005) The impact of mitochondrial genetics on male infertility. Int J Androl 28,65-73.

Steinbock B (2004) Payment for egg donation and surrogacy. Mt Sinai J Med 71,255-265. 
Sutovsky P (2003) Ubiquitin-dependent proteolysis in mammalian spermatogenesis, fertilization, and sperm quality control: killing three birds with one stone. Microsc Res Tech 61,88-102.

Sutovsky P, Leyen van K, McCauley T, Day BN and Sutovsky M (2003) Degradation of paternal mitochondria after fertilization: implications for heteroplasmy, assisted reproductive technologies and mtDNA inheritance. Reproductive BioMedicine Online 8,21-33.

Taivassalo $\mathrm{T}$ and Haller RG (2004) Implications of exercise training in mtDNA defects--use it or lose it? Biochim Biophys Acta 1659,221-231.

Taivassalo T, Shoubridge EA, Chen J, Kennaway NG, DiMauro S, Arnold DL and Haller RG (2001) Aerobic conditioning in paticnts with mitochondrial myopathies: physiological, biochemical, and genetic effects. Ann Neurol 50,133-141.

Tang Y., Schon E. A., Wilichowski E., Vazquez-Memije M. E., Davidson E. and P. KM (2000) Rearrangements of Human Mitochondrial DNA (mtDNA): New Insights into the Regulation of mtDNA Copy Number and Gene Expression. Molecular Biology of the Cell 11,1471-1785.

Tanhauser SM and Laipis PJ (1995) Multiple deletions are detectable in mitochondrial DNA of aging mice. J Biol Chem 270,24769-24775.

Taylor RW, Barron MJ, Borthwick GM, Gospel A, Chinnery PF, Samuels DC, Taylor GA, Plusa SM, Needham SJ, Greaves LC, et al. (2003) Mitochondrial DNA mutations in human colonic crypt stem cells. J Clin Invest 112,1351-1360.

Taylor RW, Giordano C, Davidson MM, d'Amati G, Bain H, Hayes CM, Leonard H, Barron MJ, Casali C, Santorelli FM, et al. (2003) A homoplasmic mitochondrial transfer ribonucleic acid mutation as a cause of maternally inherited hypertrophic cardiomyopathy. J Am Coll Cardiol 41,1786-1796.

Taylor RW, McDonnell MT, Blakely EL, Chinnery PF, Taylor GA, Howell N, Zeviani M, Briem E, Carrara F and Turnbull DM (2003) Genotypes from patients indicate no paternal mitochondrial DNA contribution. Ann Neurol 54,521-524.

Taylor RW, Wardell TM, Smith PM, Muratovska A, Murphy MP, Turnbull DM and Lightowlers RN (2001) An antigenomic strategy for treating heteroplasmic mtDNA disorders. Adv Drug Deliv Rev 49,121-125. 27,349-362.

Thorburn DR (2004) Mitochondrial disorders: prevalence, myths and advances. J Inherit Metab Dis

Thorburn DR and Dahl HH (2001) Mitochondrial disorders: genetics, counseling, prenatal diagnosis and reproductive options. Am J Med Genet 106,102-114.

Thorburn DR, Sugiana C, Salemi R, Kirby DM, Worgan L, Ohtake A and Ryan MT (2004)

Biochemical and molecular diagnosis of mitochondrial respiratory chain disorders. Biochim Biophys Acta 1659,121-128.

Thundathil J, Filion F and Smith LC (2005) Molecular control of mitochondrial function in preimplantation mouse embryos. Mol Reprod Dev 71,405-413.

Torroni A, Campos Y, Rengo C, Sellitto D, Achilli A, Magri C, Semino O, Garcia A, Jara P, Arenas J, et al. (2003) Mitochondrial DNA haplogroups do not play a role in the variable phenotypic presentation of the A3243G mutation. Am J Hum Genet 72,1005-1012.

Treem WR and Sokol RJ (1998) Disorders of the mitochondria. Semin Liver Dis 18,237-253.

Trifunovic A, Wredenberg A, Falkenberg M, Spelbrink JN, Rovio AT, Bruder CE, Bohlooly YM, Gidlof S, Oldfors A, Wibom R, et al. (2004) Premature ageing in mice expressing defective mitochondrial DNA. polymerase. Nature 429,417-423.

Tsao K, Aitken PA and Johns DR (1999) Smoking as an aetiological factor in a pedigree with Leber's hereditary optic neuropathy. Br J Ophthalmol 83,577-581.

Usami S, Abe S, Akita J, Namba A, Shinkawa H, Ishii M, Iwasaki S, Hoshino T, Ito J, Doi K, et al. (2000) Prevalence of mitochondrial gene mutations among hearing impaired patients. J Med Genet 37,38-40. Van Blerkom J, Davis P and Alexander S (2001) A microscopic and biochemical study of fragmentation phenotypes in stage-appropriate human embryos. Hum Reprod 16,719-729.

Van Blerkom J, Davis PW and Lee J (1995) ATP content of human oocytes and developmental potential and outcome after in-vitro fertilization and embryo transfer. Hum Reprod 10,415-424. 
Van Coster R, Smet J, George E, De Meirleir L, Seneca S, Van Hove J, Sebire G, Verhelst H, De Bleecker J, Van Vlem B, et al. (2001) Blue native polyacrylamide gel electrophoresis: a powerful tool in diagnosis of oxidative phosphorylation defects. Pediatr Res 50,658-665.

Van Coster RN, Janssens S, Misson JP, Verloes A and Leroy JG (1998) Prenatal diagnosis of pyruvate carboxylase deficiency by direct measurement of catalytic activity on chorionic villi samples. Prenat Diagn 18,1041-1044.

van den Heuvel L and Smeitink J (2001) The oxidative phosphorylation (OXPHOS) system: nuclear genes and human genetic diseases. Bioessays 23,518-525.

van den Ouweland JM, Lemkes HH, Gerbitz KD and Maassen JA (1995) Maternally inherited diabetes and deafness (MIDD): a distinct subtype of diabetes associated with a mitochondrial tRNA(Leu)(UUR) gene point mutation. Muscle Nerve 3,S124-130.

Van Goethem G, Dermaut B, Lofgren A, Martin JJ and Van Broeckhoven C (2001) Mutation of POLG is associated with progressive external ophthalmoplegia characterized by mtDNA deletions. Nat Genet 28,211212.

Vekemans BC, Bonnefont JP, Aupetit J, Royer G, Droin V, Attie-Bitach T, Saudubray JM and Thuillier $L$ (2003) Prenatal diagnosis of camitine palmitoyltransferase 2 deficiency in chorionic villi: a novel approach. Prenat Diagn 23,884-887.

Wallace DC (1999) Mitochondrial diseases in man and mouse. Science 283,1482-1488.

Wallace DC (2001) Mouse models for mitochondrial disease. Am J Med Genet 106,71-93.

Wallace DC, Shoffner JM, Trounce I, Brown MD, Ballinger SW, Corral-Debrinski M, Horton T, Jun AS and Lott MT (1995) Mitochondrial DNA mutations in human degenerative diseases and aging. Biochim Biophys Acta 1271,141-151.

Wallace DC, Singh G, Lott MT, Hodge JA, Schurr TG, Lezza AM, Elsas LJ, 2nd and Nikoskelainen EK (1988) Mitochondrial DNA mutation associated with Leber's hereditary optic neuropathy. Science 242,14271430.

Wang J, Wilhelmsson H, Graff C, Li H, Oldfors A, Rustin P, Bruning JC, Kahn CR, Clayton DA, Barsh GS, et al. (1999) Dilated cardiomyopathy and atrioventricular conduction blocks induced by heart-specific inactivation of mitochondrial DNA gene expression. Nat Genet 21,133-137.

Weber K, Wilson JN, Taylor L, Brierley E, Johnson MA, Turnbull DM and Bindoff LA (1997) A new mtDNA mutation showing accumulation with time and restriction to skeletal muscle. Am J Hum Genet 60,373380.

Wei YH and Lee HC (2002) Oxidative stress, mitochondrial DNA mutation, and impairment of antioxidant enzymes in aging. Exp Biol Med (Maywood) 227,671-682.

Weitzel JM, Iwen KA and Seitz HJ (2003) Regulation of mitochondrial biogenesis by thyroid hormone. Exp Physiol 88,121-128.

White SL, Collins VR, Wolfe R, Cleary MA, Shanske S, DiMauro S, Dahl HH and Thorburn DR (1999) Genetic counseling and prenatal diagnosis for the mitochondrial DNA mutations at nucleotide 8993. Am $\mathrm{J}$ Hum Genet 65,474-482.

White SL, Shanske S, Biros I, Warwick L, Dahl HM, Thorburn DR and Di Mauro S (1999) Two cases of prenatal analysis for the pathogenic $\mathrm{T}$ to $\mathrm{G}$ substitution at nucleotide 8993 in mitochondrial DNA. Prenat Diagn 19,1165-1168.

White SL, Shanske S, McGill JJ, Mountain H, Geraghty MT, DiMauro S, Dahl HH and Thorburn DR (1999) Mitochondrial DNA mutations at nucleotide 8993 show a lack of tissue- or age-related variation. J Inherit Metab Dis 22,899-914.

Wong LJ, Wong H and Liu A (2002) Intergenerational transmission of pathogenic heteroplasmic mitochondrial DNA. Genet Med 4,78-83.

Xin H, Woriax V, Burkhart W and Spremulli LL (1995) Cloning and expression of mitochondrial translational elongation factor Ts from bovine and human liver. J Biol Chem 270,17243-17249.

Zeviani M (2001) The expanding spectrum of nuclear gene mutations in mitochondrial disorders. Semin Cell Dev Biol 12,407-416. 
Zeviani M and Di Donato S (2004) Mitochondrial disorders. Brain 127,2153-2172.

Zhang H, Barcelo JM, Lce B, Kohlhagen G, Zimonjic DB, Popescu NC and Pommier Y (2001) Human mitochondrial topoisomerase I. Proc Natl Acad Sci U S A 98,10608-10613.

Zhang Y and Spremulli LL (1998) Identification and cloning of human mitochondrial translational release factor 1 and the ribosome recycling factor. Biochim Biophys Acta 1443,245-250. 
Pearson syndrome and the role of deletion dimers and duplications in the mtDNA

L.J.A.M. Jacobs' ${ }^{1}$, R.J.E. Jongbloed ${ }^{1}$, F.A. Wijburg' ${ }^{2}$, J.B.C. de Klerk ${ }^{3}$, J.P.M. Geraedts ${ }^{1}$, J.G. Nijland ${ }^{1}$, H.R. Scholte ${ }^{4}$, I.F.M. de $\mathrm{Coo}^{5}$, H.J.M. Smeets ${ }^{1}$. ${ }^{\prime}$ Department of Genetics and Cell Biology, University of Maastricht, Research Institute Growth and Development (GROW), Maastricht. ${ }^{2}$ Department of Paediatrics, Academic Medical Centre Amsterdam, Amsterdam. ${ }^{3}$ Department of Paediatrics, ${ }^{4}$ Biochemistry and ${ }^{5}$ Neurology, Erasmus MC-University Medical Center Rotterdam Journal of Inherited Metabolic Disease, Vol. 27, pp. 47-55, 2004 


\begin{abstract}
Pearson syndrome is an often fatal multisystem disease associated with mitochondrial DNA rearrangements. Here we report a patient with a novel mtDNA deletion of $3.4 \mathrm{~kb}$ ranging from nucleotides 6097 to 9541 in combination with deletion dimers. The mutation percentage in different tissues (blood, muscle and liver) varied between $64 \%$ and $95 \%$. After a remission period of about a year the patient suddenly died at the age of three years due to a severe lactic acidosis. A second patient with a previously reported deletion of $8 \mathrm{~kb}$ and a milder phenotype was found to have mitochondrial duplications and died at the age of ten years. From these data and data from previous reports we hypothesised that duplications might be beneficial in the clinical course of the disease and in life expectancy.
\end{abstract}

\title{
Introduction
}

Pearson syndrome (McKusick 557000) is a multisystem disease including refractory anaemia, vacuolisation of marrow precursors and pancreatic fibrosis (Pcarson H.A., 1979). The disease starts during infancy and affects various tissues and organs. Most children diagnosed with Pearson syndrome die before the age of three years. It has been reported that children who survive eventually develop Kearns-Sayre syndrome (KSS) (Rotig et al., 1995) (McKusick 530000) a progressive multisystem disease characterised by ophthalmoplegia, retinal pigmentary degeneration and at least one of the following symptoms: elevated cerebrospinal fluid protein, heart block sensorineural hearing loss, ataxia, small stature, ptosis, lactic acidosis and endocrine dysfunction (Kearns T.P., 1958; DiMauro, 1993). Age at onset of KSS usually occurs before the age of 20 years.

Pearson syndrome is caused by mtDNA deletions (Rotig et al., 1990) and the most common deletion is a 4977 bp deletion located between nt 8488 and nt 13460. This deletion has been identified in more than $80 \%$ of the affected children. Since the first report in 1990 (Rotig et al., 1990), many other deletions have been detected (MITOMAP, 2001). Here we describe a novel small mtDNA deletion in a young patient with Pearson syndrome. The phenotype and genotype of this patient have been compared to a previously described patient with Pearson syndrome (van den Ouweland et al., 2000), who carried an $8 \mathrm{~kb}$ deletion. The presence and phenotypic affect of deletion dimers and duplications was investigated.

\section{Patients}

Patient 1: Patient 1, a girl, was born after a normal pregnancy to healthy unrelated parents who had no family history of mitochondrial myopathy and 2 healthy siblings. At 16 months of age the first symptoms became manifest and the girl was examined for a slight growth retardation and pancytopenia of unknown origin with anaemia. At 22 months of age, after a viral infection, the patient was hospitalised because of severe tachypnoea, lethargy and dyspnoea accompanied by fever. Biochemical analysis revealed a metabolic acidosis with a high lactate value in blood of 8.2 $\mathrm{mM}$ (normal 0.6-2.0 mM). These symptoms indicated Pearson syndrome, which was confirmed by DNA investigation. Biochemical tests of muscle revealed a respiratory chain defect. After one month the situation of the child improved 
spontaneously and further hospitalisation was not necessary. One year later the condition of the child deteriorated rapidly due to an infection and she died at the age of 39 months of severe metabolic failure with a very high blood lactate level of $28 \mathrm{mM}$.

Patient 2: Patient 2 has been described previously (van den Ouweland et al., 2000). This patient carried an 8034 bp mtDNA deletion spanning from position 7934 to 15968 flanked by an imperfect 11 bp repeat. She showed a failure to thrive as the first sign of disease in her first year of life. At the age of three years this was followed by other signs of Pearson syndrome with anaemia, a severe Fanconi-like tubulopathy, lactic acidosis and diabetes mellitus type II, but no signs of exocrine pancreas dysfunction. After a period of about a year in which she seemed to recover, she developed a full blown Kearns-Sayre syndrome with ataxia, retinitis pigmentosa, external ophthalmoplegia, sensorineural deafness and growth hormone deficiency. The deletion was present in different percentages of mutated mtDNA in different tissues. The deletion could not be detected in the DNA from the patient's mother and the younger brother. Biochemical analysis of muscle and liver at age $2 \mathrm{y}, 11 \mathrm{~m}$ and $4 \mathrm{y}, 8 \mathrm{~m}$ indicated deficiency of complex IV (on wet weight basis: muscle 23 and $43 \%$ of controls, liver 21 and 12\%), with highly increased citrate synthetase in muscle (204 and 305\% of controls). The activity of complex I was 50 and $78 \%$ in muscle and $65 \%$ in liver, and that of complex II+III 23 and $43 \%$ and 21 and $12 \%$. The oxidative phosphorylation in isolated muscle mitochondria was normal. The oxidation of pyruvate plus malate was normal on protein basis but decreased on basis of citrate synthetase to 41 and $51 \%$ of the average controls. She gradually developed more symptoms including renal disease until she died at the age of 10 years.

\section{Methods}

Long range PCR: Total DNA was extracted from peripheral blood, muscle and liver samples as described previously (Miller et al., 1988). A $16.2 \mathrm{~kb}$ amplified mtDNA fragment was generated by using the Expand Long PCR kit (Roche, Basel, Switzerland). Amplification was performed in a total volume of $50 \mu \mathrm{l}$, using dNTP's (Amersham Pharmacia Biotech $A B$, Uppsala, Sweden, $25 \mathrm{mM}$ each), $5 \mu$ Buffer 2 (provided with the Expand-Long PCR kit), 1.75 U DNA polymerase and $100 \mathrm{ng}$ of each primers (forward primer (F): nt 15149-15175: 5'-TGAGGCCAAATATCATTCTGAGGGGC-3' and reverse primer (R): nt 14816-14790: 5'-TTTCATCATGCGGAGATGTTGGATGG-3'). The PCR reactions were carried out in a 9600 thermocycler (Perkin-Elmer) using the following conditions: $94^{\circ} \mathrm{C} 1 \mathrm{~min} ; 14$ cycles of $98^{\circ} \mathrm{C}$ for $10 \mathrm{~s}$ and $68^{\circ} \mathrm{C}$ for $15 \mathrm{~min} ; 16$ cycles of $98^{\circ} \mathrm{C}$ for $10 \mathrm{~s}$ and $68^{\circ} \mathrm{C}$ for 15 min plus $15 \mathrm{~s}$ per elongation step; and a final 10 min elongation at $72^{\circ} \mathrm{C}$.

Short range PCR: Short range amplification has been performed in a total volume of $25 \mu$, using dNTPs (Amersham Pharmacia Biotech AB, Uppsala, Sweden, $4 \mathrm{mM}$ each), $15 \mathrm{mM}$ $\mathrm{MgCl}_{2}, 0.5 \mathrm{M} \mathrm{KCl}, 0.1 \mathrm{M}$ Tris-HCl, $1 \mathrm{U}$ Taq DNA polymerase (Invitrogen, Life Technologies, Breda, The Netherlands) and $100 \mathrm{ng}$ of each primer. The PCR reactions were 
carried out in a 9700 thermocycler (Perkin-Elmer) using the following conditions: $94^{\circ} \mathrm{C}$ for 3 min; 32 cycles of $92^{\circ} \mathrm{C}$ for $1 \mathrm{~min}$, annealing temperature for $1 \mathrm{~min}$ and $72^{\circ} \mathrm{C}$ for $2 \mathrm{~min}$; and a final 7 min elongation at $72^{\circ} \mathrm{C}$

Sequence analysis: Scquencing reactions were performed in a total volume of $20 \mu \mathrm{l}$ using 2 $\mu l$ Big Dye termination solution according to the protocols of the manufacturer (Applied Biosystems, Foster City, USA) and 50 ng forward or reverse primer. Results were obtained on the ABI Prism 377 DNA automatic sequencer (Applied Biosystems, Foster City, USA) and analysed by using ABI software version 3.1.

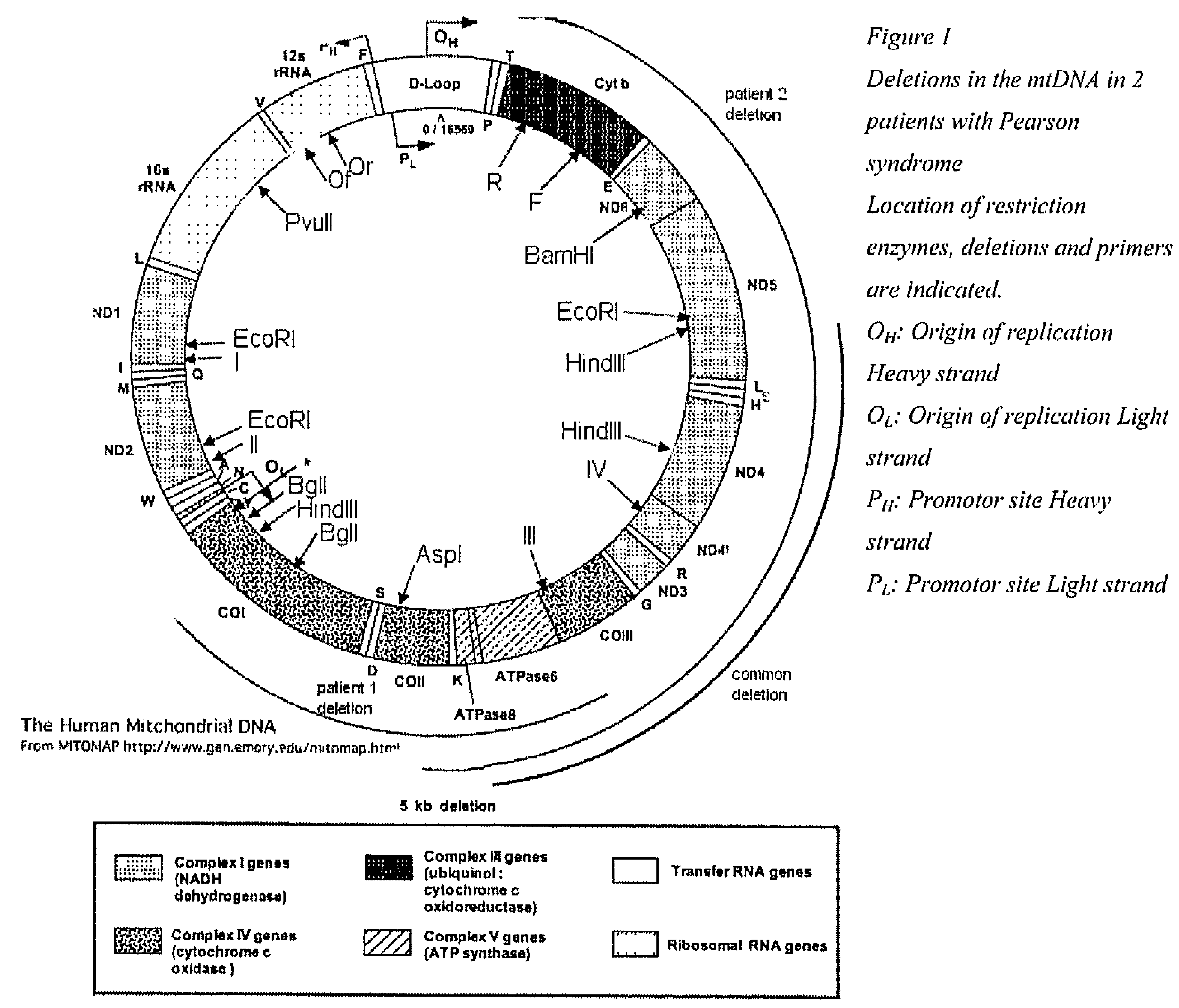

Southern blot analysis: Total genomic DNA $(5 \mu \mathrm{g})$ and PCR amplified mtDNA products were digested with different restriction endonucleases (Boehringer-Mannheim, Bayern, Germany). Subsequently DNA fragments were separated by electrophoresis on $0.9 \%$ agarose gels (MethaPhor; Biozym, Landgraaf, The Netherlands), transferred onto Hybond $\mathrm{N}^{+}$ membrane by Southern blotting (Sambrook, 1998) and hybridised with a, random primed 
(Invitrogen, Life technologies, Breda, The Netherlands) ${ }^{32} \mathrm{P}$ dCTP-labelled amplified mtDNA fragment containing either the origin domain (forward primer Of 1330-1355 and reverse primer Or 778-753) or fragments located in the deleted region of the patients. Hybridisation and washing conditions are performed according to the standard conditions (Sambrook, 1998). Hybridisation signals were visualised on an X-ray film (Kodak Nederland B.V. Service Center Amsterdam, The Netherlands) by autoradiography and quantified using the Intelligent Quantifier software (B\&L systems, Maarssen, The Netherlands).

\section{Results}

The amplified mtDNA fragment of patient 1 revealed a deletion of about $3.4 \mathrm{~kb}$ (figure 1). The fragment containing the deletion junction was sequenced and the deletion turned out to range from position 6097 to 9541 . The deletion included several structural (COI partial, COII, ATPase8, ATPase6 and COIII partial) and tRNA (tRNA ${ }^{\text {ser }}$, tRNA ${ }^{\text {asp }}$ and tRNA ${ }^{\text {lys }}$ ) genes. At the junction site a short direct repeat sequence "AAT" was detected. Southern blot analysis of the PvuII digested DNA sample of patient 1 revealed a normal and a discrete $3.4 \mathrm{~kb}$ smaller mtDNA fragment (figure 2). The percentages of the deleted mtDNA were determined by measuring X-ray signal intensities of the normal mtDNA fragment and the deleted fragment from several tissues. The signal intensity of the deleted fragment was divided by the sum of the intensities of both the deleted and normal fragment, giving a molecular ratio. The proportion of deleted to total mtDNA was $74 \%$ in blood, $63 \%$ in muscle and $95 \%$ in liver. The deletion was undetectable in blood cells of the patient's mother analysed by Southern blot (results not shown).

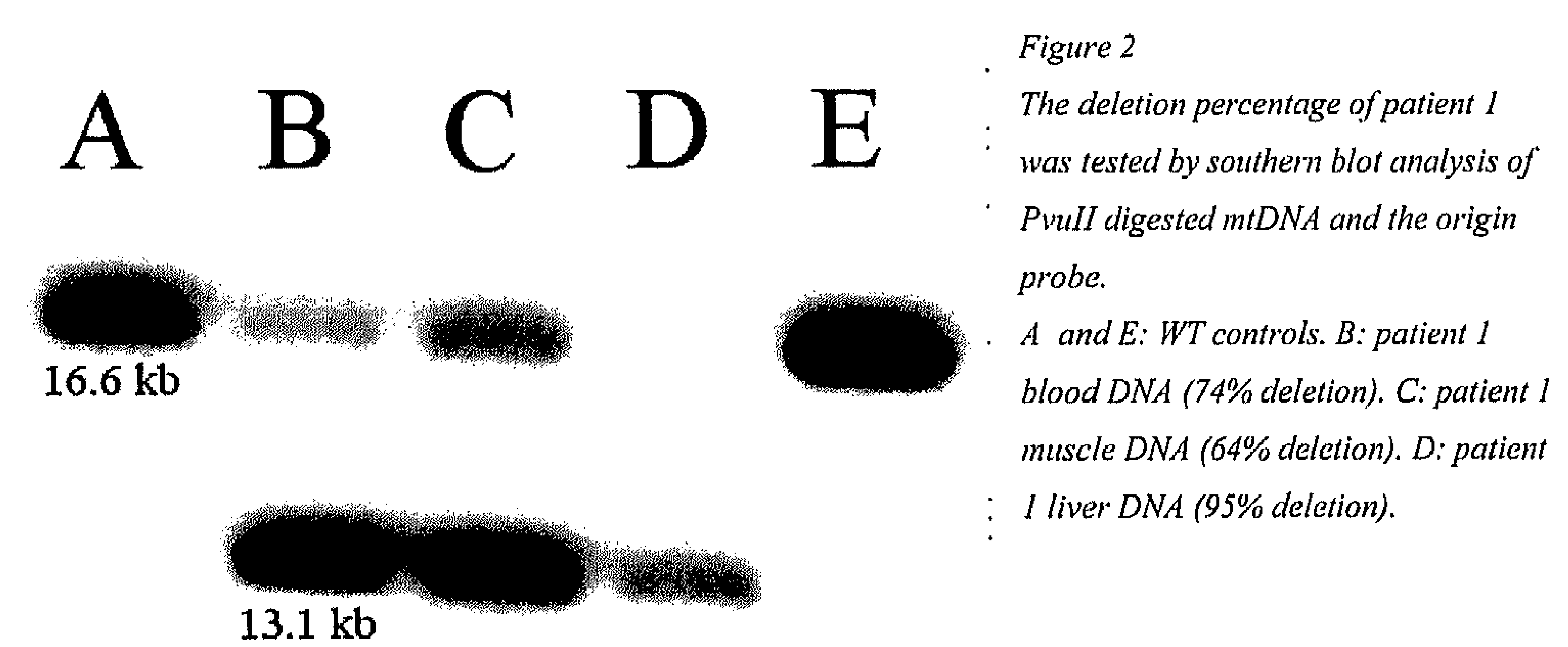

It has been hypothesised (Poulton and Holt, 1994; Poulton et al., 1994) that the presence of deletion dimers (a combination of two deleted fragments) and/or duplications (a combination of a normal and a deleted fragment) may affect the progression of the disease. Therefore, we investigated this in our patients. Deletion dimers and duplications were identified by cutting 
the mtDNA with enzymes, which recognise restriction sites inside, or outside the deleted fragment and hybridising them with mtDNA probes inside or outside the deleted fragment. Digestions have been performed with PvuII, AspI or BamHI (Figure 1 and 3). PvulI cuts outside the deleted fragment of both patients, while the AspI and the BamHI enzyme cut inside the mitochondrial deletion of the first and second patient respectively. In the presence of deletion dimers or duplications, larger fragments than the wild-type mtDNA will appear on the Southern blot results, when using the origin probe and a restriction enzyme that cuts inside the deletion. These fragments include circular and nicked circular monomeric deletion fragments, dimeric fragments and circular dimeric fragments. However by using a probe located inside the deletion fragment a larger fragment will only be seen in case of a duplication. If a deletion dimer is present when using the deletion probe, only the normal mtDNA fragment will be visible on the southern blot.
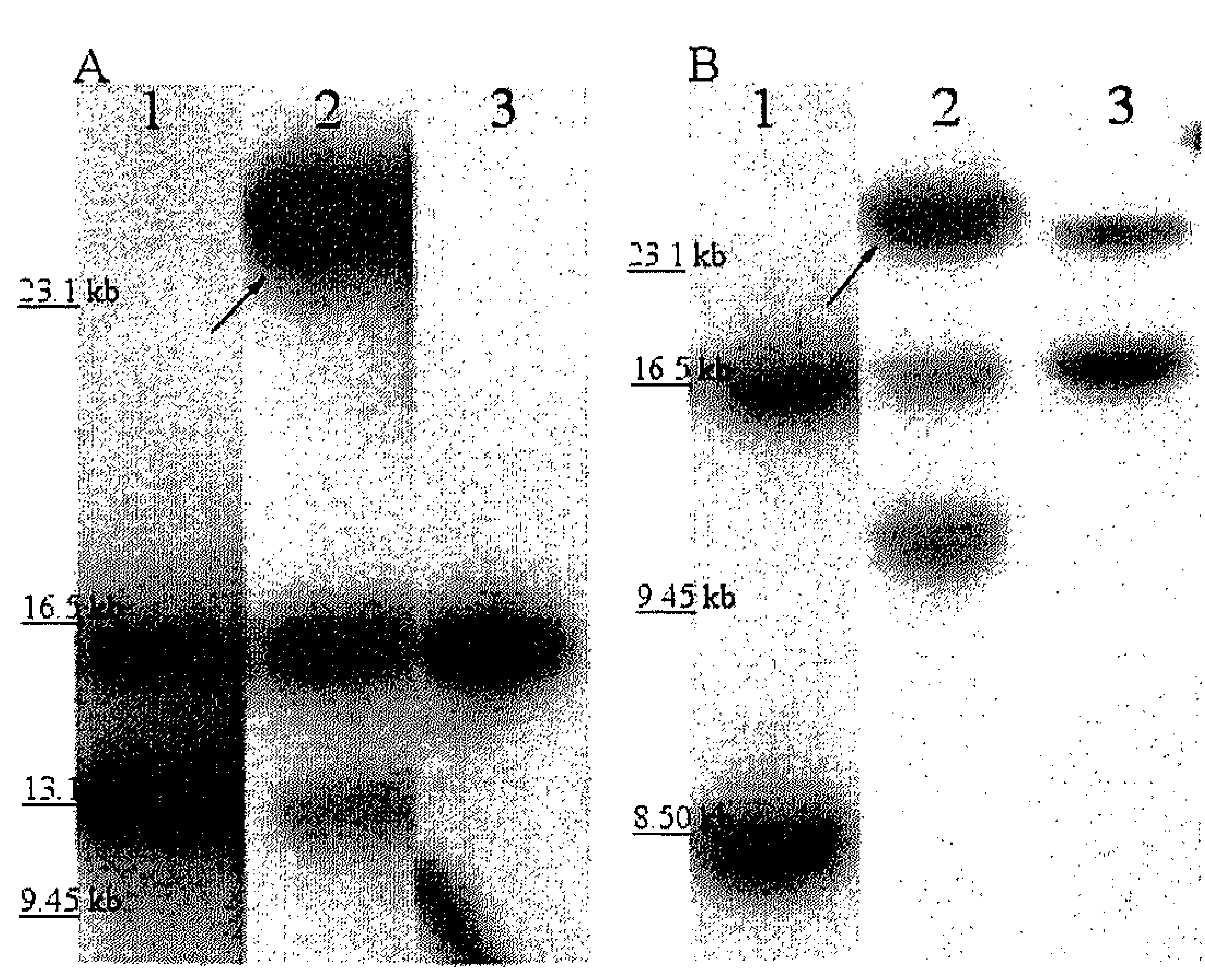

Figure 3

Deletion dimers and diplications of normal and deleted miDNA in two patients with Pearson Syndrome.

A: Patient 1 with a $m t D N A$ deletion and $a$ deletion dimer.

The mtDNA is digested with PvuII (lane 1) and AspI (lanes 2 and 3) and hybridised with the origin probe (lane I and 2) or a deletion-specific probe (lane 3). The normal mtDNA band of

$16.5 \mathrm{~kb}$ is seen in all lanes, together with $a 13.1 \mathrm{~kb}$ deletion fragment in lanes 1 and 2 (3.4 kb deletion) and a larger fragment of about $26 \mathrm{~kb}$ in lane 2 (indicated by an arrow) which is a deletion dimer. B: Patient 2 with a $m t D N A$ deletion and a duplication

The mtDNA is digested with PvuII (lane 1) and BamHI (lanes 2 and 3) and hybridised with the origin probe (lane 1 and 2) or a deletion-specific probe. The normal fragment of $16.5 \mathrm{~kb}$ is seen in all lanes, together with an $8.5 \mathrm{~kb}$ deletion fragment in lane 1 ( $8 \mathrm{~kb}$ deletion) a circular deletion monomer and a duplication (arrow) in lane 2 and 3.

Fragment length is determined by using a $\lambda$-HindIII marker (sizes are indicated), restriction sites are as indicated in figure 1 . 
The first patient has a larger fragment after digestion using AspI as can be seen in lane 2 of figure $3 \mathrm{~A}$. This fragment could be a circular version of the deletion monomer but given the size and location of the monomeric deletion fragment, which is identical in lane 1 and 2 , and of the larger fragment it is more likely to be a deletion dimer. The deletion is linearised by breaks in the DNA (results not shown) raised during DNA extraction or because of the age of the DNA. The deletion dimer is seen in all tissues tested but there are no signs of duplications (figure 3A lane 3 ). In the blood of the second patient a deletion fragment of $8.5 \mathrm{~kb}$ can be seen in lane 1 of figure 3B. In lane 2 after digestion using BamHI a slightly larger fragment is visible of about $11 \mathrm{~kb}$, this is a circular version of the deletion fragment. A larger fragment of about $25 \mathrm{~kb}$ is visible in lanes 2 and 3 . Because this fragment is also visible using a deletion probe we can conclude that it is a duplication.

\section{Discussion}

We report a novel mtDNA deletion in a child whom initially improved after being severely ill from Pearson syndrome but died a few months later. A short 3 bp repeat sequence (AAT) flanks the deletion. The vast majority of delctions reported are flanked by short repeat sequences as well, ranging from 3-14 bp in length (Tanaka et al., 1989; Mita et al., 1990; Ota et al., 1994). It has been hypothesised that these deletions are the result of loop formations between these repeat sequences during mtDNA replication in the developing oocyte. No minimal area of overlap is found between the different deletions reported, either causing Pearson syndrome or any of the other deletion syndromes, so there is no minimal region in the mtDNA that has to be deleted to cause symptoms. It is however known that at least one tRNA gene has to be removed to cause one of the common deletion syndromes (KSS, CPEO or Pearson syndrome) (Tang Y. et al., 2000). The $3.4 \mathrm{~kb}$ deletion in patient 1 was detected in all tissue samples tested including blood, muscle and liver. It belongs to the category of small deletions, although the clinical phenotype is severe and eventually fatal. Compared to other previously reported deletions located within the same area, no correlation can be found between the location and size of the deletion and the severity of the disease (Rotig et al., 1995). In comparison with our patient 1 who has a $78 \%$ amount of a $3.4 \mathrm{~kb}$ deletion (position 6097-9541), Rötig et al. (1995) described a 5 year old Pearson patient having $80 \%$ of a $3.1 \mathrm{~kb}$ deletion (nt 6074-9179), this deletion is comparable to the one found in our patient ( $78 \%$ of a $3.4 \mathrm{~kb}$ deletion at position 6097-9541). But there patient suffered from primarily diarrhoea and anaemia and had no signs of pancreatic or hepatic involvement.

Patient 2 carried a deletion of $8 \mathrm{~kb}$ spanning from position 7934 to 15968 (van den Ouweland et al., 2000). The differences between patient 1 and 2 involve the sizes of the deletions, the presence of dimers/duplications, the age at onset and the life expectancy. The deletion identified in the second patient was larger than the deletion in patient 1 and encompasses more genes (partial COII, ATPases 6 and 8, COIII, ND3, ND4L, ND4, ND5, ND6, cytb and 8 tRNAs (Lys, Gly, Arg, His, Ser, Leu, Glu, Thr and partial Pro)). However, the deletion percentages were comparable in 3 tissues tested in both patients. Despite the larger deletion, 
patient 2 presents a less severe phenotype and died later than patient 1 . This has been documented before in several deletion syndromes. Rotig et al. (1995) detected a $85 \% 6.7 \mathrm{~kb}$ deletion in blood of a 3 year old child with less severe symptoms and a better life expectancy than a child that died at the age of 13 months with more severe symptoms and a $55 \% 4.2 \mathrm{~kb}$ deletion in lymphoblastoid cells. This indicates that the size and percentage of the deletion are no good predictors of the clinical course and severity of the disease.

An alternative explanation for differences in life expectancy and phenotype could be the presence of deletion dimers or duplications in the mtDNA (Poulton and Holt, 1994; Rotig et $a l ., 1995)$. Both our patients displayed other mtDNA rearrangements in addition to the deletion in the form of dimerisations or duplications. The significance of these deletiondimers and duplications is still unclear. Several investigations point towards little or no pathogenic significance of mtDNA duplications (Rotig et al., 1995; Muraki et al., 2001), although others find that mtDNA duplications might influence the severity of the deletion disease in a positive way (Poulton and Holt, 1994). MtDNA duplications may also be involved in the progression from Pearson syndrome to KSS, as duplications are a distinctive feature of KSS. Children with Pearson syndrome who progress to KSS, harbour duplications which could not be detected in children with only Pcarson syndrome (Poulton and Holt, 1994; Poulton et al., 1994; Poulton et al., 1995). Increasing deletion dimers appear to be correlated with worsening of the disease symptoms (Poulton and Holt, 1994). Rötig et al (1995) on the other hand found that most patients who develop KSS do not harbour duplications or deletion dimers and that there is no correlation between the rearrangements and the clinical course of the disease. As duplications may be missed by the method used it should be worthwhile to test these patients with a duplication specific PCR method (Muraki et al., 2001).

Another aspect reported regularly for mitochondrial duplications but only once for deletions is that duplications can be maternally inherited (Rotig et al., 1992; Dunbar et al., 1993; Poulton et al., 1993; Ballinger et al., 1994; Manfredi G. et al., 1997; Shanske et al., 2002), suggesting that the recurrence risk for the mother of patient 2 may be increased. It is thought that deletions in oocytes could impair the fertilisation of the oocyte (Hsieh et al., 2002) but this interference is neither known nor tested for duplications. This could be investigated by testing the mtDNA for deletions and duplications in oocytes of women with idiopathic infertility.

Here we describe two patients with Pearson like syndromes with a different clinical course. We have been looking for a relation between phenotypic differences and the presence of dimerisations and duplications. Our results confirm the earlier observations of Poulton (Poulton and Holt, 1994; Poulton et al., 1995) that duplications, in contrast to dimerisations, may lead to a better life expectancy and a less severe phenotype with KSS-like symptoms. 


\section{References}

Ballinger SW, Shoffner JM, Gebhart S, Koontz DA and Wallace DC (1994) Mitochondrial diabetes revisited. Nat Genet 7,458-459.

DiMauro (1993) Mitochondrial encephalomyopathies. The molecular and genetic basis of neurological disease. Boston, Butterworth-Heimann,665-694.

Dunbar DR, Moonie PA, Swingler RJ, Davidson D, Roberts R and FIolt IJ (1993) Maternally transmitted partial direct tandem duplication of mitochondrial DNA associated with diabetes mellitus. Hum Mol Genet 2,1619-1624.

Hsieh RH, Tsai NM, Au HK, Chang SJ, Wei YH and Tzeng CR (2002) Multiple rearrangements of mitochondrial DNA in unfertilized human oocytes. Fertil Steril 77,1012-1017.

Kearns T.P. SGP (1958) Retinitis pigmentosa, external opthalmoplegia, and complete herat block. Unusual syndrome with histologic study in one of two cases. Arch Opthalmol 60,280-289.

Manfredi G., Vu T., Bonilla E., Schon E. A., DiMauro S., Arnaudo E., Zhang L., Rowland L. P. and M. $\mathrm{H}$ (1997) Association of Myopathy with Large-Scale Mitochondrial DNA Duplications and Deletions: Which is Pathogenic? Annals of Neurology 42,180-188.

Miller SA, Dykes DD and Polesky HF (1988) A simple salting out procedure for extracting DNA from human nucleated cells. Nucleic Acids Res 16,1215.

Mita S, Rizzuto R, Moraes CT, Shanske S, Arnaudo E, Fabrizi GM, Koga Y, DiMauro S and Schon EA (1990) Recombination via flanking direct repeats is a major cause of large- scale deletions of human mitochondrial DNA. Nucleic Acids Res 18,561-567. MITOMAP (2001) MITOMAP: A Human Mitochondrial Genome Database. Center for Molecular Medicine, Emory University, Atlanta, GA, USA. httn://www.gen.emory.edu/mitomap.html. Muraki K, Sakura N, Ueda H, Kihara H and Goto Y (2001) Clinical implications of duplicated mtDNA in Pearson syndrome. Am J Med Genet 98,205-209.

Ota Y, Miyake Y, Awaya S, Kumagai T, Tanaka M and Ozawa T (1994) Early retinal involvement in mitochondrial myopathy with mitochondrial DNA deletion. Retina 14,270-276.

Pearson H.A. ea (1979) A new syndrome of refractory sideroblastic anemia with vacuolization of marrow precursors and exocrine pancreatic dysfunction. Joumal of pediatrics 95,976-984.

Poulton J, Deadman ME, Bindoff L, Morten K, Land J and Brown G (1993) Families of mtDNA rcarrangements can be detected in patients with mtDNA deletions: duplications may be a transient intermediate form. Hum Mol Genet 2,23-30.

Poulton J and Holt IJ (1994) Mitochondrial DNA: does more lead to less? Nat Genet 8,313-315.

Poulton J, Morten KJ, Marchington D, Weber K, Brown GK, Rotig A and Bindoff L (1995)

Duplications of mitochondrial DNA in Kearns-Sayre syndrome. Muscle Nerve 3,S154-158.

Poulton J, Morten KJ, Weber K, Brown GK and Bindoff L (1994) Are duplications of mitochondrial

DNA characteristic of Kearns-Sayre syndrome? Hum Mol Genet 3,947-951.

Rotig A, Bessis JL, Romero N, Cormier V, Saudubray JM, Narcy P, Lenoir G, Rustin P and Munnich A (1992) Maternally inherited duplication of the mitochondrial genome in a syndrome of proximal tubulopathy, diabetes mellitus, and cerebellar ataxia. Am J Hum Genet 50,364-370.

Rotig A, Bourgeron T, Chretien D, Rustin P and Munnich A (1995) Spectrum of mitochondrial DNA rearrangements in the Pearson marrow- pancreas syndrome. Hum Mol Genet 4,1327-1330.

Rotig A, Cormier V, Blanche S, Bonnefont JP, Ledeist F, Romero N, Schmitz J, Rustin P, Fischer A, Saudubray IM, et al. (1990) Pearson's marrow-pancreas syndrome. A multisystem mitochondrial disorder in infancy. J Clin Invest 86,1601-1608.

Sambrook J, E. F. Fritsch and T. Maniatis (1998). Molecular Cloning: a Laboratory Manual. 2nd ed.. NY., Cold Spring Harbor Press.

Shanske S, Tang Y, Hirano M, Nishigaki Y, Tanji K, Bonilla E, Sue C, Krishna S, Carlo JR, Willner J, et al. (2002) Identical mitochondrial DNA deletion in a woman with ocular myopathy and in her son with pearson syndrome. Am J Hum Genet 71,679-683. 
Tanaka M, Sato W, Ohno K, Yamamoto T and Ozawa T (1989) Direct sequencing of deleted mitochondrial DNA in myopathic patients. Biochem Biophys Res Commun 164,156-163.

Tang Y., Schon E. A., Wilichowski E., Vazquez-Memije M. E., Davidson E. and P. KM (2000) Rearrangements of Human Mitochondrial DNA (mtDNA): New Insights into the Regulation of mtDNA Copy Number and Gene Expression. Molecular Biology of the Cell 11,1471-1785.

van den Ouweland JM, de Klerk JB, van de Corput MP, Dirks RW, Raap AK, Scholte HR, Huijmans JG, Hart LM, Bruining GJ and Maassen JA (2000) Characterization of a novel mitochondrial DNA deletion in a patient with a variant of the Pearson marrow-pancreas syndrome. Eur J Hum Genet 8,195-203. 


\section{cancin 4}

\section{Transmission and prenatal diagnosis of the $\mathrm{T} 9176 \mathrm{C}$ mitochondrial}

DNA mutation

L.J.A.M. Jacobs ${ }^{1}$, I.F.M. de Coo ${ }^{2}$, J.G. Nijland ${ }^{1}$, RJ.H. Galjaard ${ }^{3}$, F.J. Los ${ }^{3}$, K. Schoonderwoerd $^{4}$, M.F. Niermeijer ${ }^{5}$, J.P.M. Geraedts' ${ }^{1}$, H.R. Scholte ${ }^{4}$, H.J.M. Smeets ${ }^{1}$. ${ }^{1}$ Department of Genetics and Cell Biology, Research Institute GROW, University Maastricht. Department of ${ }^{2}$ Child Neurology, ${ }^{3}$ Clinical Genetics and ${ }^{4}$ Biochemistry, Erasmus MCUniversity Medical Center Rotterdam, ${ }^{5}$ Department of Human Genetics, University Medical Center Nijmegen, St Radboud, Nijmegen. Molecular Human Reproduction, Vol.11, No.3, pp. 223-228, 2005 


\begin{abstract}
A family presented with 3 affected children with Leigh syndrome, a progressive neurodegenerative disorder. Analysis of the OXPHOS complexes in muscle of two of the affected patients showed an increase in activity of pyruvate dehydrogenase and a decrease of complex V activity. Mutation analysis revealed the T9176Cmutation in the mt ATPase 6 gene (OMIM 516060) and the mutation load was above $90 \%$ in the patients. Unaffected maternal relatives were tested for carrier-ship and one of these with a mutation load of $55 \%$ in blood was pregnant of her first child. The possibility of prenatal diagnosis was evaluated. The main problem was the lack of data on genotype-phenotype correlations for the T9176C mutation and on variation of the mutation percentage in tissues and in time. Therefore multiple tissues of affected and unaffected carriers were analyzed. Eventually prenatal diagnosis was offered with understanding by the couple that there could be considerable uncertainty in the interpretation of the results. Prenatal diagnosis was carried out twice on cultured and uncultured chorion villi and amniotic fluid cells. The result was a mutation percentage just below the assumed threshold of expression (90\%). The couple decided to continue the pregnancy and an apparently healthy child was born with an as yet unclear prognosis. This is the first prenatal diagnosis for a carrier of the T9176C mutation. Prenatal diagnosis for this mutation is technically reliable but the prognostic predictions are not straightforward. Key words: Leigh syndrome, mtDNA, prenatal diagnosis, preimplantation genetic diagnosis
\end{abstract}

\title{
Introduction
}

Leigh syndrome (OMIM 256000) or subacute necrotizing encephalomyopathy is a progressive neurodegenerative disorder with a poor prognosis and most of the patients die within a few years after age at onset (Rahman et al., 1996). Symptoms, occurring in early infancy or childhood, are psychomotor developmental regression, optic atrophy, ophthalmoparesis, nystagmus, ataxia, dystonia, failure to thrive and respiratory abnormalities. Characteristics are bilateral necrotic lesions on MRI in basal ganglia and brainstem and lactic acidosis. Leigh syndrome is caused by functional or molecular defects in the enzyme complexes involved in the mitochondrial energy production, including pyruvate dehydrogenase and OXPHOS complexes I, II, IV and V (DiMauro and Tanji, 1997; Dahl, 1998: Tanji et al., 2001). The inheritance of Leigh syndrome is either autosomal recessive, autosomal dominant, X-linked or maternal, and defects in nuclear genes or mitochondrial DNA (mtDNA) can cause this disease.

In this paper, we describe a family with Leigh disease caused by a mutation in the ATPase 6 gene (OMIM 516060) at position 9176 of the mtDNA (Thyagarajan et al., 1993; Campos et al., 1997; Dionisi-Vici et al., 1998; Makino et al., 1998; Makino et al., 2000; Wilson et al., 2000; Akagi et al., 2002). The severe clinical manifestations of this disease occur at mutation percentages above 90\% (Thyagarajan et al., 1993; Campos et al., 1997; Dionisi-Vici et al., 1998; Makino et al., 1998; Makino et al., 2000; Wilson et al., 2000; Akagi et al., 2002). The mutation is maternally transmitted, but the percentage of this mutation may 
vary widely between oocytes, making the transmission of the associated Leigh disease fairly unpredictable (Hauswirth and Laipis, 1982; Howell et al., 2000). Mitochondria go through a genetic bottleneck in oogenesis or early embryogenesis, which involves both a reduction in number of mitochondria and of mtDNA molecules to only a very few, that subsequently repopulate the oocyte. For point mutations in the mtDNA three criteria have been proposed to allow reliable prenatal diagnosis (Poulton and Marchington, 2000; Poulton and Turnbull, 2000).

(I) A close correlation between the proportion of mutant: wild-type mtDNA (mutation load) and disease severity.

(II) A uniform distribution of mutant mtDNA in all tissues.

(III) No change in mutant load over time.

For most mtDNA mutations this information is lacking. Only a few mutations meet these criteria like the T8993G/C (associated with another form of Leigh syndrome) and A8344G (associated with MERRF syndrome i.e. myoclonic epilepsy and ragged red fibers) mutation, but not the common A3243G (associated with the MELAS syndrome, i.e. mitochondrial encephalopathy with lactic acidosis and stroke like episodes). Here we describe the segregation of the T9176C mutation in a family with Leigh syndrome and the development and implementation of a prenatal test for this mutation.

\section{Patients and Methods}

\section{Patients}

Case reports from a family with maternal Leigh syndrome.

The index patient (III-2, fig 1) first presented at the age of 21 months, with a sub-acute onset of cerebellar ataxia and speech retardation. The pregnancy was complicated by toxicosis but delivery and development during the first year were unremarkable. She walked at 12 months. At the age of 3 years, after a period with fever, she had an attack with loss of tone of her right arm and leg that lasted for three days. Clinical examination showed a further increased cerebellar ataxia with signs of dystonic posturing of the right arm and leg. She was a happy child and was apparently not impeded by the handicap. She spoke a few words only but was able to express herself with gestures. At 4 years and 9 months of age she was admitted in the hospital because of the suspicion of a metabolic derangement, after four weeks of stomachache, dyspnoea, and increasing fatigue and weakness. A sick girl was seen with irregular breathing and deep set eyes. Apart from the cerebellar ataxia there were pyramidal tract signs with very easily elicited reflexes and extensor toe signs on both feet. Magnetic resonance imaging and computerized tomography of the brain showed extensive vaguely demarcated hypodensities in the cerebellar hemispheres, pons and mesencephalon. Supratentorially there were hypodense lesions in the caudate nuclei, the internal capsule and the basal ganglia. Peripheral and central CSF spaces were enlarged. Lesions could be compatible with infarctions in parts of the basilar and the internal carotid artery region. The clinical phenotype combined with lactic acidosis and CSF involvement made a mitochondrial 
encephalopathy or Leigh-like syndrome likely. The child's condition worsened and in the following two weeks time she developed severe apnoeic and hypoventilation spells and became ventilator dependent. She died from progressive brainstem dysfunction. She underwent a muscle biopsy a few hours before death but there has been no post mortem examination.

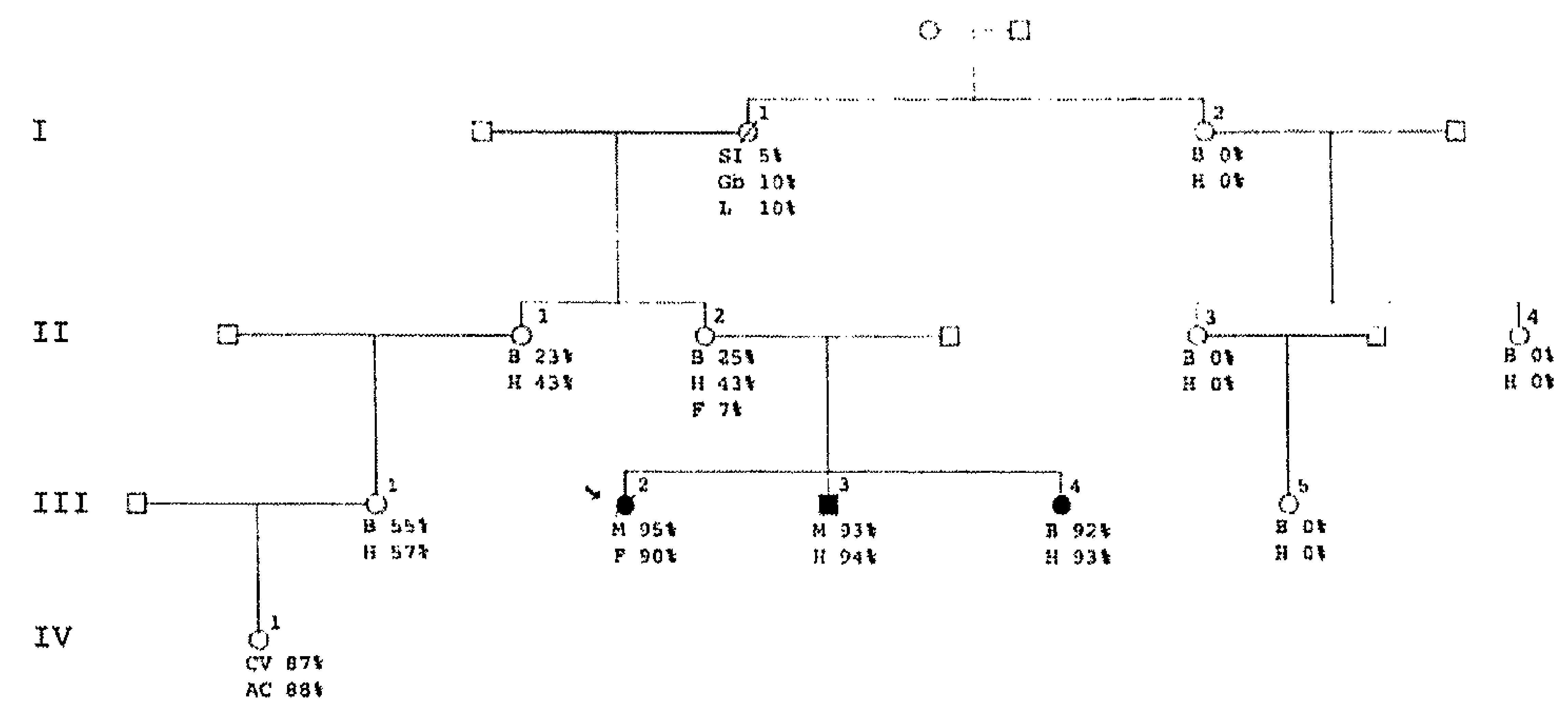

Figure I

Segregation of the mtDNA T9176C mutation in a large Dutch family with Leigh syndrome.

The percentage of the mutation is indicated below each individual. Solid symbols indicate affected and open symbols unaffected individuals. B: Blood, M: Muscle, F: Fibroblasts, H: Hair roots, Gb: Gall bladder, SI: Small intestine, CV: Uncultured Chorion villi, L: Liver, AC: Uncultured Amniotic fluid cells.

The younger brother (III-3) and sister (III-4) of the index patient (III-2) developed a cerebellar ataxia with an onset at age 2 years. Their language development was slightly delayed. Both received, from age 4 and 2 respectively, daily vitamin B complex containing $100 \mathrm{mg}$ vit $\mathrm{Bl}, 2,3,5,6,50 \mathrm{mg}$ vitamin $\mathrm{E}$ and $3 \mathrm{dd} 330 \mathrm{mg}$ carnitine. From the age of 3 , after viral illnesses, attacks of one to several days occurred with loss of tone resulting in paraparesis losing ambulation, sighing, dyspnoea and dystonic movements. At the age of 4 the diagnosis mitochondrial encephalomyopathy of the boy was confirmed by determination of the T9176C mutation in DNA from muscle and blood (van Den Bosch et al., 2000). Subsequently the DNA analysis in the other family members took place. The boy (III-3) was still ambulant at age 8 , with a cerebellar ataxia, generalized mild dystonic movement disorder, a discrete pyramidal syndrome and speaks only a few words. His total IQ is 55 . The EEG showed a slight delay of the background pattern. The cerebellar hemispheres showed in the cortical and subcortical regions on MRI extensive abnormalities in the flair and T2 spin echo. A quadriceps muscle biopsy showed at electron microscopy an increase of lipid droplets and enlarged mitochondria. At the age of 6 , the girl (III-4) had milder problems than her brother. She speaks in short, poorly articulated sentences. Her EEG showed a slight delay in 
background pattern. The MRI showed very discrete abnormalities in the cerebellar hemispheres.

The mother of the index patient (II-2) has periodically stomach ache but no neurological abnormalities. None of the unaffected family members showed movement disorders or other neurological or psychiatric abnormalities. All numbered patients (fig 1) were clinically examined except the grandmother of the index patient (I-1). She died from a gastrointestinal tumor.

\section{Methods}

\section{Muscle biochemistry}

Muscle biopsies were obtained from the index patient (quadriceps) and brother under generalized anesthesia. Frozen muscle specimens were weighed and homogenised in $0.25 \mathrm{M}$ sucrose, $10 \mathrm{mM}$ Hepes and $1 \mathrm{mM}$ EDTA, pH 7.1. The enzyme activities were assayed at $37^{\circ} \mathrm{C}$, unless indicated otherwise. Complex I, NADH-coenzyme Q reductase, was measured as the rotonone sensitive oxidation of $\mathrm{NADH}$ with decylubiquinone as electron acceptor(De Vries et al., 1996). Complex II + III, succinate cytochrome $\mathrm{c}$ reductase, was measured as the antimycin sensitive reduction of cytochrome $\mathrm{c}$ in the presence of appropriate inhibitors at $25^{\circ} \mathrm{C}$ (Scholte et al., 1995). Complex II, succinate-coenzyme Q reductase, was determined as the theonyl trifluoroacetone ( $2 \mathrm{mM}$ ) sensitive reduction of 2,6-dichlorophenolindophenol (DCPIP) by succinate in the presence of decylubiquinone (Trounce et al., 1996). Complex III, ubiquinol cytochrome $\mathrm{c}$ reductase, was assayed as the antimycin sensitive reduction of cytochrome c by decylubiquinol at $25^{\circ} \mathrm{C}^{2}$, in the presence of lauryl maltoside. Complex IV, cytochrome $c$ oxidase, was measured as described (Cooperstein and Lazarow, 1951) at $25^{\circ} \mathrm{C}$, or with the detergent (Mayr and Sperl, 2000) Tween-20, at $37^{\circ} \mathrm{C}$. Complex V, ATP synthase, was determined as oligomycin sensitive uncoupler stimulated Mg-ATPase by assay of ADP with pyruvate kinase, phosphoenolpyruvate, lactate dehydrogenase and NADH (Rustin et al., 1994). This reaction was started by sonication (Mayr and Sperl, 2000). Pyruvate dehydrogenase was assayed as in Arts et al.(Arts et al., 1987) and citrate synthase according to Srere (Srere, 1969). The other methods were as in Scholte et al.(Scholte et al., 1995)

\section{DNA extraction}

DNA was extracted from blood, cultured fibroblast cells, hair roots, muscle tissue, chorionic villi cells (CVS) and amniotic fluid cells. DNA extraction from blood was done as described previously (Miller et al., 1988). DNA extraction from hair roots was performed using the Qiagen RNA/DNA minikit (Qiagen GmbH, Hilden, Germany). For the DNA extraction of the other samples the standard phenol/chloroform method was used (Sambrook, 1998).

\section{Quantitative analysis of the T9176C mutation}

The mtDNA was amplified using the polymerase chain reaction (PCR) with primers, corresponding to positions 09035-09055 of the L-strand and positions 09203-09177 of the H- 
strand. The latter primer contains a mismatch at location 09184-09186 to create a restriction site for the restriction enzyme BstXI in case of the T9176C mutation. The PCR was performed using $4 \mathrm{mM}$ for each dNTP (Amersham Pharmacia Biotech AB, Uppsala, Sweden, $25 \mathrm{mM}$ each), $15 \mathrm{mM} \mathrm{MgCl}_{2}, 0.5 \mathrm{M} \mathrm{NaCl}, 0.1 \mathrm{M}$ Tris-HCl, $50 \mathrm{ng}$ per primer, $1 \mathrm{U}$ Taq DNA polymerase (Life Technologies, Breda, Netherlands) in a $25 \mu$ volume. PCR conditions were $94^{\circ} \mathrm{C}$ for $5 \mathrm{~min}$, followed by $32 \mathrm{cycles}$ of $92^{\circ} \mathrm{C}$ for $1 \mathrm{~min}, 52^{\circ} \mathrm{C}$ for $1 \mathrm{~min}$ and $72^{\circ} \mathrm{C}$ for $45 \mathrm{sec}$ and a final step of $7 \mathrm{~min}$ at $72^{\circ} \mathrm{C}(9600$ Thermocycler, Applied Biosystems, Foster City, USA). In the last cycle $50 \mathrm{fmol}$ R6G labeled dUTP (Applied Biosystems, Foster City, USA) was added. The PCR product was purified with the Qiagen PCR purification kit (Qiagen GmbH, Hilden, Germany), digested with BstXI (Boehringer-Mannheim, Bayem, Germany) and separated by electrophoresis on a $4 \%$ non denaturing polyacrylamide gel at $40^{\circ} \mathrm{C}(\mathrm{ABI}$ 377 Applied Biosystems, Foster City, USA). The wildtype fragment has a length of $169 \mathrm{bp}$ and the mutatcd fragment is cleaved in fragments of 148 and $21 \mathrm{bp}$. The mutation percentage is determined by calculating the ratio between the area of the mutant peak (148 bp) and the total area of the mutant and normal peak (169 bp). The calculated mutation percentage is multiplied by 1.06 to correct for lower number of fluorescently labeled dUTPs that can be incorporated in the mutant peak. The experimental variation of this method is $3 \%$.

\section{Prenatal Diagnosis}

Data from literature and of the family were used to determine if this mutation was suitable for prenatal diagnosis. CVS was obtained after 12 weeks of gestation and amniotic fluid after 17 weeks of gestation. Both samples were analyzed for the T9176C mutation immediately and after a culture period of two weeks.

\section{Results}

\section{Clinical Biochemistry}

In the index patient (III-2) blood lactate was $3.2 \mathrm{mmol} / \mathrm{l}$ (normal $<1.8 \mathrm{mmol} / \mathrm{l}$ ) and pyruvate was as in healthy (normal $<160 \mu \mathrm{mol} / \mathrm{l}$ ). Lactate $4.6 \mathrm{mmol} / \mathrm{l}$ (normal range $0.9-2.8$ $\mathrm{mmol} / \mathrm{l}$ ) was also elevated in cerebrospinal fluid (CSF). CSF pyruvate was $80 \mu \mathrm{mol} / \mathrm{l}$. A muscle biopsy of the quadriceps muscle of the index patient (III-2) appeared normal. Histochemical staining of cytochrome $c$ oxidase and succinate hydrogenase yielded normal results. Electronmicroscopy showed some irregularly formed fibrils with thickening of the Zbands. One concentric laminated body was seen possibly derived from mitochondria. A muscle biopsy from patient III-3 also showed a normal morphology by routine histology and histochemistry. Electronmicroscopy showed enlarged intermyofibrillar mitochondria and increased lipid droplets. One small aggregate was seen of elongated subsarcolemmal mitochondria. The brother (III-3) of the index patient showed a blood lactate of $2.2 \mathrm{mmol} / \mathrm{l}$ and a pyruvate of $140 \mu \mathrm{mol} / \mathrm{l}$. CSF lactate was $3.2 \mathrm{mmol} / \mathrm{l}$. Blood lactate in the sister (III-4) of the index patient was $2.3 \mathrm{mmol} / \mathrm{l}$ and pyruvate $150 \mu \mathrm{mol} / \mathrm{l}$. 


\section{Muscle Biochemistry}

Mitochondrial enzyme activities were strikingly abnormal with a severe decrease of complex V activity and an increase of pyruvate dehydrogenase activity. Complex V/ CS is 0.10 and 0.08 (normal 0.40 ) and pyruvate dehydrogenase/ CS is 0.10 and 0.09 (normal 0.03 ) for patient III-2 and III-3 respectively.

\section{Mutation analysis and prenatal diagnosis}

The identification of the T9176C mutation in muscle of the index patient was reported previously (van Den Bosch et al., 2000). The internal variation of the method used to determine the mutation percentages is $\pm 3 \%$. The mutation percentage in muscle was about $95 \%$ and in fibroblasts $90 \%$. The same mutation was identified in a symptomatic brother and sister. The brother had a mutation percentage of about $93 \%$ in muscle and $94 \%$ in hair roots. The sister had a mutation percentage of about $92 \%$ in blood and $93 \%$ in hair roots (pedigree figure 1). A number of maternal relatives were tested showing either the absence or presence of the mutation (figure 1). Mutation percentages appeared to be more constant among tissues in patients with the higher mutation ranges $(>90 \%)$. One of the female family members (III1) was 6 weeks pregnant at the time of investigation. The mutation load in blood and hair roots was about $55 \%$ and $57 \%$. She was at risk of having severely affected offspring, although the exact risk was unknown.
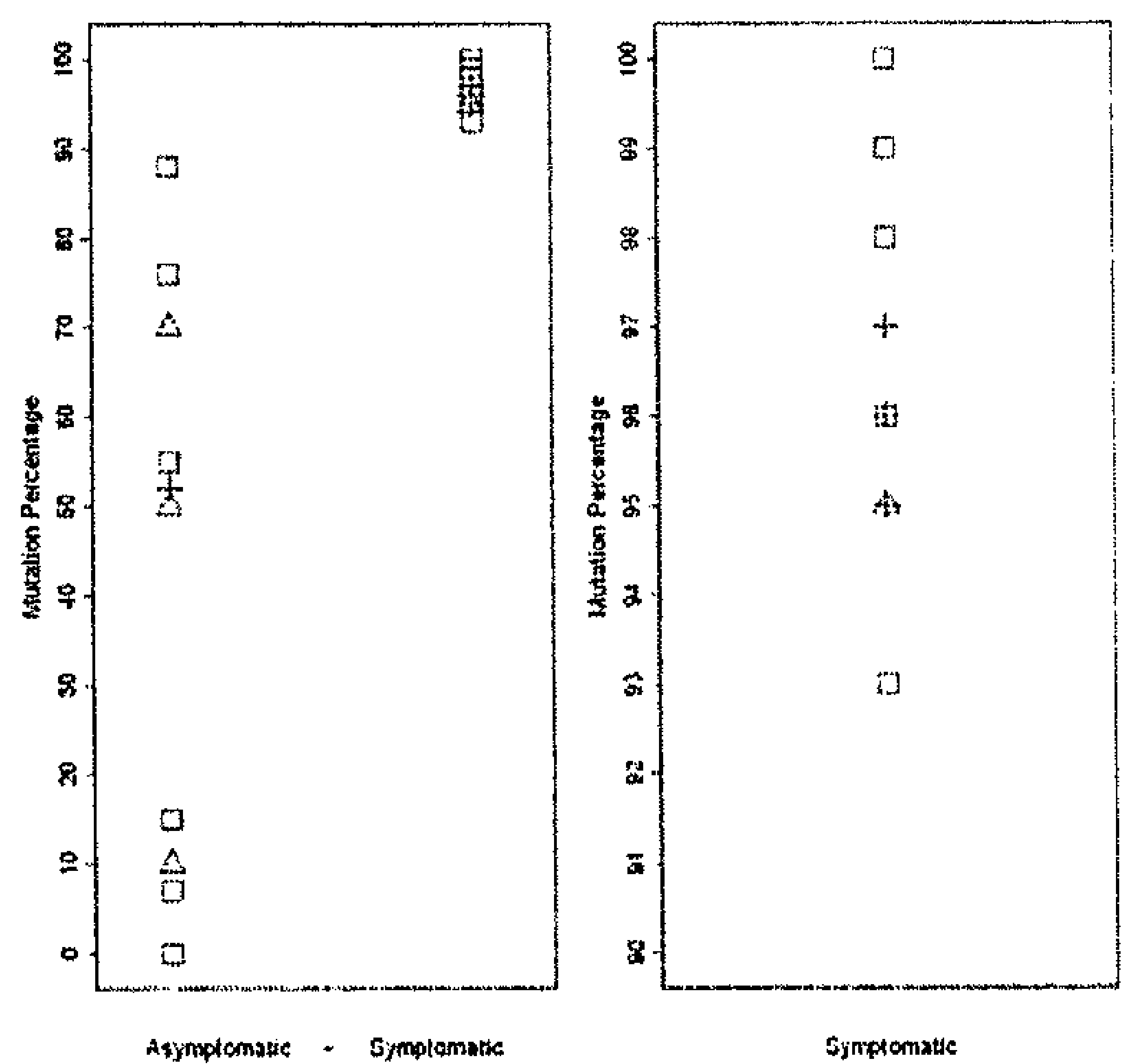

Figure 2

Scatter plots of literature data on the genotypephenotype correlation of the mtDNA T9176C mutation and the detection methods use. Asymptomatic carriers show a variation in the mutation percentage of $0 \%$ to $88 \%$, and symptomatic carriers show a variation in the mutation percentage of $93 \%$ to $100 \%$. 17 Method A: Last cycle addition of $\left[\alpha-{ }^{32} P\right] d A T P$. Quantification by scanning in a Betascope 603 blot analyzer (Thyagarajan et al., 1993; Campos et al., 1997; Wilson et al., 2000). Variance of the method is estimated to be $\pm 5 \%$ heteroplasmy. $\triangle$ Method $B$ : Ethidium Bromide staining. Quantification using

UV detection (Dionisi-Vici et al., 1998). Variance of the method is estimated to be $\pm 10 \%$ heteroplasmy.

+Method C: Last cycle addition of rhodamine-labeled forward primer. Quantification on an image analyzer FMBIO II (Makino et al., 1998; Makino et al., 2000). Variance of the method is estimated at $\pm 5 \%$ heteroplasmy.

We investigated whether this mutation would meet the criteria to allow reliable prenatal diagnosis (Poulton and Turnbull, 2000). Both data from literature (figure 2) and of the family (figure 1) were used. No symptomatic patients have been reported with a mutation 
percentage below $90 \%$, although the methods used vary in their precision. An estimate of the experimental variation is calculated, as it was not given in most references, and the number of patients is small (figure 2). Only one healthy individual had a percentage between $80 \%$ en $90 \%$ and two between $70 \%$ and $80 \%$. All patients developed symptoms between 0 and 8 years except for one patient with a mutation percentage of $96 \%$ who developed symptoms at the age of 29. Obviously, data on the distribution of the mutation among different tissues was mainly limited to patients, all of whom had $>90 \%$ mutation load in every tissue analyzed. Since no unaffected mutation carrier with less than $90 \%$ mutation has been followed during a longer period no firm conclusion is possible on either time related changes in the mutation percentage or the onset of symptoms in carricrs with subcritical mutation percentages. Based on these limited data and on the data of the T9176G (Carrozzo et al., 2001; Akagi et al., 2002) (which has a somewhat more malignant disease course and also a lower mutation threshold for clinical expression of about $70 \%$ ) and two other mutations in the ATPase 6 gene (T89993G/C) (which have been studied in much more detail and for which reliable prenatal diagnosis is possible (Harding et al., 1992; Bartley J. et al., 1996; Ferlin et al., 1997; White et al., 1999; White et al., 1999; Leshinsky-Silver et al., 2003)), we decided to offer prenatal diagnosis. The prenatal sampling was undertaken with the strict understanding by the couple, written in an informed consent, that there could be considerable uncertainty in the interpretation of the results given the scarcity of data available. Somewhat arbitrary, a mutation percentage in fetal cells above $70 \%$ was considered a high risk of being affected, a mutant load between 50 and $70 \%$ would be inconclusive and a mutant load of less than $50 \%$ would mean a high chance of being unaffected.

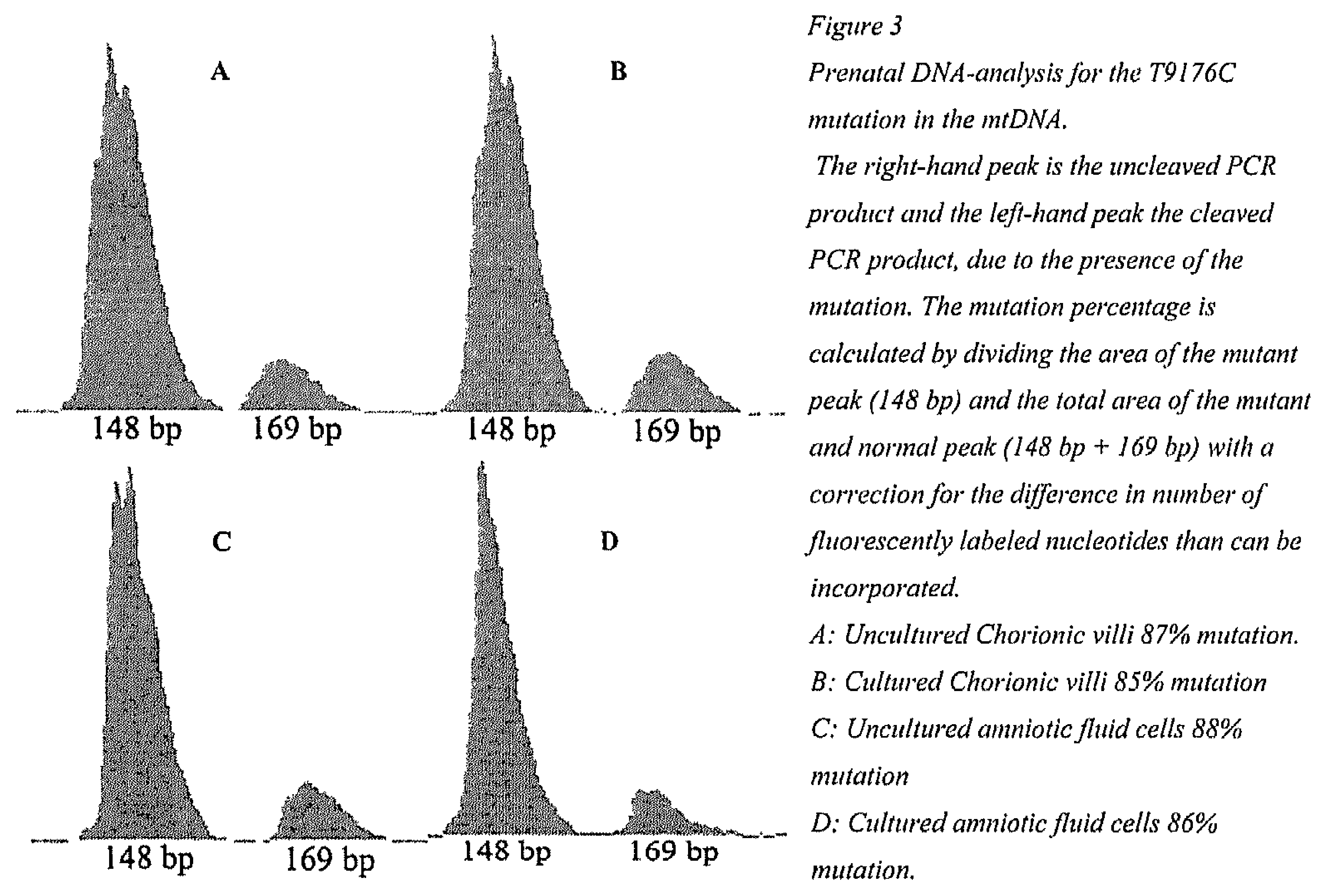


To gather more information on tissue variation of the mutation and the time factor, we decided to analyze both a chorionic villus sample (12 weeks of gestation) and an amniotic fluid sample (17 weeks of gestation) directly and after a culturing period. The mutation percentage in CVS was about $87 \%$ and after culturing $85 \%$ (figure $3 \mathrm{a}$ and $3 \mathrm{~b}$ ) and in amniotic fluid cells $88 \%$ and after culturing $86 \%$ (figure $3 \mathrm{c}$ and $3 \mathrm{~d}$ ). The difference between cultured and uncultured cells is not statistically significant as the experimental variation was determined to be about $3 \%$. Therefore the fetus was diagnosed as at risk of becoming severely affected, although the mutation percentage was just below the level of the other three affected children. Despite these results, uncertainties and associated risks the couple decided to continue the pregnancy. A healthy child was born at term after a normal pregnancy. The child did not show any abnormalities at the age of one year and for ethical reasons no further biochemical or genetic test will be performed as long as the child is healthy. It is important that the child remains under clinical control as the other affected children with a slightly higher mutation level did not show clinical signs of disease until the age of two.

\section{Discussion}

The segregation of point mutations in the mtDNA is not completely understood and the transmission of the mutation load is often unpredictable for heteroplasmic mutations. The family reported in this paper, with 3 affected children with Leigh disease and the T9176C mutation, is a clear illustration of this. Maternal relatives of the patients either do not carry the mutation or carry the mutation in varying percentages. They are all below the threshold of clinical expression, although in most cases no extensive neurological and biochemical examinations have been performed. In such families only DNA studies can provide evidence for the carrier status of an individual and can identify those at risk of transmitting the disease. The exact estimate of the risk of having an affected child is not possible due to the genetic bottleneck for mtDNA mutations and the limited number of data available for this mutation (Thyagarajan et al., 1993; Campos et al., 1997; Dionisi-Vici et al., 1998; Makino et al., 1998; Makino et al., 2000; Wilson et al., 2000). It has been proposed that oocyte sampling and testing could be an acceptable approach to determine the mutation load in individual oocytes and estimate the recurrence risk (Poulton and Marchington, 2002; Thorburn, 2004).

Because of these uncertainties prenatal diagnosis, based on DNA analysis of mtDNA mutations, is controversial. Until now seven prenatal tests were reported, for the T8993G and T8993C mutations (Harding et al., 1992; Bartley J. et al., 1996; Ferlin et al., 1997; White et al., 1999; White et al., 1999; Leshinsky-Silver et al., 2003). These mutations fulfill the criteria mentioned before and have well-established genotype-phenotype correlations, based on sufficient number of families tested. Recurrence risks have been calculated dependent on the mutation load of the mother and a safe margin for the mutant load in case of prenatal diagnosis is established. Disease caused by the T8993C mutation is clinically less severe than the T8993G mutation. The probability of having severe symptoms of the T8993C and the T8993G mutations are low if mutation loads are below $80 \%$ and $60 \%$ respectively. 
The differences in recurrence risk for diseases caused by point mutations in the mtDNA and the potential pitfalls prompted a statement by a group of researchers, supported by the European NeuroMuscular Consortium, concerning prenatal options for carriers of mtDNA mutations (Poulton and Marchington, 2000; Poulton and Turnbull, 2000). Sufficient data are available for only 3 mutations today to judge these criteria properly. For the T8993G/C and A8344G mutation prenatal diagnosis can be reliably performed, but for the A3243G mutation this is not possible. For other mutations this is still unknown and the families involved can only be counselled in general terms. Whether prenatal diagnosis will be an option for these families will depend on the frequency of the mutation and the ethical discussions on acceptable risks.

The T9176C mutation has been described only a few times in literature (Thyagarajan et al., 1993; Campos et al., 1997; Dionisi-Vici et al., 1998; Makino et al., 1998; Makino et al., 2000; Wilson et al., 2000). As the methods used are often not comparable and as usually no information is provided on detection level and experimental variation, it is difficult to draw general conclusions on the mutation threshold for clinical expression. Until now severe symptoms were only reported for paticnts with mutation percentages above $90 \%$ in various tissues. As the T9176C mutation is located in the same gene as the T8993G/C mutation and shows some resemblance in clinical symptoms and progression of the disease, we considered this additional, though arguable, evidence that the T9176C mutation is also suitable for DNAprenatal diagnosis. For the T9176C also a T9176G variant has been found with a somewhat more malignant progression similar to the T8993G mutation compared to the T8993C mutation (Carrozzo et al., 2000; Carrozzo et al., 2001; Akagi et al., 2002). Given the high chance of an affected foetus or a borderline result it was advised not to offer prenatal diagnosis but consider oocyte donation or preimplantation genetic diagnosis (PGD) to carriers with a mutation percentage of more than $50 \%$ of the $\mathrm{T} 8993 \mathrm{G} / \mathrm{C}$ mutation (Poulton and Turnbull, 2000). Because the woman in our study was already pregnant it was not possible to discuss alternatives, but PGD will be offered for future pregnancies. The parents were informed about the uncertainties of borderline mutation percentages and the risk on an affected fetus and decided to continue with the prenatal diagnosis. The prenatal diagnosis revealed a percentage of $85 \%-88 \%$ with a variation of $3 \%$. Although there was a high likelihood that the child would be affected the parents decided to continue the pregnancy. Assuming that the bottleneck occurs during oocyte development (Poulton, 1998), preimplantation genetic diagnosis (PGD) could be offered in case of mtDNA mutations as an alternative for conventional prenatal diagnosis, (Thorburn and Dahl, 2001). For PGD, one or two blastomeres are removed from an 8-cellular embryo, obtained by IVF procedures and intracytoplasmic sperm injection (ICSI), and these blastomeres are tested for the specific mutation. Healthy embryos are transferred to the uterus. PGD is technically easier for mtDNA mutations than for nuclear genes, as the copy number is much higher. Protocols have been optimized at the single cell level in our lab (Jacobs L.J. et al., in preparation.). Data from heteroplasmic mice show that mutation percentages quantified in the biopsied cell are representative for the entire embryo (Dean et al., 2003). The same criteria apply for prenatal 
diagnosis as for PGD, but the main advantage of PGD is that no termination of pregnancy has to be considered in case of affected offspring. That these chances can be very high has been demonstrated in the oocytes of a carrier of the T8993G/C mutation ( $50 \%$ in blood), who had 6 oocytes with more than $95 \%$ mutation and 1 oocyte with no mutation at all (Blok et al., 1997), yielding a chance of more than $85 \%$ for offspring being affected. PGD can prevent multiple terminations of pregnancy in those cases.

\section{Acknowledgements}

Dr. P.A. van Doorn and Prof. Dr. HFM Busch performed routine histology and histochemistry and electronmicroscopy.

\section{References}

Akagi M, Inui K, Tsukamoto H, Sakai N, Muramatsu T, Yamada M, Matsuzaki K, Goto Y, Nonaka I and Okada S (2002) A point mutation of mitochondrial ATPase 6 gene in Leigh syndrome. Neuromuscul Disord $12,53-55$

Arts WF, Scholte HR, Loonen MC, Przyrembel H, Fernandes J, Trijbels JM and Luyt-Houwen IE (1987) Cytochrome c oxidase deficiency in subacute necrotizing encephalomyelopathy. J Neurol Sci 77,103-115. Bartley J., Senadheera D., Park P., Brar H., Abad D. and L-J. W (1996) Prenatal Diagnosis of T8993G mitochondrial DNA point mutation in amniocytes by heteroplasmy detection. American Journal of Human Genetics 59,A316.

Blok RB, Gook DA, Thorburn DR and Dahl HH (1997) Skewed segregation of the mtDNA nt 8993 (T-$>G$ ) mutation in human oocytes. Am J Hum Genet 60,1495-1501.

Campos Y, Martin MA, Rubio JC, Solana LG, Garcia-Benayas C, Terradas JL and Arenas J (1997) Leigh syndrome associated with the T9176C mutation in the ATPase 6 gene of mitochondrial DNA. Neurology 49,595-597.

Carrozzo R, Murray J, Santorelli FM and Capaldi RA (2000) The T9176G mutation of human mtDNA gives a fully assembled but inactive ATP synthase when modeled in Escherichia coli. FEBS Lett 486,297-299.

Carrozzo R, Tessa A, Vazquez-Memije ME, Piemonte F, Patrono C, Malandrini A, Dionisi-Vici C, Vilarinho L, Villanova M, Schagger $\mathrm{H}$, et cl. (2001) The T9176G mtDNA mutation severely affects ATP production and results in Leigh syndrome. Neurology 56,687-690.

Cooperstein SJ and Lazarow A (1951) A microspectrophotometric method for the determination of cytochrome oxidase. J Biol Chem 189,665-670.

Dahl HH (1998) Getting to the nucleus of mitochondrial disorders: identification of respiratory chainenzyme genes causing Leigh syndrome. Am J Hum Genet 63,1594-1597.

De Vries DD, Went LN, Bruyn GW, Schoite HR, Hofstra RM, Bolhuis PA and van Oost BA (1996) Genetic and biochemical impairment of mitochondrial complex I activity in a family with Leber hereditary optic neuropathy and hereditary spastic dystonia. Am J Hum Genet 58,703-711.

Dean NL, Battersby BJ, Ao A, Gosden RG, Tan SL and Shoubridge EA (2003) Prospect of preimplantation genetic diagnosis for heritable mitochondrial DNA diseases. Mol Hum Reprod 9,631-638.

DiMauro S and Tanji K (1997) Mitochondrial disorders. Jpn J Hum Genet 42,473-487.

Dionisi-Vici C, Seneca S, Zeviani M, Fariello G, Rimoldi M, Bertini E and De Meirleir L (1998) Fulminant Leigh syndrome and sudden unexpected death in a family with the T9176C mutation of the mitochondrial ATPase 6 gene. J Inherit Metab Dis 21,2-8.

Ferlin T, Landrieu P, Rambaud C, Fernandez H, Dumoulin R, Rustin P and Mousson B (1997) Segregation of the G8993 mutant mitochondrial DNA through generations and embryonic tissues in a family at risk of Leigh syndrome. J Pediatr 131,447-449. 
Harding AE, Holt IJ, Sweeney MG, Brockington M and Davis MB (1992) Prenatal diagnosis of mitochondrial DNA8993 T----G disease. Am J Hum Genet 50,629-633.

Hauswirth WW and Laipis PJ (1982) Mitochondrial DNA polymorphism in a maternal lineage of Holstein cows. Proc Natl Acad Sci U S A 79,4686-4690.

Howell N, Chinnery PF, Ghosh SS, Fahy E and Turnbull DM (2000) Transmission of the human mitochondrial genome. Hum Reprod 15 Suppl 2,235-245.

Leshinsky-Silver E, Perach M, Basilevsky E, Hershkovitz E, Yanoov-Sharav M, Lerman-Sagie T and Lev D (2003) Prenatal exclusion of Leigh syndrome due to T8993C mutation in the mitochondrial DNA. Prenat Diagn 23,31-33.

Makino M, Horai S, Goto Y and Nonaka I (1998) Confirmation that a T-to-C mutation at 9176 in mitochondrial DNA is an additional candidate mutation for Leigh's syndrome. Neuromuscul Disord 8,149-151.

Makino M, Horai S, Goto Y and Nonaka I (2000) Mitochondrial DNA mutations in Leigh syndrome and their phylogenetic implications. $J$ Hum Genet 45,69-75. Med Res 5,47.

Mayr JA and Sperl W (2000) Increased sensitivity and Linearity in enzymatic OXPHOS analysis. Eur J

Miller SA, Dykes DD and Polesky HF (1988) A simple salting out procedure for extracting DNA from human nucleated cells. Nucleic Acids Res 16,1215.

Pouiton J (1998) Does a common mitochondrial DNA polymorphism underlie susceptibility to diabetes and the thrifty genotype'? Trends Genet 14,387-389.

Poulton J and Marchington DR (2000) Progress in genetic counselling and prenatal diagnosis of maternally inherited mtDNA diseases. Neuromuscul Disord 10,484-487.

Poulton J and Marchington DR (2002) Segregation of mitochondrial DNA (mtDNA) in human oocytes and in animal models of mtDNA discase: clinical implications. Reproduction 123,751-755.

Poulton J and Turnbull DM (2000) 74th ENMC international workshop: mitochondrial diseases 19-20 november 1999, Naarden, the netherlands. Neuromuscul Disord 10,460-462.

Rahman S, Blok RB, Dahl HH, Danks DM, Kirby DM, Chow CW, Christodoulou J and Thorburn DR (1996) Leigh syndrome: clinical features and biochemical and DNA abnormalities. Ann Neurol 39,343-351.

Rustin P, Chretien D, Bourgeron T, Gerard B, Rotig A, Saudubray JM and Munnich A (1994)

Biochemical and molecular investigations in respiratory chain deficiencies. Clin Chim Acta 228,35-51.

Sambrook J, E. F. Fritsch and T. Maniatis (1998). Molecular Cloning: a Laboratory Manual. 2nd ed.. NY., Cold Spring Harbor Press.

Scholte HR, Busch HF, Bakker HD, Bogaard JM, Luyt-Houwen IE and Kuyt LP (1995) Riboflavinresponsive complex I deficiency. Biochim Biophys Acta 1271,75-83.

Srere PA (1969) Citrate Synthase. Methods of Enzymology 13,3-11.

Tanji K, Kunimatsu T, Vu TH and Bonilla E (2001) Neuropathological features of mitochondrial disorders. Semin Cell Dev Biol 12,429-439.

Thorburn DR (2004) Mitochondrial disorders: prevalence, myths and advances. J Inherit Metab Dis 27,349-362.

Thorburn DR and Dahl HH (2001) Mitochondrial disorders: genetics, counseling, prenatal diagnosis and reproductive options. Am J Med Genet 106,102-114.

Thyagarajan D, Shanske S, Vazquez-Memije M, De Vivo D and DiMauro S (1993) A novel mitochondrial ATPase 6 point mutation in familial bilateral striatal necrosis. Ann Neurol 38,468-472.

Trounce IA, Kim YL, Jun AS and Wallace DC (1996) Assessment of mitochondrial oxidative phosphorylation in patient muscle biopsies, lymphoblasts, and transmitochondrial cell lines. Methods Enzymol 264,484-509.

van Den Bosch BJ, de Coo RF, Scholte HR, Nijland JG, van Den Bogaard R, de Visser M, de DieSmulders CE and Smeets HJ (2000) Mutation analysis of the entire mitochondrial genome using denaturing high performance liquid chromatography. Nucleic Acids Res 28,E89. 
White SL, Collins VR, Wolfe R, Cleary MA, Shanske S, DiMauro S, Dahl HH and Thorburn DR (1999) Genetic counseling and prenatal diagnosis for the mitochondrial DNA mutations at nucleotide 8993. Am J Hum Genet 65,474-482.

White SL, Shanske S, Biros I, Warwick L, Dahl HM, Thorburn DR and Di Mauro S (1999) Two cases of prenatal analysis for the pathogenic $T$ to $G$ substitution at nucleotide 8993 in mitochondrial DNA. Prenat Diagn 19,1165-1168.

Wilson CJ, Wood NW, Leonard JV, Surtees R and Rahman S (2000) Mitochondrial DNA point mutation T9176C in Leigh syndrome. J Child Neurol 15,830-833. 


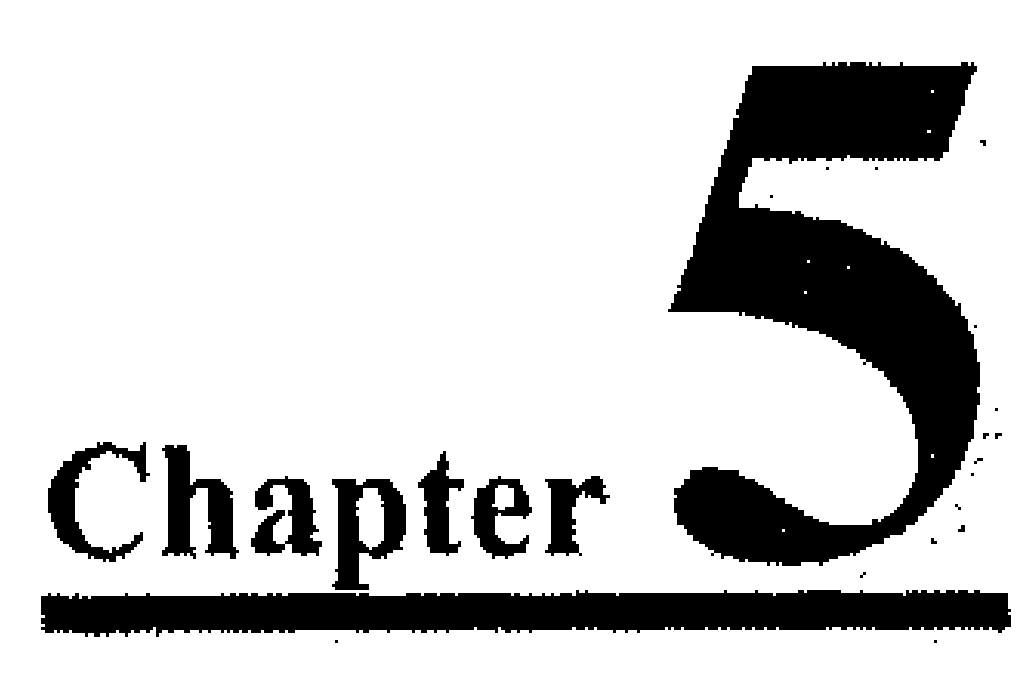

Skewed heteroplasmy levels in single fibroblasts and lymphocytes of carriers of the Leigh syndrome m.9176T $>C$ mutation

LJAM Jacobs ${ }^{1}$, M Drusedau ${ }^{1}$, IFM de Coo², P.J. Lindsey ${ }^{1}$, HJM Smeets ${ }^{1}$ 'Department of Genetics and Cell Biology, University of Maastricht, Research Institute Growth and Development (GROW), Maastricht. ${ }^{2}$ Department Neurology, Erasmus MC-

University Medical Center Rotterdam

In preparation 


\begin{abstract}
Mitochondria are important organelles involved in energy production and necessary for a correct functioning of the cell. Mutations in the mitochondrial DNA (mtDNA) have a major impact on the function of a cell, illustrated by the long list of mtDNA related diseases. However, the segregation of heteroplasmic mtDNA from cell to daughter cells is a complex, only partly understood process. The distribution pattern of mutated mtDNA in different single cell types might help to clarify possible factors influencing the final mutation load in each cell. For this reason we studied the distribution of the mutant load of the m.9176T $>C$ mutation (associated with a form of Leigh syndrome) in single lymphocytes and single fibroblast from carriers and patients. We observed a skewed distribution pattern of the mutation in both lymphocytes and fibroblast of the three carriers. The skewing is more extreme in 2 carriers and in fibroblasts and less in the third and in lymphocytes. This contrasts with the distribution pattern in lymphocytes and fibroblast of two patients, which is close to a normal Gaussian distribution pattern. If these differences in skewing would also occur in oocytes of these carriers, then this would imply a different recurrence risk based on the distribution pattern rather than on the mutation level. Further studies on distribution patterns of mutation load and data on the offspring are required to determine if there is a (genetically determined) factor that influences the distribution of the mutations and if these data can be used in the counseling process to determine the risk of affected offspring
\end{abstract}

\title{
Introduction
}

To date more than 200 point mutations and over 300 deletions have been reported in the mtDNA and new mutations are found at a constant pace (Brandon et al., 2005). Heteroplasmy (the presence of two or more different types of mitochondrial DNA [mtDNA] molecules) is a common characteristic of pathogenic mtDNA mutations, although homoplasmic disease causing point mutations have been described as well. Heteroplasmic mutations become clinically manifest above a mutation-, tissue- and individual-specific threshold. This threshold is usually lower in tissues with a high energy demand such as brain and muscle (Larsson and Clayton, 1995). For many mutations differences have been observed in heteroplasmy level between tissues and in time during life, whereas other mutations appear to maintain more constant levels.

Mutations can also be studied at the single cell level. Every cell contains multiple (12approx. 300.000) mitochondria. Although mitochondria are generally depicted as isolated kidney-shaped structures, they are in fact part of a larger cellular mitochondrial network. The mtDNA is organized into nucleoids, which are dynamic protein-rich structures that are able to divide and redistribute in the mitochondrial network and which are suggested to be the mitochondrial unit of inheritance. Cell can contain up to hundreds of nucleoids that contain 2$8 \mathrm{mtDNA}$-molecules each (Garrido et al. 2003; Legros et al. 2004). Several studies have analysed heteroplasmy levels in single cells or fibres, for the m3243A>G, the m.8993T $>\mathrm{G}$ or m.8993 $>C$ and the m.8344A $>\mathrm{G}$ mutations and demonstrated variation between single cells, meaning that the heteroplasmy percentage is not constant between cells of one person. These 
studies also revealed different types of distribution patterns of the mutations when analyzing multiple single cells. These distribution patterns can vary per individual and per mutation type and often differ from a normal Gaussian distribution pattern (Anderson et al., 1981; Mita et al., 1998; Silvestri et al., 2000; He et al., 2002; Gigarel et al., 2005). Substantial variation in single cells and a skewed distribution exist for mutations (like the m.8993T $>\mathrm{G} / \mathrm{C}$ mutations) with a relative constant mutation load in different tissues. For the m.3243A>G mutation the largest variation between cells was observed in tissues with a high heteroplasmy value especially in single lymphocytes (Ozawa et al., 1998; Saitoh et al., 1999). Most cybrid clones carrying the $\mathrm{A} 3243 \mathrm{G}$ pathogenic mutation, display two patterns: stable heteroplasmy, caused by correct replication, and heteroplasmy shifting to either wild-type or mutant. These processes are under genetic control (Enriquez et al, 2003). A number of studies (Mita et al., 1998; Moslemi et al., 1998; Ozawa et al., 1998; Koga et al., 2000) have been performed on muscle fibres of affected patients and in these cases the largest variance is found in normal fibres whereas Cox-negative fibres usually display higher and more constant heteroplasmy levels. The variance is less as the tissue heteroplasmy level is at the extreme (highest or lowest 10\%) of the scale (Mita et al., 1998; Moslemi et al., 1998; Koga et al., 2000; Silvestri et al., 2000; He et al., 2002; Gigarel et al., 2005). The question remains whether the distribution of mtDNA heteroplasmy among single cells is purely random or that selection occurs, which may depend on the nucleoid organization and replicative behaviour of the specific mutation, the tissue or the individual itself. The distribution pattern in oocytes is important for predicting the recurrence risk for carriers of point mutations in the mtDNA.

During the transmission of the mtDNA a so called "bottleneck" occurs in the early development of female oocytes. The currently prevailing hypothesis that the mtDNA bottleneck is generated by a small absolute mtDNA copy number in PGCs (Jansen and de Boer, 1998) has recently been questioned and data were presented that the mtDNA bottleneck in the germ line is created through a small effective number of segregating units (Cao et al. 2007) leading to extreme shifts in mutation load in the offspring. Still, in case of random distribution of the mutated mtDNA molecules and a limited number of cell divisions an overall distribution around the mean would be expected, which has been shown for 82 primary oocytes of a woman harboring the m.3243A>G mutation. The level of mutant mtDNA appeared to be determined by random genetic drift leading to a binominal distribution in oocyte mutant load (Brown et al., 2001). On the other hand, non-random distribution has been observed for the m.8993T $>\mathrm{G}$ mutation in oocytes and during embryonic development. The analysis of seven oocytes of a woman harboring the m.8993T $>\mathrm{G}$ mutation revealed a skewed segregation pattern with six oocytes showing a mutant load $>95 \%$ and one oocyte with no evidence of mutation (Blok et al., 1997). Three PGD embryos were analyzed for the m.8993T $>$ G mutation and one revealed a $100 \%$ mutation load whereas in the remaining two no mutation was observed. This segregation pattern was also observed for a $\mathrm{C}$ tract polymorphism (between nucleotide 303 and 315) in embryos although at a slightly lesser extend (Steffann et al., 2006). A distribution to the extremes in oocytes implies on the one hand a high risk of severely affected offspring, but on the other hand also the possibility to 
have mutation free oocytes or embryos. This would also mean that prenatal diagnosis (PND) or, more likely, pre-implantation diagnosis (PGD) would allow selection of those healthy embryos. For this reason oocyte sampling could be useful for a female carrier to predict the chance of mitochondrial disease in a future pregnancy and to judge the possible success of the choice for PND or PGD (Poulton and Marchington, 2000). The aspiration of oocytes is however a difficult and painful procedure and it is of ethical concern, if it can be applied for counseling purposes only (Poulton and Marchington, 2000; Chinnery, 2004).

To get a better insight in the distribution of mtDNA mutation among single cells, we studied single lymphocytes and fibroblasts of five relatives from a family with the m.9176T $>$ C mutation in the ATPase6 genc. Our aim is to determine if different cells of mutation carriers may differ with respect to the distribution of the mutations and if this can be related to the segregation pattern.

\section{Materials and Methods}

Leigh syndrome family with the m.9176T>C

Single cells were collected in a family with the m.9176 $>C$ mutation from three carriers and two patients with Leigh syndrome. Both patients are the younger brother (patient one, age nine) and sister (patient two, age eight) of a patient who died of Leigh syndrome at the age of four. Carrier one is the mother of these children and carrier two is the sister of carrier one. Carrier three is the daughter of carrier two [Figure 1, (Jacobs et al., 2005)].

\section{Single cell collection}

Human lymphocytes and fibroblasts were collected in Petri dishes (Greiner Bio-one B.V., Alphen a/d Rijn, The Netherlands) in $2 \mu \mathrm{Ca}^{2+}$ and $\mathrm{Mg}^{2+}$-free phosphate-buffered saline solution (PBS) with $1 \%$ polyvinylpyrrolidone (PVP) molecular weight $360 \mathrm{kDa}$ (Sigma, Aldrich Chemie BV, Zwijdrecht, The Netherlands) and $0.1 \mathrm{mg} / \mathrm{ml}$ Phenol Red (Sigma), with the help of a micromanipulator (ONO-121; Narishige, Paes Nederland BV) mounted on an inverted microscope (IX-70; Olympus, Zoeterwoude, The Netherlands). Cells were transferred in the PBS mixture to a $0.2 \mathrm{ml}$ reaction tube using a mouth controlled glass micropipette. Cells were stored at $-20^{\circ} \mathrm{C}$ until PCR was performed.

\section{Quantitative analysis of the m.9176T>C mutation in single cells}

Prior to PCR, the alkaline lysis buffer and the PCR mix without primers or AmpliTaq Gold DNA polymerase (Applied Biosystems, Foster City, USA), were decontaminated from DNA by UV-C irradiation for $1 \mathrm{~h}$ using an UV-C lamp type TUV 30W/G30T8 longlife (Philips, Eindhoven, The Netherlands). Blank samples were included in every PCR series to monitor DNA contamination. Cells were lysed by adding $2.5 \mu \mathrm{l}$ of alkaline lysis buffer [50 $\mathrm{mmol} / \mathrm{l}$ dithiothreitol (DTT; Pharmacia Biotech, Benelux, Roosendaal, The Netherlands)/200 $\mathrm{mmol} / \mathrm{l} \mathrm{NaOH}$ ] followed by $10 \mathrm{~min}$ of incubation at $65^{\circ} \mathrm{C}$. PCR was performed with the GeneAmp $^{(7)}$ PCR System 9700 (Applied Biosystems, Foster City, USA) using primers (Applied Biosystems, Foster City, USA), corresponding to positions 09035-09055 of the L- 
strand for the forward primer and positions 09203-09177 of the $\mathrm{H}$-strand for the reverse primer. The latter primer contains a mismatch at location 09184-09186 to create a restriction site for the restriction enzyme BstXI in case of the T9176C mutation. PCR was performed using $1.5 \mathrm{mM}$ for each dNTP (Amersham Pharmacia Biotech AB, Uppsala, Sweden, $25 \mathrm{mM}$ each), $15 \mathrm{mM} \mathrm{MgCl} 2,0.5 \mathrm{M} \mathrm{NaCl}, 0.1 \mathrm{M}$ Tris- $\mathrm{HCl}, 50 \mathrm{ng}$ per primer, $20 \mathrm{mmol} / \mathrm{l}$ Tricine $\mathrm{pH}$ 4.95 (Sigma, The Netherlands) and $1 \mathrm{U}$ Amplitaq Gold DNA polymerase (Applied Biosystems, Foster City, USA) in a $25 \mu \mathrm{l}$ volume. PCR conditions were $94^{\circ} \mathrm{C}$ for $7 \mathrm{~min}$, followed by 45 cycles of $92^{\circ} \mathrm{C}$ for $1 \mathrm{~min}, 52^{\circ} \mathrm{C}$ for $1 \mathrm{~min}$ and $72^{\circ} \mathrm{C}$ for $45 \mathrm{sec}$ and a final step of 7 min at $72^{\circ} \mathrm{C}$. In the last cycle $10 \mathrm{pmol} \mathrm{Fam-labeled} \mathrm{Forward} \mathrm{primer} \mathrm{(Applied} \mathrm{Biosystems,}$ Foster City, USA) was added. The PCR product was digested with BstXI (BoehringerMannheim, Bayern, Germany) and purified with the Qiagen PCR purification kit (Qiagen $\mathrm{GmbH}$, Hilden, Germany). $3 \mu \mathrm{l}$ of this purified product was separated by capillary electrophoresis on an ABI3100 Genetic Analyzer (ABI PRISM Applied Biosystems, The Netherlands) using POP- $6^{\mathrm{TM}}$ as a polymer. The results were analysed with GeneScan Analysis software version 3.7 provided by the manufacturer. The PCR fragment sizes were calculated using GeneScan ${ }^{\mathrm{TM}}{ }_{-500}$ TAMRA $^{\mathrm{TM}}$ Size Standard. The wild-type fragment has a length of 169 $\mathrm{bp}$ and the mutated fragment is cleaved in fragments of 148 and $21 \mathrm{bp}$. The mutation percentage is determined by calculating the ratio between the area of the mutant peak (148 bp) and the total area of the mutant and normal peak (169 bp).

\section{Statistical analysis}

An independent-sample t-test is used to evaluate the significance of the difference observed between the single cell results of the two tested tissues, using SPSS. Grouped data were expressed as the mean \pm standard deviation. A p-value of $<0.05$ was considered to have statistical significance. Non parametrical tests (Mann-Withey U test, Kolmogorov-Smirnov Z test and the Chi-Square test) were used to analyse a possible difference in single cell distribution.

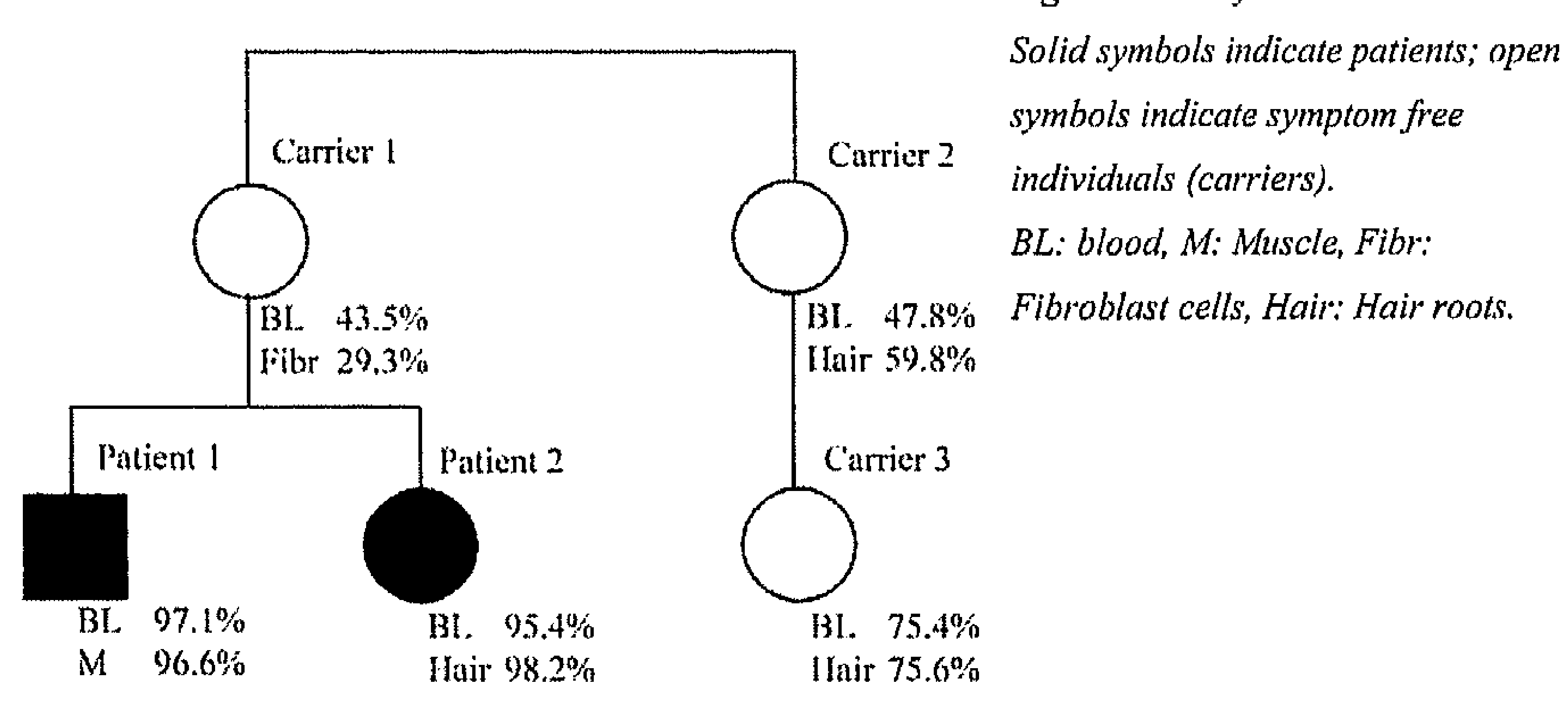




\section{Results}

A family with 3 children with Leigh syndrome due to the m.9176 $\mathrm{T}>\mathrm{C}$ mutation, was studied for the mutation load in several tissues (figure 1) and single cells. This family has been described before (Jacobs et al., 2005). The use of a labeled primer instead of labeled nucleotides has allowed a more accurate determination of the mutation load, which is in general higher than previously reported, especially in case of the carriers. The mutation load was determined in at least 25 single lymphocytes and fibroblasts of the same individual and the mean level of heteroplasmy and variation among the single cells was calculated (table I). Missing values were not included in the analysis since their number was negligible ( 7 out of 633 cells analyzed). The mean result from the combined single lymphocyte analyses deviates from the mean results acquired when analyzing the whole blood DNA samples, most likely because this contains also other cell types. The difference between the results however stays within one standard deviation obtained from the single lymphocytes sample. For fibroblasts this is not the case as cell cultures have been used.

Table I. Results of single cell analysis

\begin{tabular}{|c|c|c|c|c|c|c|}
\hline Tissue/individual & Cell number & Mean \pm stdev & minimal & maximum & $P^{*}$ & $P^{H t}$ \\
\hline & & \multicolumn{3}{|c|}{ heteroplasmy level } & & \\
\hline Lymphocytes/ carrier 1 & 152 & $36.3 \% \pm 38.2$ & $0 \%$ & $96.5 \%$ & \multirow[t]{2}{*}{0.143} & \multirow[t]{2}{*}{0,007} \\
\hline Fibroblasts/ carrier 1 & 136 & $29.4 \% \pm 41.5$ & $0 \%$ & $99.9 \%$ & & \\
\hline Lymphocytes/ carrier 2 & 26 & $54.4 \% \pm 20.2$ & $18.95 \%$ & $83.53 \%$ & \multirow[t]{2}{*}{0.180} & \multirow[t]{2}{*}{0,024} \\
\hline Fibroblasts/ carrier 2 & 84 & $45.5 \% \pm 31.8$ & $0 \%$ & $94.5 \%$ & & \\
\hline Lymphocytes/ carrier 3 & 47 & $69.1 \% \pm 27.5$ & $0 \%$ & $91.5 \%$ & \multirow[t]{2}{*}{0.124} & \multirow[t]{2}{*}{0,015} \\
\hline Fibroblasts/ carrier 3 & 51 & $77.7 \% \pm 27.1$ & $0 \%$ & $94.1 \%$ & & \\
\hline Lymphocytes/patient 1 & 24 & $95.3 \% \pm 8.9$ & $59 \%$ & $100 \%$ & \multirow[t]{2}{*}{0.449} & \multirow[t]{2}{*}{0,191} \\
\hline Fibroblasts/ patient 1 & 48 & $93.2 \% \pm 11.9$ & $37.5 \%$ & $100 \%$ & & \\
\hline Lymphocytes/patient 2 & 31 & $88.1 \% \pm 8.4$ & $73.1 \%$ & $100 \%$ & \multirow[t]{2}{*}{0.384} & \multirow[t]{2}{*}{0,644} \\
\hline Fibroblasts/ patient 2 & 27 & $85.6 \% \pm 11.5$ & $59.0 \%$ & $100 \%$ & & \\
\hline
\end{tabular}

$P^{*}$ : Statistical analysis of the proportion mutant miDNA between lymphocytes and fibroblasts

$P^{\#}$ : Statistical analysis of the distribution of the mutant miDNA between single lymphocytes and single

fibroblasts using the Kolmogorov-Smirnov Z-test

To determine whether the single cell variation has a normal Gaussian distribution, histograms were drawn using the percentages of single cell values divided over 10 categories, ranging from $0 \%-10 \%$ to $90 \%-100 \%$ (figure 2 ). The distribution is not normal (Gaussian) in both lymphocytes and fibroblasts of carriers and patients, although the two patients approach a normal distribution pattern. The distribution patterns in the carriers are different and show pronounced skewing. Striking is the difference between the distribution patterns of both cell types. The pattern in fibroblasts in all three carriers is more to the extreme heteroplasmy percentages than in lymphocytes. The heteroplasmy distribution of the lymphocytes in carrier 
2 is closest to a normal pattern. The most skewed percentages are observed in carrier 1 showing an accumulation at the maximum and minimum heteroplasmy percentages in both cell types.

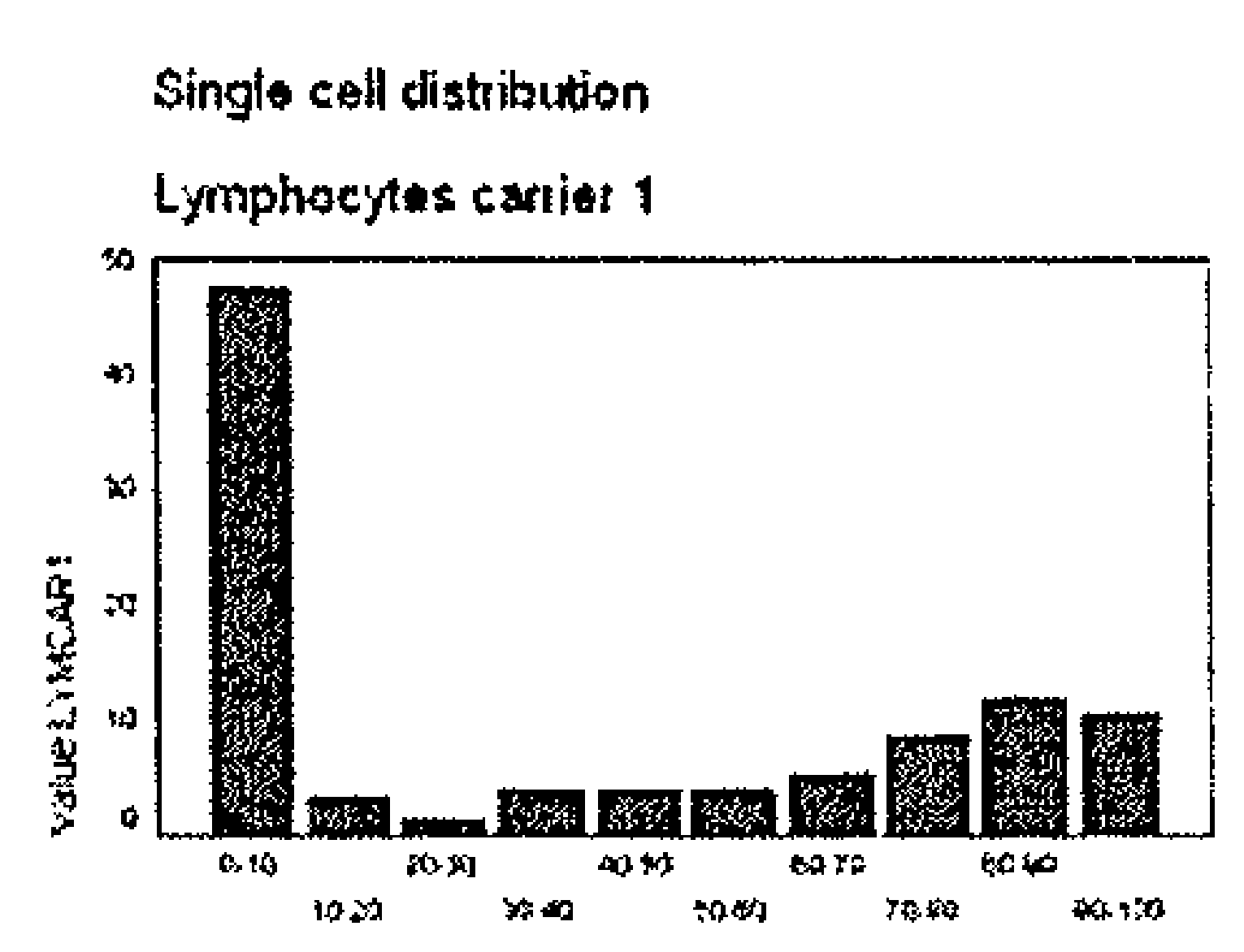

FERCENTR

Single cell distribution

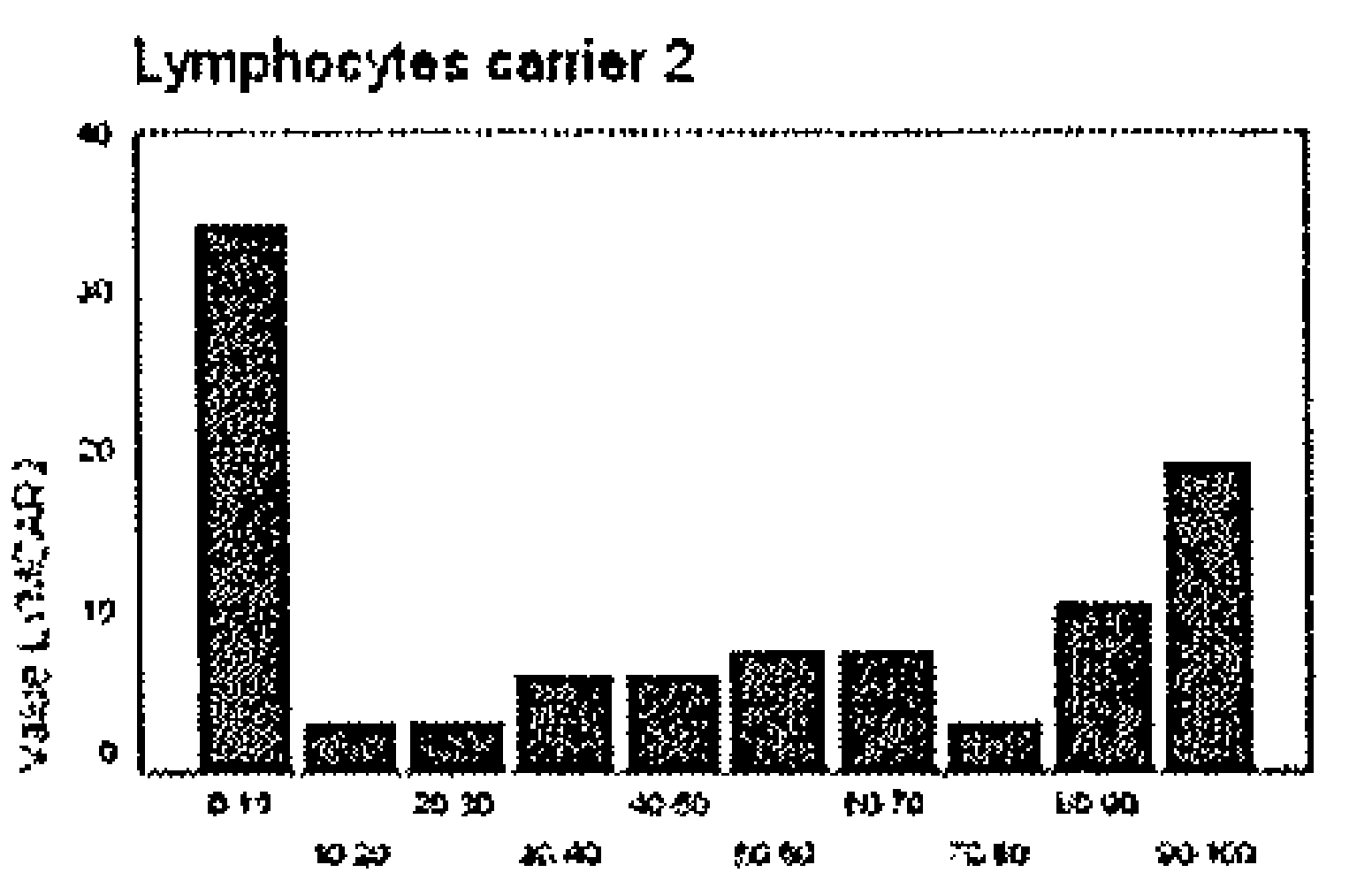

PERCENTA

Single cell distribution

Lymphocytas cartiat 3

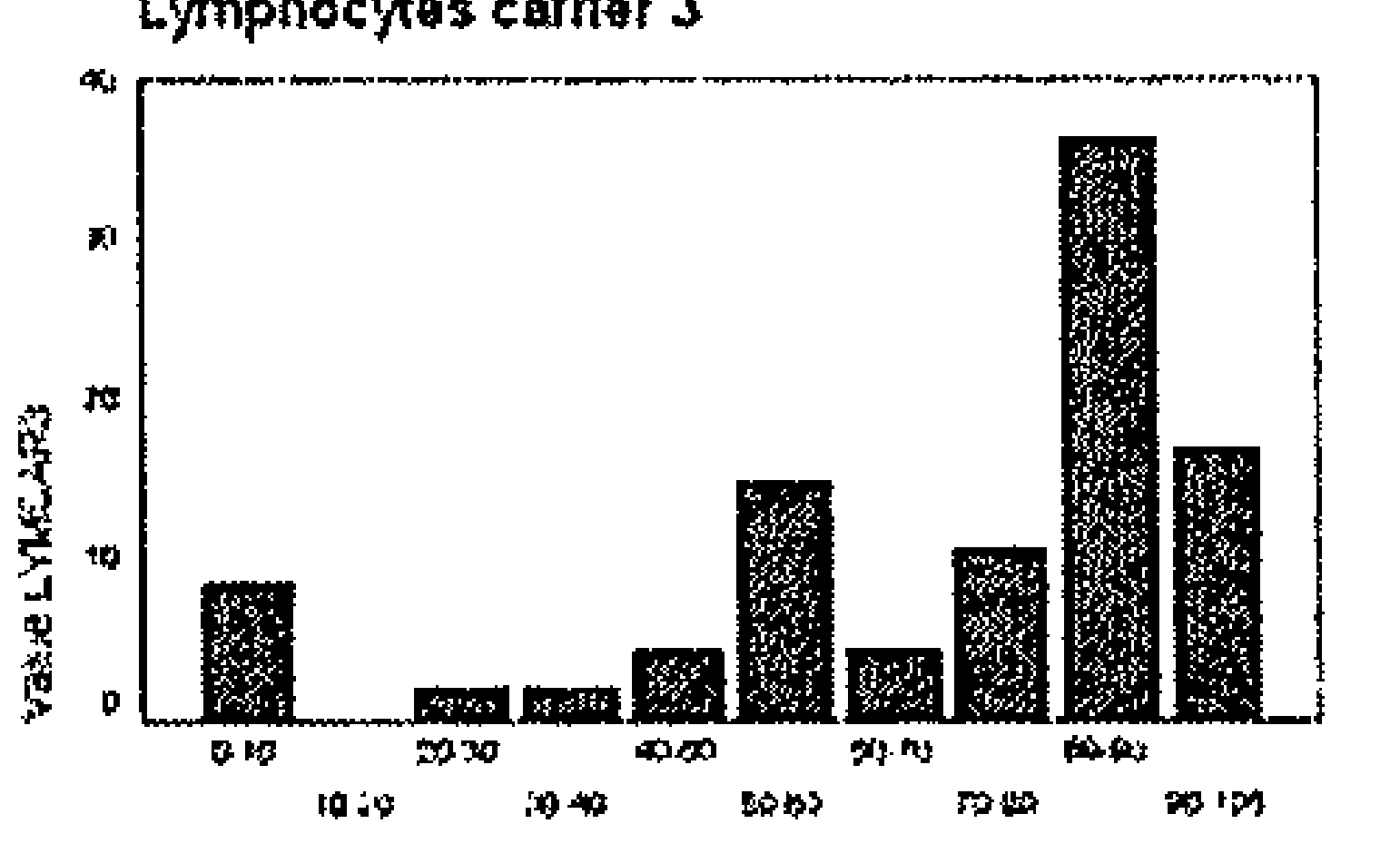

PER:ENTA

Singlo coll distribution

lymphocytes pationt 1

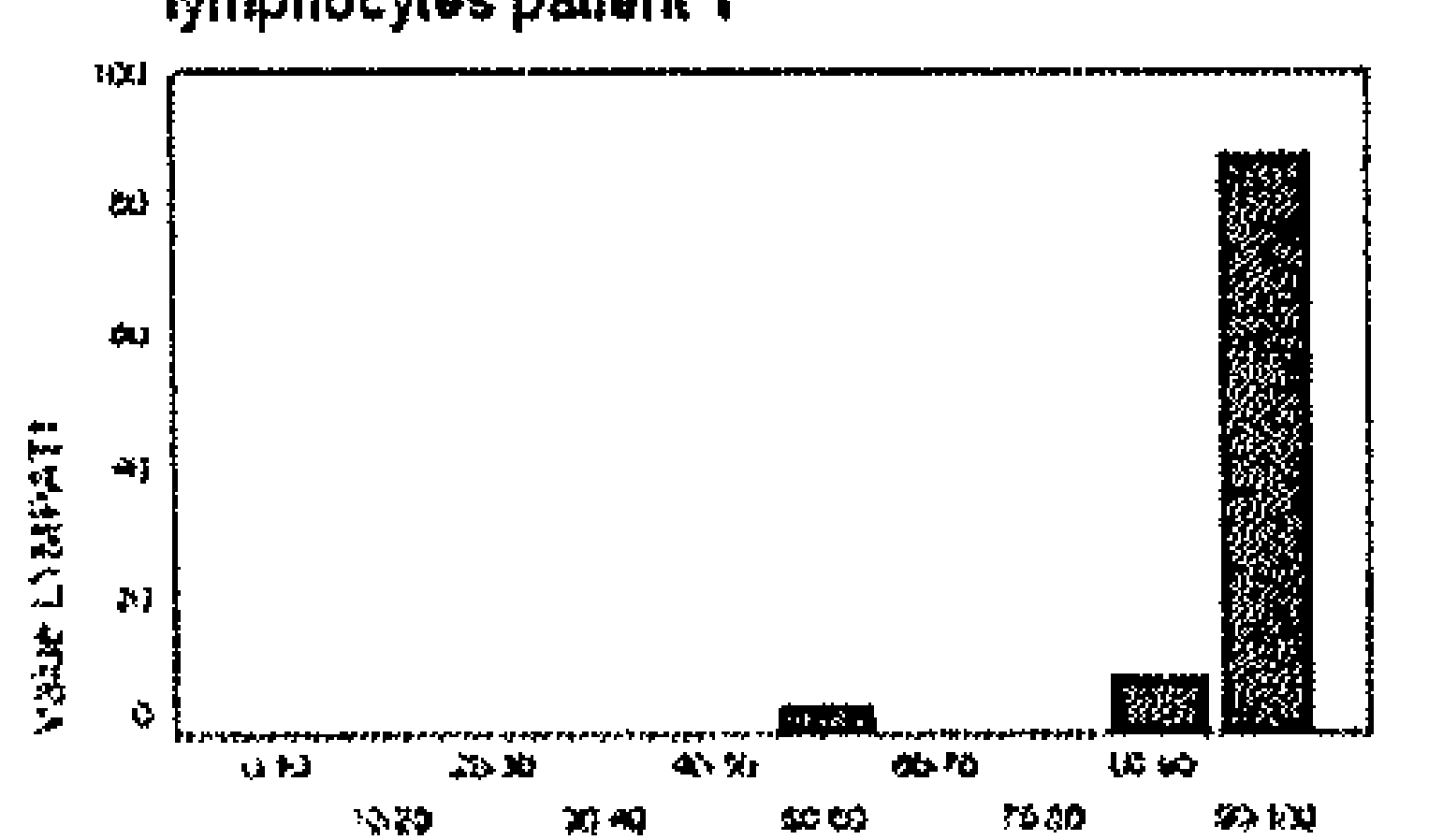

FERCGHTA

Single call distribution

Iymphocytes pationt 2

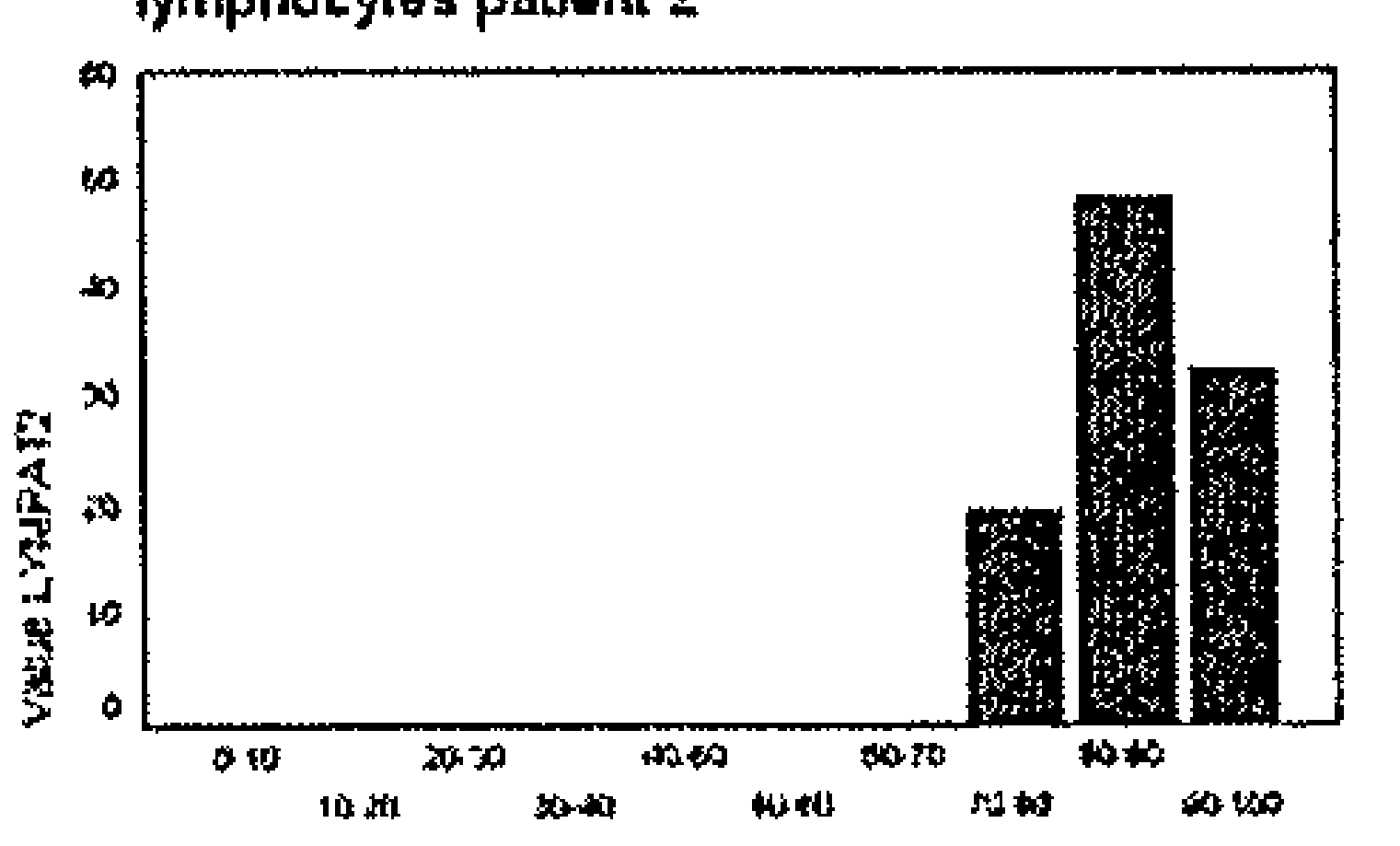

PEREENTA

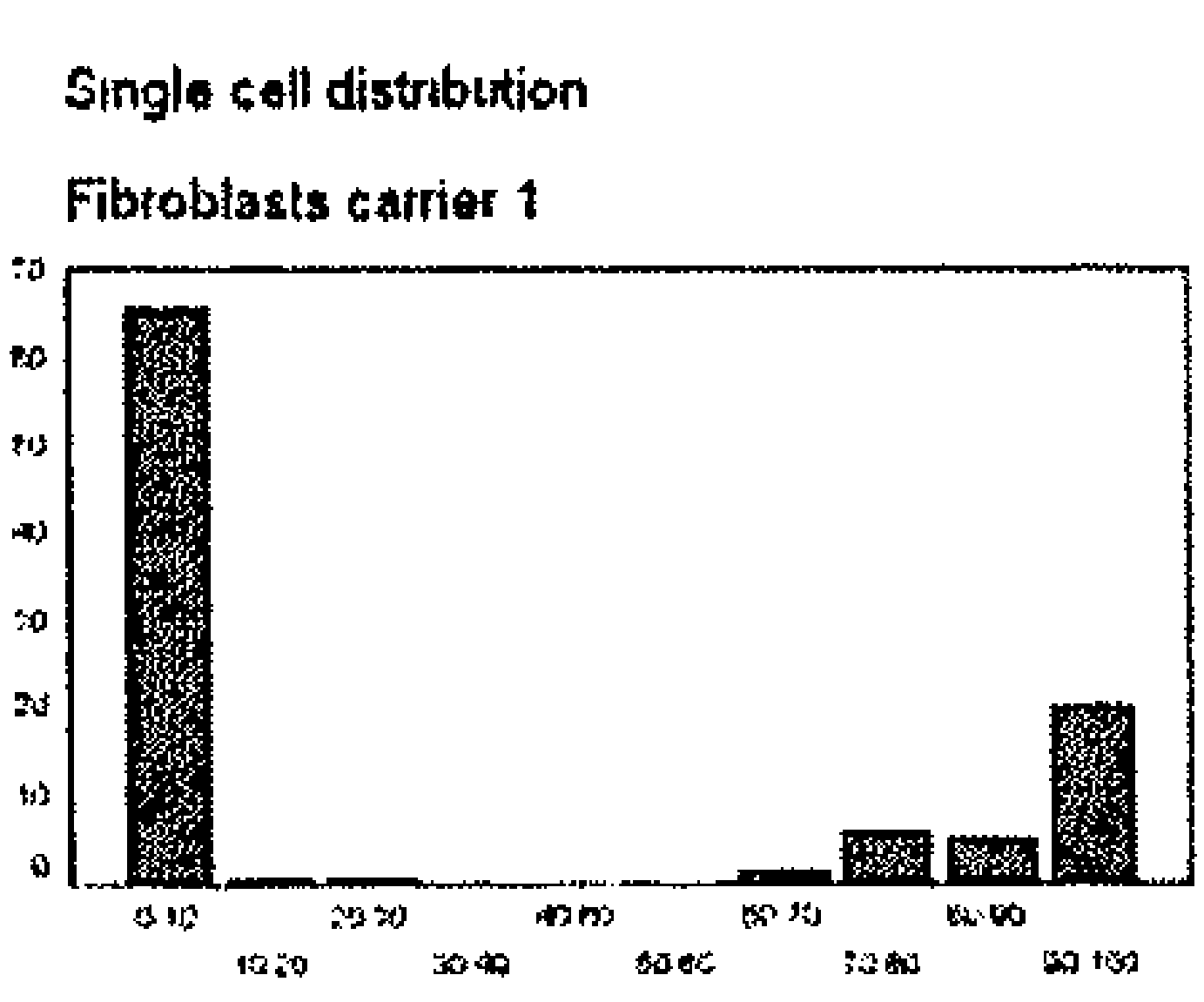

PEPSENTYA

Single cell distribution

Fibroblasts carrier 2

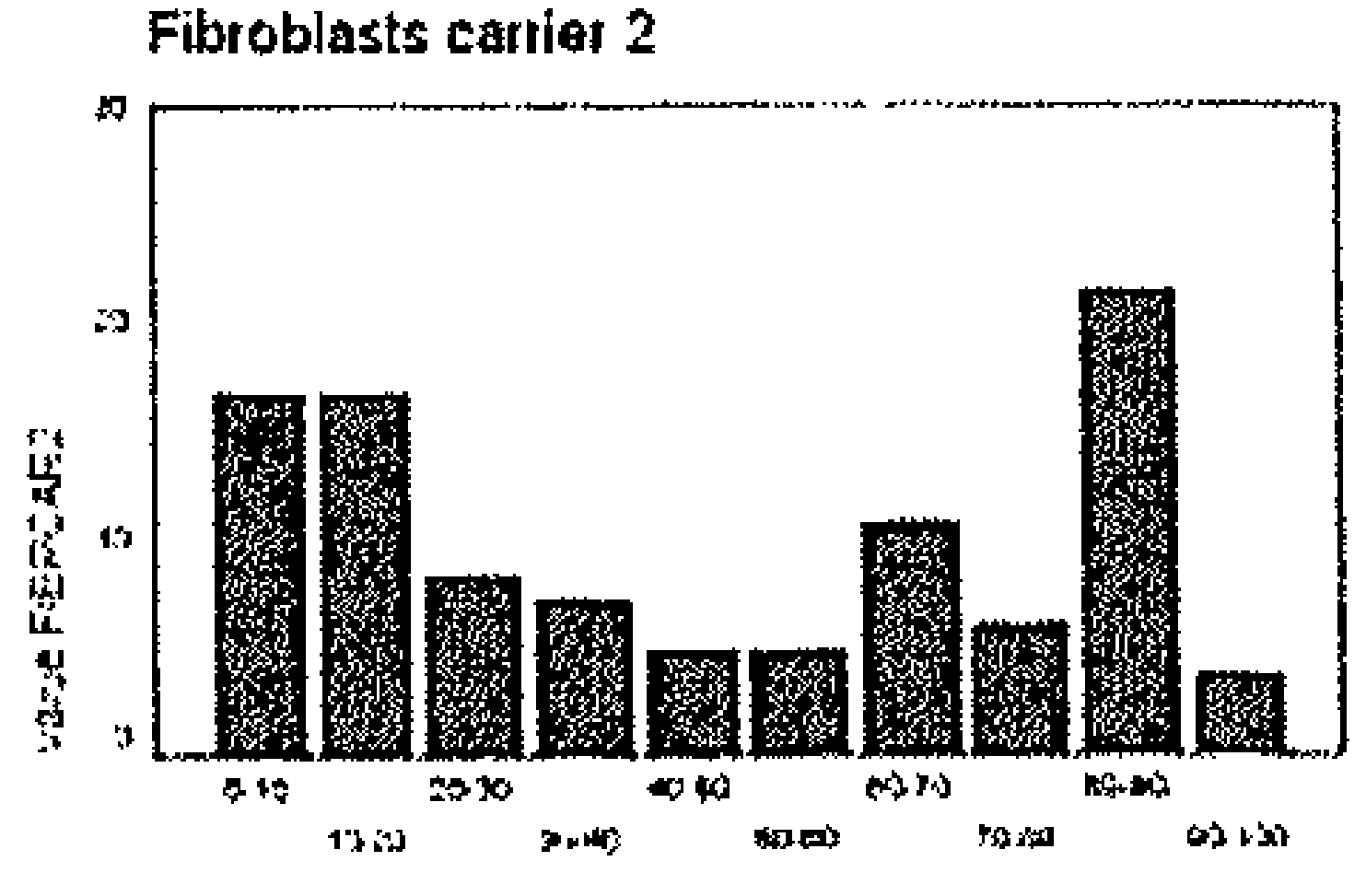

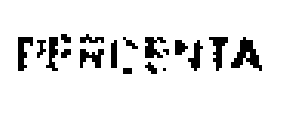

Singla call distribution

Fibroblasts carrier 3

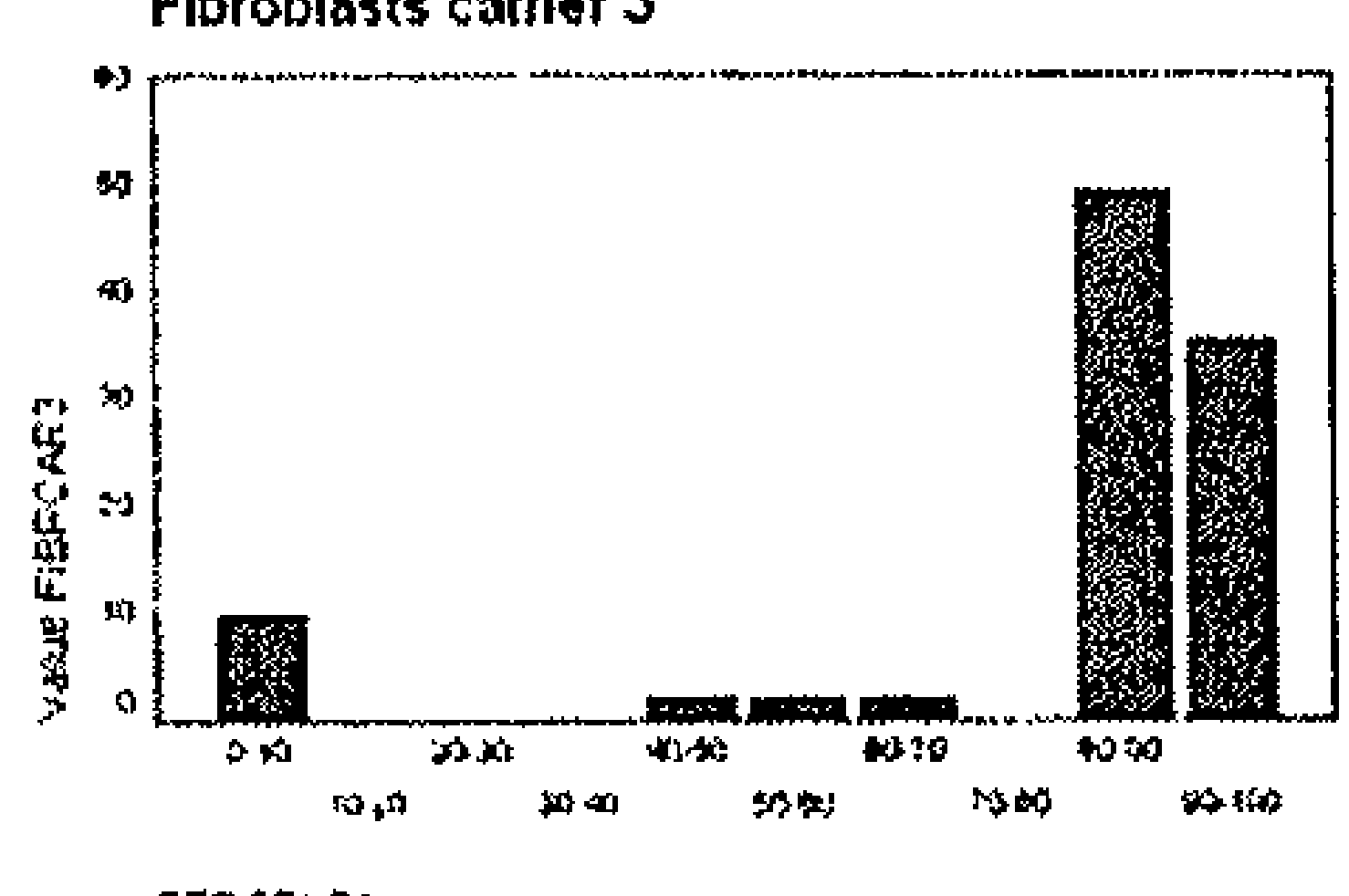

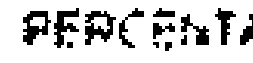

Single cell distribution

fibroblests patient 1

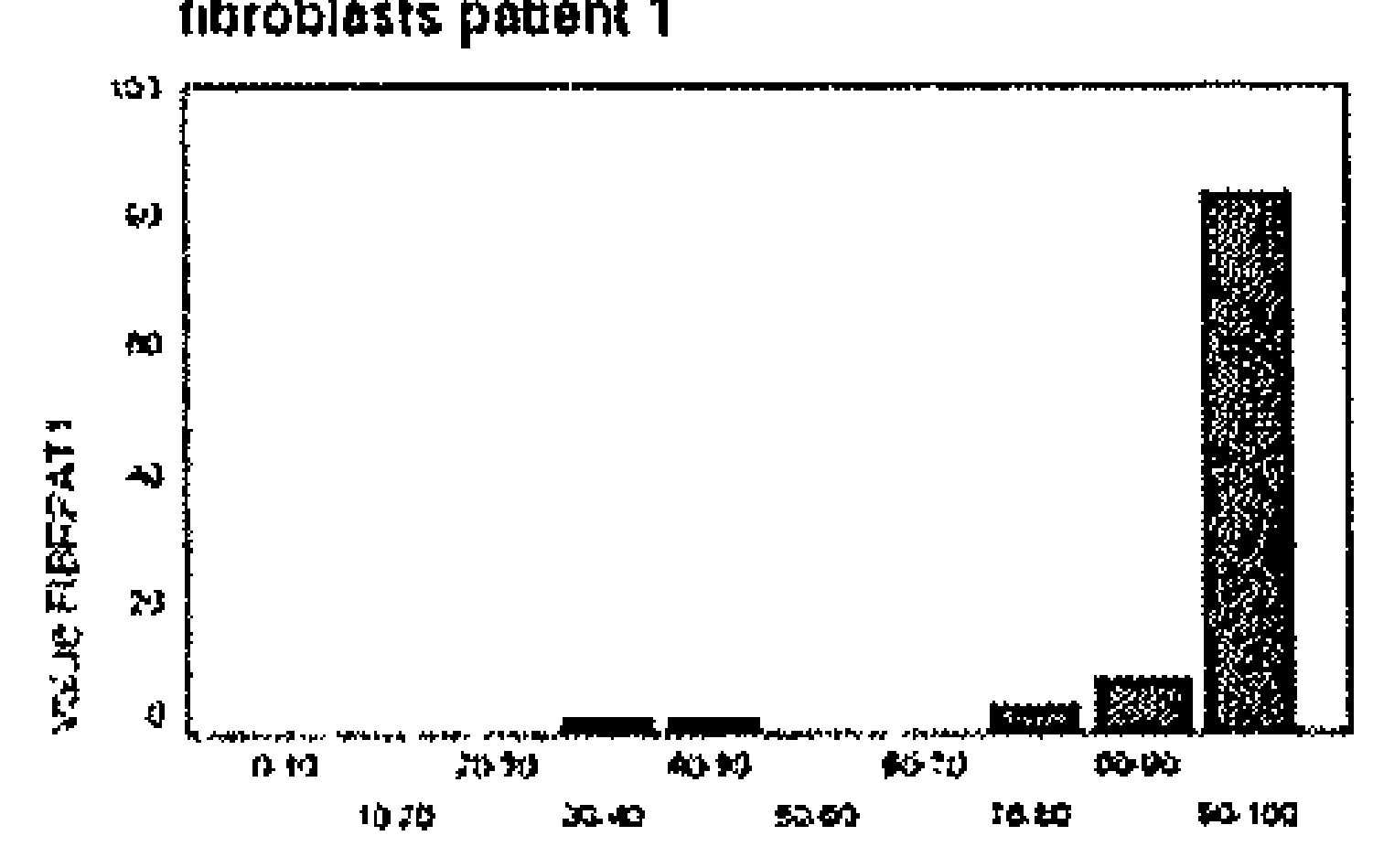

PERCENIA

Singlo cell distribution

fitroblests patient?

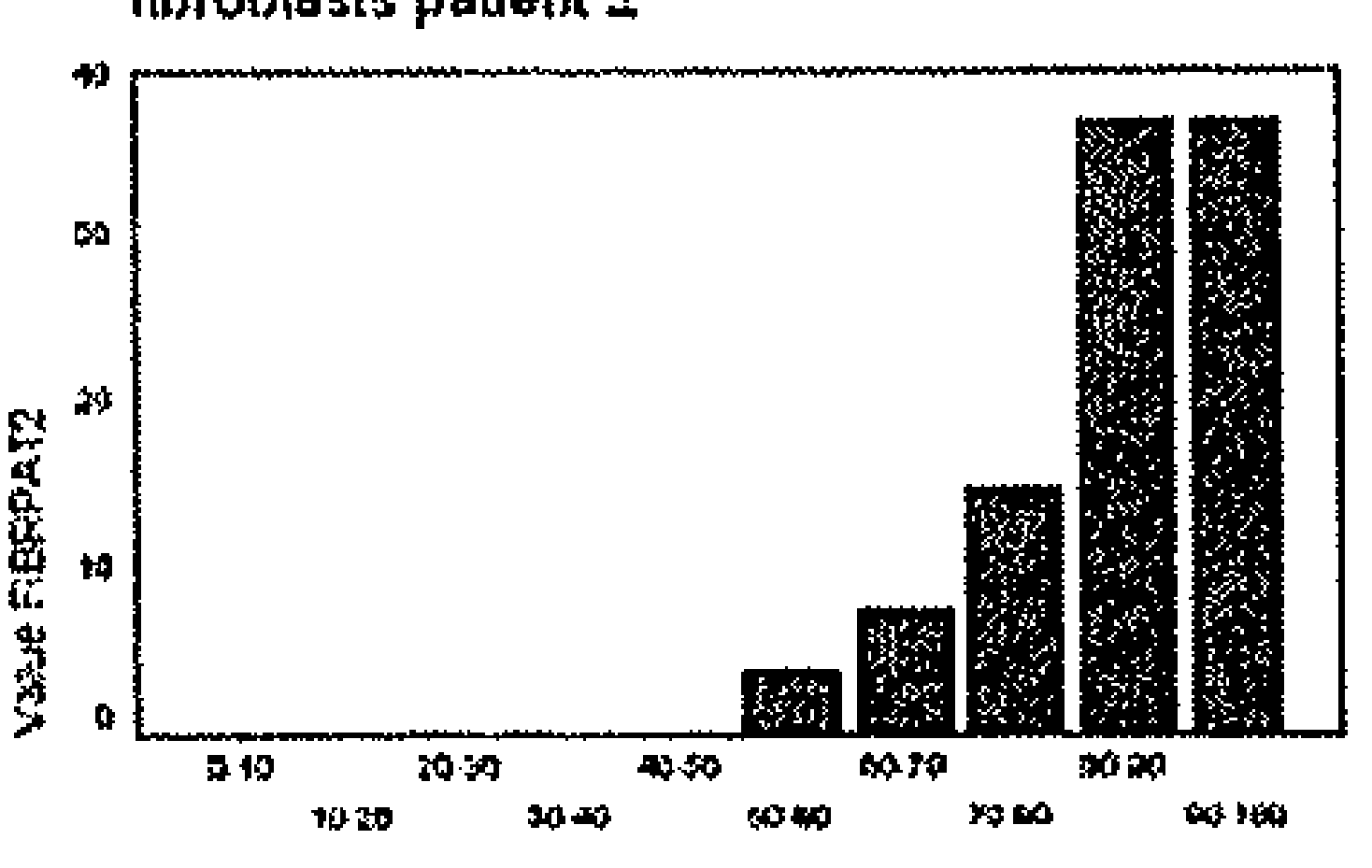

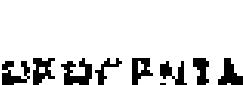

Figure 2: Single cell

distribution of the

m.9176T>C mutation in

lymphocytes (left) and

fibroblasts (right) of carriers

(the first three graphs) and

patients (bottom two graphs). 


\section{Statistical analysis}

Using statistics the mean of the single cell heteroplasmy values between both cell types of one person was compared. This revealed no significant difference between lymphocytes and fibroblasts (table 1). The mean single cell heteroplasmy value obtained from lymphocytes was compared to the earlier determined heteroplasmy value in blood (figure 1). Also this test revealed no significant difference between the mean single cell value and the blood heteroplasmy value (results not shown). No statistical difference was observed between the values from single fibroblasts and entire cultures from carrier 1. Non-parametrical statistical tests were used to compare the distribution pattern (figure 2) between the two cell types from the carriers. These tests did not reveal a significant difference for all but carrier 1 based on the two-sample Kolmogorov-Smirnov test. A trend for more extreme heteroplasmy values was, however, demonstrated in the other carriers in the fibroblast samples as compared with the lymphocyte samples. Patients did not show a difference in distribution pattern of the single cell values. Comparing the distribution patterns (figure 2), only carrier 1 has a distribution pattern, which differs from the other carriers or patients. The likelihood of carrier 1 to receive three severely affected children based on the distribution pattern of the mutation in her fibroblast cells was estimated to be around $3.5 \%$.

\section{Discussion}

The m.9176T $>\mathrm{C}$ mutation shows extensive variation in mutation levels in single cells of an individual. This variation is especially evident in the three carriers (Figure 1) who all show heteroplasmy levels between $0 \%$ and $>90 \%$ in single cells. Despite this variation there is no statistical difference between the overall heteroplasmy value for blood and fibroblasts and the mean single cell value for lymphocytes and fibroblasts. This means that for this mutation the tissue heteroplasmy value is a good representation of the mean heteroplasmy value of single cells in this tissue, although it does not mean that the majority of cells have mutation percentages around the mean. Another striking observation is the significant difference in distribution pattern between lymphocytes and fibroblasts in the three carriers, but most prominent in carrier 1, based on $5 \%$ confidence. In all three carriers fibroblasts have more extreme heteroplasmy levels than lymphocytes. The distribution of the mutation levels in lymphocytes and fibroblasts is not normal and skewed to both extremes. The patients with mutation levels above $90 \%$ are closest to a normal distribution around the mean. Normal and abnormal distribution of single cell heteroplasmy values has been shown before in other investigations analyzing single cells or muscle fibers from mtDNA patients (Mita et al., 1998; Ozawa et al., 1998; Saitoh et al., 1999; Silvestri et al., 2000; He et al., 2002; Gigarel et al., 2005), but the differences were not as extreme as in our study. Studies addressing heteroplasmy levels of mtDNA point mutations, like the m.3243A $>\mathrm{G}$ and m.8344A $>\mathrm{G}$, have analysed single muscle fibres, discriminating between COX-positive, COX-negative and normal fibres. The highest mutation load was present in the COX-negative fibres and the lowest in the normal fibres. The distribution within one type of fibre is in general a normal distribution around the mean value of the fibre type (Mita et al., 1998; Moslemi et al., 1998; 
Koga et al., 2000; Silvestri et al., 2000). Other studies analysing an mtDNA deletion and the m.3243A $>G$ mutation in muscle fibres show a distribution pattern with values reaching towards homoplasmy especially in patients with median mean heteroplasmy values (Ozawa $e t$ al., 1998; He et al., 2002).

Variation can be caused by cell division when the mitochondria are randomly divided between the daughter cells (Rotig and Munnich, 2003). This random division leads to slight differences between cells eventually leading to extreme variations and the situation of homoplasmy (Enriquez et al, 2003). This process has elegantly been shown for fixation of new mtDNA mutations in colonic crypt cells (Taylor et al. 2003). The model used predicts that the random partitioning of mitochondrial genomes during crypt cell division, which occurs every 24 hour, will cause random genetic drift and lead to the clonal expansion of somatic mtDNA mutations during human life. The observed distribution of single cell heteroplasmy values in our and other studies could reflect a similar process, although the lesser number of cell divisions and the differences observed between individuals might indicate a more specific process. It is known that genetic factors may be involved (Enriquez, 2003). Also, in a mouse model a tissue specific selection for different mtDNA genotypes has revealed three quantitative-trait loci (QTLs) that could account for this tissue specificity ((Battersby et al., 2003). Identification of the factors involved would open up strategies to induce a shift in the heteroplasmy percentage, which could be of major therapeutic importance (Smith et al., 2004) (Chinnery et al., 1999; Chinnery, 2002)..

The question remains whether processes involved in the somatic nucleoid segregation could affect for example disease progression or mutation transmission. We have only preliminary information from one family, but our data suggest that it is worthwhile to explore this further. The heteroplasmy percentage in blood of carrier 1 and 2, who are sisters, is comparable, respectively $43.5 \%$ and $47.8 \%$, but the distribution pattern in fibroblasts differ and also the mutation load in their children (figure 1). The more random dispersion of the mutation in carrier 2 might reflect random segregation with a likelihood of mutation levels in her children around the mean, whereas the skewed distribution in fibroblasts of carrier 1 might indicate an increased chance of very high and very low mutation load. The mutation load observed in the children fits with this hypothesis. So it would be worthwhile to test mothers of children with mtDNA disease to see if the distribution pattern in fibroblasts is in line with the distribution of the mutation load in their children. If this can be confirmed then the distribution pattern of the mutation in the mother could be important for determining the recurrence risk and the success rate of PND or PGD.

\section{References}

Anderson S, Bankier AT, Barrell BG, de Bruijn MH, Coulson AR, Drouin J, Eperon IC, Nierlich DP, Roe BA, Sanger F, et al. (1981) Sequence and organization of the human mitochondrial genome. Nature $290,457-465$.

Battersby BJ, Loredo-Osti JC and Shoubridge EA (2003) Nuclear genetic control of mitochondrial DNA segregation. Nat Genet 33,183-186. 
Blok RB, Gook DA, Thorburn DR and Dahl HH (1997) Skewed segregation of the mtDNA nt 8993 (T-$>\mathrm{G}$ ) mutation in human oocytes. Am J Hum Genet 60,1495-1501.

Brandon MC, Lott MT, Nguyen KC, Spolim S, Navathe SB, Baldi P and Wallace DC (2005)

MITOMAP: a human mitochondrial genome database--2004 update. Nucleic Acids Res 33 Database Issue,D611-613.

Brown DT, Samuels DC, Michael EM, Turnbull DM and Chinnery PF (2001) Random genetic drift determines the level of mutant mtDNA in human primary oocytes. Am J Hum Genet 68,533-536.

Chinnery PF (2002) Modulating heteroplasmy. Trends Genet 18,173-176.

Chinnery PF (2004) New approaches to the treatment of mitochondrial disorders. Reprod Biomed Online 8,16-23.

Chinnery PF, Zwijnenburg PJ, Walker M, Howell N, Taylor RW, Lightowlers RN, Bindoff L and Turnbull DM (1999) Nonrandom tissue distribution of mutant mtDNA. Am J Med Genet 85,498-501.

Gigarel N, Ray PF, Burlet P, Frydman N, Royer G, Lebon S, Bonnefont JP, Frydman R, Munnich A and Steffann J (2005) Single cell quantification of the 8993T>G NARP mitochondrial DNA mutation by fluorescent PCR. Mol Genet Metab 84,289-292.

He L, Chinnery PF, Durham SE, Blakely EL, Wardell TM, Borthwick GM, Taylor RW and Turnbull DM (2002) Detection and quantification of mitochondrial DNA deletions in individual cells by real-time PCR. Nucleic Acids Res 30,e68.

Jacobs LJ, de Coo IF, Nijland JG, Galjaard RJ, Los FJ, Schoonderwoerd K, Niermeijer MF, Geraedts JP, Scholte HR and Smeets HJ (2005) Transmission and prenatal diagnosis of the T9176C mitochondrial DNA mutation. Mol Hum Reprod.

Koga Y, Koga A, Iwanaga R, Akita Y, Tubone J, Matsuishi T, Takane N, Sato Y and Kato H (2000) Single-fiber analysis of mitochondrial $\mathrm{A} 3243 \mathrm{G}$ mutation in four different phenotypes. Acta Neuropathol (Berl) 99,186-190.

Larsson NG and Clayton DA (1995) Molecular genetic aspects of human mitochondrial disorders. Annu Rev Genet 29,151-178.

Mita S, Tokunaga M, Uyama E, Kumamoto T, Uekawa K and Uchino M (1998) Single muscle fiber analysis of myoclonus epilepsy with ragged-red fibers. Muscle Nerve 21,490-497.

Moslemi AR, Tulinius M, Holme E and Oldfors A (1998) Threshold expression of the tRNA(Lys) A8344G mutation in single muscle fibres. Neuromuscul Disord 8,345-349.

Ozawa M, Nonaka I and Goto Y (1998) Single muscle fiber analysis in patients with 3243 mutation in mitochondrial DNA: comparison with the phenotype and the proportion of mutant genome. J Neurol Sci 159,170-175.

Poulton J and Marchington DR (2000) Progress in genetic counselling and prenatal diagnosis of maternally inherited mtDNA diseases. Neuromuscul Disord 10,484-487.

Rotig A and Munnich A (2003) Genetic features of mitochondrial respiratory chain disorders. J Am Soc Nephrol 14,2995-3007.

Saitoh S, Momoi MY, Yamagata T, Nakauchi H, Nihei K and Fujii M (1999) Single-cell analysis of mitochondrial DNA in patients and a carrier of the tRNA(Leu)(UUR) gene mutation. J Inherit Metab Dis $22,608-614$

Silvestri G, Rana M, Odoardi F, Modoni A, Paris E, Papacci M, Tonali P and Servidei S (2000) Singlefiber PCR in MELAS(3243) patients: correlations between intratissue distribution and phenotypic expression of the mtDNA(A3243G) genotype. Am J Med Genet 94,201-206.

Smith PM, Ross GF, Taylor RW, Turnbull DM and Lightowlers RN (2004) Strategies for treating disorders of the mitochondrial genome. Biochim Biophys Acta 1659,232-239.

Steffann J, Frydman N, Gigarel N, Burlet P, Ray PF, Fanchin R, Feyereisen E, Kerbrat V, Tachdjian G, Bonnefont JP, et al. (2006) Analysis of mtDNA variant segregation during early human embryonic development: a tool for successful NARP preimplantation diagnosis. J Med Genet 43,244-247. 
Taylor RW, Barron MJ, Borthwick GM, Gospel A, Chinnery PF, Samuels DC, Taylor GA, Plusa SM, Needham SJ, Greaves LC, Kirkwood TB, Tumbull DM (2003) Mitochondrial DNA mutations in human colonic crypt stem cells. J Clin Invest. 112:1351-60. 


\section{$\underline{0.06}$}

MtDNA point mutations are present at various levels of heteroplasmy in human oocytes

Lorraine Jacobs $^{1,2}$, Mike Gerards ${ }^{1}$, Patrick Chinnery ${ }^{3}$, John Dumoulin ${ }^{4}$, Ireneaus de Coo ${ }^{5}$, Joep Geraedts ${ }^{1}$, Hubert Smeets ${ }^{1}$

${ }^{1}$ Departement of Genetics and Cell Biology and ${ }^{2}$ Research institute GROW, University of Maastricht. ${ }^{3}$ Mitochondrial Research Group, University of Newcastle upon Tyne, Newcastle Upon Tyne, UK. ${ }^{4}$ Department of IVF, Academic Hospital Maastricht. ${ }^{5}$ Department of Neurology, Erasmus Medical Center Rotterdam

Molecular Human Reproduction, Vol. 13, no. 3, pp.149-54, 2007 


\begin{abstract}
Little is known about the load of mutations and polymorphisms in the mtDNA of human oocytes and the possible effect these mutations may have during life. To investigate this, we optimised at the single cell level the recently developed method to screen the entire mtDNA for mainly heteroplasmic mutations by denaturing high performance liquid chromatography (DHPLC) analysis. This method is sensitive ( $1 \%$ heteroplasmy detectable), specific and rapid. The entire mtDNA of 26 oocytes of 13 women was screened by this method. Ten different heteroplasmic mutations, of which only one was located in the D-loop and of which two were observed twice, were detected in seven oocytes with mutation loads ranging from less than $5 \%$ to $50 \%$. From 8 women more than one oocyte was received and in four of them heteroplasmic differences between oocytes of the same woman were observed. In one of these four also two homoplasmic D-loop variants were detected. Additionally, four oocytes of a single woman were sequenced using the MitoChip ${ }^{\boxplus}$ (which lacks the D-loop region), but all sequences were identical. It is concluded that heteroplasmic mtDNA mutations are common in oocytes and that depending on the position and mutation load they might increase the risk on developing OXPHOS disease early or later in life.
\end{abstract}

\title{
Introduction
}

A large number of mutations (more than 200) and polymorphisms has been reported for the mitochondrial DNA (mtDNA) (Brandon et al., 2005). One of the reasons is that the mtDNA is located in the mitochondria near the OXPHOS system, which produces mutagenic reactive oxygen species (ROS) as part of the electron transport to produce energy in the form of ATP (Kuchino et al., 1987). This high mutation rate in combination with a lack of good repair mechanisms and recombination and the exclusive maternal transmission of mtDNA would predict a decay of the mtDNA during evolution. This does not happen due to the 'mtDNA bottleneck' which is a restriction in the number of mtDNA molecules to be transmitted, followed by an amplification of these founder molecules in oocytes (Howell et al., 1992). The bottleneck occurs during the early stages of oocyte development, in order to maintain homoplasmic mtDNA and minimize heteroplasmy (Cummins, 1998; Cummins, 2001). Because this happens very early during development the chance to preserve age-related mutations in the early oocyte is small, although the low amount of mtDNA copies per mitochondria in the early developmental stages of the oocytes renders these oocytes vulnerable for mutational events at this stage (Keefe et al., 1995). As a result of the mtDNA bottleneck a preferentially healthy mtDNA population is maintained in oocytes and offspring. Several reports have shown that this bottleneck is no absolute safeguard (Poulton, 1995; Degoul et al., 1997; Lutz et al., 2000). There have been a number of investigations on the load of mtDNA deletions in oocytes that failed to develop into metaphase II oocytes (Chen $e t$ al., 1995; Keefe et al., 1995; Brenner et al., 1998; Reynier et al., 1998; Barritt et al., 1999; Hsieh et al., 2002) and on average $50 \%$ of the human oocytes contain mtDNA deletions although usually in extremely low heteroplasmy percentages. 
Little is known about the presence of point mutations in the mtDNA of human oocytes. This is a major concern as, at least for children with mtDNA mutations, maternal inheritance is the exception rather than the norm and many children carry de novo mutations in the mtDNA (Thorburn, 2004). Therefore we screened the entire mtDNA of 26 oocytes for heteroplasmic mutations by denaturing high performance liquid chromatography (DHPLC) analysis (van Den Bosch et al., 2000) and, additionally, 4 oocytes of 1 woman for homoplasmic and, less sensitive than by DHPLC, heteroplasmic variants by the resequencing MitoChip ${ }^{\boxplus}$ (Maitra et al., 2004). The presence and mutation load of point mutations in these oocytes might provide a clue for the chance of developing "spontaneous" severe OXPHOS disease or age-related complications, due to mtDNA defects. Furthermore, it may provide insight in the performance of the bottleneck.

\section{Materials and Methods}

\section{Human oocytes}

A total of 26 oocytes from 13 women were donated by consenting couples undergoing in vitro fertilisation (IVF) or intra cytoplasmic sperm injection (ICSI) because of male infertility problems, except for two women who had an obstruction of the fallopian tube. The oocytes used were apparently normal in morphological appearance, but immature in development although several oocytes developed into metaphase II oocytes prior to analysis. There was no enrichment for poor quality oocytes, in which an increase of mtDNA rearrangements has been previously reported (Barritt et al., 1999). Oocytes were collected anonymously and no additional maternal material could be obtained. From the 26 oocytes four were germinal vesicles (GV), 13 were in metaphase I (MI) and nine were in the fully developed metaphase II (MII) stage. Donated oocytes were washed three times in sterile MQ in plastic dishes, and then transferred to a $0.2 \mathrm{ml}$ tube in $1-2 \mu \mathrm{l}$ volume. The oocytes were used immediately or frozen at $-20^{\circ} \mathrm{C}$. All pipetting was performed with a sterile, filtered mouth pipette.

\section{Cell lysis}

DNA was extracted from the oocytes using a proteinase $\mathrm{K}$-based isolation method (Zhou et al., 1997). Briefly, oocytes were thawed at room temperature and $10 \mu$ of the DNA extraction solution (50 mM Tris-HCl, pH8.5, $1 \mathrm{mM}$ EDTA, and $0,5 \%$ Tween 20, containing $200 \mu \mathrm{g} / \mathrm{ml}$ proteinase $\mathrm{K}$ ) was added. Samples were incubated at $55^{\circ} \mathrm{C}$ for two hours, followed by 10 minutes incubation at $95^{\circ} \mathrm{C}$ to inactivate the proteinase $\mathrm{K}$.

\section{$P C R$ amplification of the mtDNA in single cells}

Two rounds of nested PCR were performed. In the first round the entire mtDNA was amplified using three Expand Long PCR reactions (at positions I: 612-7165 II: 6642-12639 III: 11909-742 using primers IF: gaaaatgtttagacgggctcac IR: cgccgatgaatatgatagtgaa IIF: tatcctaccaggcttcggaata IIR: atgatggaccatgtaacgaaca IIIF: aaccacgttctcctgatcaaat IIIR: 
atcgtggtgatttagagggtga). The reactions were performed using the Expand ${ }^{\mathrm{TM}}$ Long Template PCR System (Roche, Basel, Switzerland) containing $500 \mu \mathrm{M}$ per dNTP (Amersham Pharmacia Biotech AB, Uppsala, Sweden, $25 \mathrm{mM}$ each), $2 \mathrm{ng} / \mu \mathrm{l}$ of each primer, $5 \mu 110 \mathrm{x}$ PCR buffer II, $3 \mu \mathrm{l}$ cell-lysate and $0.5 \mu \mathrm{l}$ Expand Long polymerase (with proofreading capacity) in a $50 \mu \mathrm{l}$ reaction volume. The reactions were carried out in a 9700 thermocycler (Applied Biosystems, Foster City, USA) as follows: $95^{\circ} \mathrm{C} 3 \mathrm{~min} ; 10$ cycles of $93^{\circ} \mathrm{C}$ for $10 \mathrm{~s}$, $60^{\circ} \mathrm{C}$ for $30 \mathrm{~s}$ and $68^{\circ} \mathrm{C}$ for $8 \mathrm{~min} ; 20$ cycles of $93^{\circ} \mathrm{C}$ for $10 \mathrm{~s}, 60^{\circ} \mathrm{C}$ for $30 \mathrm{~s}$ and $68^{\circ} \mathrm{C}$ for $8 \mathrm{~min}$ plus $20 \mathrm{~s}$ per elongation step; and a final 7 min elongation at $68^{\circ} \mathrm{C}$. In the second round the entire mtDNA was amplified in thirteen separate fragments (van Den Bosch et al., 2000), using $3 \mu \mathrm{l}$ of the Expand Long PCR product in a reaction volume of $50 \mu \mathrm{l}$ containing $0.8 \mu \mathrm{M}$ per dNTP, $0.4 \mu \mathrm{M}$ of each primer, $1.5 \mathrm{mM} \mathrm{MgSo}_{4}, 5 \mu$ Optimase ${ }^{\boxplus}$ polymerase buffer and 2.5U Optimase ${ }^{\circledR}$ polymerase (Transgenomic, Omaha, USA). The reactions were carried out in a 9700 thermocycler (Perkin-Elmer) according to the Optimase ProtocolWriter ${ }^{\mathrm{TM}}$ as either a normal step PCR procedure or as a touchdown PCR if the melting temperature of both primers was separated by more than three degrees. Following PCR amplification the DNA samples were denatured at $95^{\circ} \mathrm{C}$ reannealed at $65^{\circ} \mathrm{C}$ and cooled to $4^{\circ} \mathrm{C}$ to form heteroduplexes. If necessary, smaller PCR fragments were amplified by using $1 \mu l$ of the expand long PCR product in a total reaction volume of $50 \mu \mathrm{l}$ containing $0.8 \mu \mathrm{M}$ per dNTP, $0.4 \mu \mathrm{M}$ of each primer, $1.5 \mathrm{mM} \mathrm{MgSO}_{4}, 5 \mu \mathrm{l}$ Optimase $^{\circledR}$ polymerase buffer and $2.5 \mathrm{U}$ Optimase ${ }^{\circledR}$ polymerase (transgenomic).

\section{DHPLC analysis of the mtDNA and fragment collection}

Amplified second round products were cleaved with restriction enzymes to obtain smaller fragments of 90 to 560 basepairs in length as described before (van Den Bosch et al., 2000). After purification with the QIAquick ${ }^{\text {TM }}$ PCR purification kit (Qiagen, GmbH, Hilden, Germany), DHPLC analysis was performed on the Transgenomic WAVE ${ }^{(1)}$ system. Low percentage heteroduplex peaks were reanalysed on the WAVE and the deviant peaks were collected using the FCX-200 fragment collector (Transgenomic,Omaha, USA). Fragment collection was performed in a two-step procedure. In the first DHPLC run the time window for the elution of the peaks of interest was determined. During a second injection DHPLC fragments were collected during the previously defined time interval.

\section{Sequence analysis of PCR fragments}

Sequencing reactions were performed in a total volume of $20 \mu \mathrm{l}$ using $2 \mu \mathrm{l}$ Big Dye termination solution according to the protocols of the manufacturer (Applied Biosystems, Foster City, USA) and $50 \mathrm{ng}$ forward or reverse primer, using a ABI Prism 3100 DNA automatic sequencer (Applied Biosystems, Foster City, USA) and ABI analysis software version 3.1 . 
Table I: Heteroplasmic mtDNA changes in 26 oocytes

\begin{tabular}{|c|c|c|c|c|c|}
\hline Oocyte & $\begin{array}{l}\text { Developmental } \\
\text { phase }\end{array}$ & $\begin{array}{l}\text { Nucleotide } \\
\text { substitutions }\end{array}$ & $\begin{array}{l}\text { Gene location: } \\
\text { Amino acid change }\end{array}$ & $\%$ heteroplamy & reference \\
\hline 1 & MII & & & & \\
\hline 2 & MII & & & & \\
\hline 3 & $\mathrm{MI}$ & & & & \\
\hline 4 & MII & & & & \\
\hline 5 & $\overline{\mathrm{MI}}$ & & & & \\
\hline 6 & MII & & & & \\
\hline 7 & $\mathrm{MI}$ & & & & \\
\hline 8 & $\overline{\mathrm{MI}}$ & & & & \\
\hline 9 & MI & G15607A & CYTB: No & $<10 \% \#$ & (Povalko et al., 2005) \\
\hline 10 & $\overline{\mathrm{GV}}$ & & & & \\
\hline $1 \mathrm{I}$ & MI & & & & \\
\hline 12 & MI & & & & \\
\hline 13 & $\overline{\mathrm{MII}}$ & & & & \\
\hline 14 & GV & & & & \\
\hline 15 & $\overline{\mathrm{GV}}$ & & & & \\
\hline 16 & $\overline{\mathrm{GV}}$ & & & & \\
\hline 17 & $\mathrm{MI}$ & A16289G & Non coding: No & $35 \%$ & (Horai et al., 1993) \\
\hline 18 & $\mathrm{MI}$ & & & & \\
\hline 19 & MI & & & & \\
\hline \multirow[t]{4}{*}{20} & \multirow[t]{4}{*}{ MI } & $\mathrm{A} 5390 \mathrm{G}$ & ND2: No & $30 \%$ & (Povalko et al, 2005 ) \\
\hline & & T6776C* & COI: No & $<5 \%$ & $\begin{array}{l}\text { (Marzuki et al, } 1991 ; \\
\text { Chinnery et al.,2001) }\end{array}$ \\
\hline & & A6791G* & COI: No & $<5 \%$ & (Marzuki et al., 1991) \\
\hline & & $\mathrm{T} 8542 \mathrm{C}^{*}$ & $\begin{array}{l}\text { ATPase } 6 \text { and 8: } \\
\text { Phe } \rightarrow \text { Leu (ATPase } \\
6 \text { ) }\end{array}$ & $<5 \%$ & NR \\
\hline 21 & MII & $\mathrm{T} 14766 \mathrm{C}$ & CYTB: Thr $\rightarrow$ Ile & $50 \%$ & \begin{tabular}{|l|} 
(Marzuki et al., \\
Povalko et al., 2005)
\end{tabular} \\
\hline 22 & MII & $\mathrm{A} 6629 \mathrm{G}^{*}$ & COI: No & $<5 \%$ & (Herrnstadt et al., 2002) \\
\hline 23 & MII & & & & \\
\hline \multirow[t]{2}{*}{24} & \multirow[t]{2}{*}{$\overline{\mathrm{MII}}$} & T6776C* & COI: No & $<5 \%$ & \begin{tabular}{|l} 
(Marzuki et al., 1991; \\
Chinnery et al., 2001) \\
\end{tabular} \\
\hline & & A6791G* & COI: No & $<5 \%$ & (Marzuki et al., 1991) \\
\hline 25 & MI & $\longdiv { \mathrm { CA } 5 1 4 \mathrm { CACA } }$ & Non coding: No & $15 \%$ & $\begin{array}{l}\text { (Tikhomirov and Baranov, } \\
\text { 2005) } \\
\end{array}$ \\
\hline 26 & $\mathrm{MI}$ & $\mathrm{A} 6408 \mathrm{G}$ & COI: Ile $\rightarrow \mathrm{Val}$ & $15 \%$ & NR \\
\hline
\end{tabular}

\#Determined using restriction fragment analysis

*Enriched by fragment collector

NR: Not reported before

GV: Germinal vesicle oocyte

MI: Metaphase I oocyte

MII: Metaphase II oocyte 
Resequencing the mtDNA in single cells with the MitoChip ${ }^{\circledR}$

The 3 initial long range PCR fragments were re-amplified and PCR products were purified from residual primers and nucleotides using QIAQuick PCR cleanup kit and resuspended in $30 \mu \mathrm{l}$ of EB buffer (QIAGEN). The yield of each PCR product after purification was determined using a nanodrop ND-1000 spectrophotometer and equimolar amounts of the three fragments were pooled. After fragmentation and labelling, the products were hybridised on a pre-hybridised MitoChip ${ }^{\boxplus}$ as described in the Affymetrix customSeq ${ }^{\mathrm{TM}}$ Resequencing protocol (Affymetrix, Santa Clara, USA). Following hybridisation, the chips were washed and stained on the GeneChip fluidics station 400 (Affymetrix) using the preprogrammed CustumSeq Resequencing wash and stain protocol (DNA ARRAY-WS2). The Mitochips were scanned using the Affymetrix GeneChip scanner 3000 creating .CEL files for subsequent batch analysis. The Affymetrix GeneChip DNA Analysis Software (GDAS) version 3.0.1.3 beta was used for the analysis of the .CEL files.

\section{Results}

The entire mtDNA of 26 oocytes was screened by DHPLC analysis. Although these are single cell, it does not mean that this is a single template analysis. Oocytes contain about $100,000 \mathrm{mtDNA}$ molecules and the number of templates is comparable to 50,000 cells for a nuclear gene. Three types of alterations were detected by DHPLC analysis: heteroduplex peaks, indicating heteroplasmic mutations, shifts of the entire homoduplex peak and the loss or gain of a restriction site. The last two alterations pointed towards homoplasmic changes and were only studied when differing between oocytes of a single woman. A total of 12 heteroduplex peaks and two homoduplex shifts (table 1 and 2) were identified and characterised by sequence analysis. All changes identified were $A$ to $G$ or $T$ to $C$ changes. For six samples, heteroplasmic peak fraction collection was required (table 1). Heteroplasmy levels were determined using restriction fragment analysis (oocyte 9) or estimated from the DHPLC and sequencing peak surfaces. In case fragment collection was required the heteroplasmy level was estimated to be below $5 \%$, based on the detection level of DHPLC analysis.

Two homoplasmic changes were observed in the non-coding D-loop region between two oocytes of the same woman. As DHPLC analysis has a limited sensitivity to detect homoplasmic alterations, we do not know how many homoplasmic mutations might have been missed, not only in the D-loop, but especially in the remaining coding part of the mtDNA. Therefore, we used the MitoChip ${ }^{\circledR}$, which contains the entire coding part of mtDNA but unfortunately not the D-loop region, to analyze the 4 oocytes of woman 4 . We did not detect any additional homoplasmic or heteroplasmic differences between the oocytes of this woman. The detection level of the MitoChip ${ }^{\boxplus}$ appears to be mutation dependent and varies from $5 \%-30 \%$ heteroplasmy in our hands (van Eijsden et al., 2006). This is less sensitive than reported by others (Jakupciak et al., 2005). 
Table II: Differences in the mtDNA of oocytes obtained from one woman

\begin{tabular}{|c|c|c|c|c|}
\hline Woman & Oacyte & $\begin{array}{l}\text { Nucleotide } \\
\text { Differences }\end{array}$ & $\begin{array}{l}\text { Gene location: Amino } \\
\text { acid change }\end{array}$ & Difference \\
\hline 1 & $1+2$ & No & & \\
\hline 3 & $4+5$ & No & & \\
\hline 4 & $6+7+8+9$ & A15607G & CYTB: $\mathrm{No}$ & $\begin{array}{l}<10 \% \text { heteroplasmy in oocyte } 9 \text { other } \\
\text { oocytes have } 100 \% \text { polymorphism }\end{array}$ \\
\hline 6 & $11+12$ & No & & \\
\hline 8 & $14+15+16$ & No & & \\
\hline \multirow[t]{6}{*}{11} & $19+20$ & $\mathrm{~A} 5390 \mathrm{G}$ & ND2: No & $30 \%$ heteroplasmy in oocyte 20 \\
\hline & & $\mathrm{T} 6776 \mathrm{C}^{*}$ & COI: $\mathrm{No}$ & $<5 \%$ heteroplasmy in oocyte 20 \\
\hline & & $\mathrm{A} 6791 \mathrm{G}^{*}$ & COI: No & $<5 \%$ heteroplasmy in oocyte 20 \\
\hline & & $\mathrm{T} 8542 \mathrm{C}^{*}$ & $\begin{array}{l}\text { ATPase } 6 \text { and } 8: \\
\text { Phe } \rightarrow \text { Leu (ATPase 6) }\end{array}$ & $<5 \%$ heteroplasmy in oocyte 20 \\
\hline & & $\mathrm{C} 150 \mathrm{~T}$ & Non coding: No & $100 \%$ polymorphism in oocyte 20 \\
\hline & & $\mathrm{A} 200 \mathrm{G}$ & Non coding: No & $100 \%$ polymorphism in oocyte 20 \\
\hline \multirow[t]{4}{*}{12} & $21+22+23+24$ & $\mathrm{C} 14766 \mathrm{~T}$ & CYTB: Thr $\rightarrow$ Ile & $50 \%$ heteroplasmy in oocyte 21 \\
\hline & & $\mathrm{A} 6629 \mathrm{G}^{*}$ & COI: No & $<5 \%$ heteroplasmy in oocyte 22 \\
\hline & & $\mathrm{T} 6776 \mathrm{C}^{*}$ & COI: No & $<5 \%$ heteroplasmy in oocyte 24 \\
\hline & & $\mathrm{A} 6791 \mathrm{G}^{*}$ & COI: No & $<5 \%$ heteroplasmy in oocyte 24 \\
\hline 13 & $25+26$ & $\mathrm{~A} 6408 \mathrm{G}$ & COI: Ile $\rightarrow \mathrm{Val}$ & $15 \%$ heteroplasmy in oocyte 26 \\
\hline
\end{tabular}

${ }^{*}$ Enriched by fragment collector

\section{Discussion}

DHPLC analysis has been frequently reported for the detection of mtDNA mutations (van Den Bosch et al., 2000; Liu et al., 2002; Conley et al., 2003; Biggin et al., 2005) and we adapted the method at the single cell level. DHPLC analysis is highly sensitive with a detection level of less than $5 \%$ and probably $1 \%$ heteroplasmy. Several different mutations were identified in oocytes with heteroplasmy percentages varying from less than $5 \%$ to $50 \%$. It is unlikely that PCR artefacts or nuclear pseudogenes can explain the low level alterations, because the DNA polymerases have a proofreading capacity and the number of mtDNA templates is high (100,000 mtDNA molecules per oocyte) compared to the two copies of a nuclear template. Based on the number of templates and PCR cycles and length of fragments, the maximum level for PCR induced mutation could be between 0.05 and $0.1 \%$ for a specific mutation, which is below the detection limit of DHPLC analysis. The possibility of a contamination has also been excluded by the use of negative controls with no DNA in each step of the procedure. All changes identified were $A$ to $G$ or $T$ to $C$ changes. Most changes were known variants, except for two, m.6408A>G and m.8542T>C, which have not been described before. Two mutations, m.6776T $>C$ and $m .6791 \mathrm{~A}>\mathrm{G}$, were identified twice, which indicates that hot spots may exist, although the majority of the heteroplasmic mutations is scattered across the mtDNA. Earlier observations using bioinformatics and perceived mutations indicated a prominent instability of the guanine nucleotide in the mitochondrial genome. This instability was however most pronounced at the 3' and/or 5' end of the protein coding genes (Tanaka and Ozawa, 1994; Samuels et al., 2003). In contrast, the variants in the oocytes are predominant in the middle part of the coding genes and do not preferentially 
involve guanine residues (Samuels et al., 2003). Three of the observed changes were located in the D-loop, which is in line with literature that predicts that many point mutations may be contained in the mitochondrial control region (Chinnery et al., 1999; Clayton, 2000; Fernandez-Silva et al., 2003). This hypervariability of the D-loop has been observed in other tissues as well especially in relation to ageing and cancer (Cormio et al., 2005), but a bias exists as often only the D-loop is studied and mutations in other areas can be missed (Lee $e t$ al., 2005; Lievre et al., 2005). Recent data suggest that also in cancer mutations are being distributed among the entire mtDNA including the D-loop (Maitra et al., 2004; Jakupciak et al., 2005). So despite a preference for the D-loop region mutations in the mtDNA can arise at any location in the oocytes.

The heteroplasmy level of the point mutations in the coding region of the mtDNA in oocytes ranged from $<5 \%$ to about $50 \%$. As the maternal sequence is unknown, the mutation load is given for the nucleotide, which is most likely the mutated one, although this can be ambiguous. In case of multiple oocytes of a single woman, the sequence which was shared by most of the oocytes was considered as the maternal sequence. Although we did not detect an evidently pathogenic mutation, it can be expected that pathogenic mutations will not be uncommon, as mutations are scattered throughout the mtDNA. On average 20 (between 15-30 locations) positions in a tRNA molecule and $25 \%$ of the amino acids in the proteins are evolutionary conserved, indicating that as an estimate about $5 \%$ of the mutations in the mtDNA can alter a conserved nucleotide and thus potentially be pathogenic. We found heteroplasmic changes in $26.9 \%$ of the oocytes, which means that probably about $1 \%$ of the oocytes will carry a pathogenic point mutation. We did not detect mutation levels above $50 \%$ (although for oocyte 17 we can not be sure, because we could not deduce the maternal reference sequence from other oocytes), which is under the threshold level for common point mutations, like m.8344A $>\mathrm{G}, \mathrm{m} .8993 \mathrm{~T}>\mathrm{G}, \mathrm{m} .8993 \mathrm{~T}>\mathrm{C}$ and m.9176T $>\mathrm{C}$ [thresholds of respectively $>70 \%,>60 \%,>80 \%$ and $>90 \%$ (Chinnery et al., 1997; White et al., 1999; Jacobs et al., 2005)], although other point mutations, like the m.3243A>G mutation, can lead to clinical symptoms at heteroplasmy levels $<30 \%$ (Thorburn and Dahl, 2001). Under the assumption that mutation levels above $50 \%$ may exist and have not been detected due to the small sample size, or that mutation levels in cells might increase in the first cell divisions, we predict that about $1 \%$ of the oocytes will have a mutation level reaching above the threshold of expression. Combined with the calculated number of pathogenic mutations in oocytes, this would account for about 1:10,000 de novo cases of mtDNA disease, which is in line with the observed prevalence of OXPHOs disease and the high frequency of de novo mutations (Chinnery and Turnbull, 2001; Thorburn, 2004) and which is supported by case reports on de novo mutations in severely affected patients (De Coo et al., 1996; Degoul et al., 1997; Maassen et al., 2002; Thorburn, 2004).

In our study no deletions were detected after analysis of the first round PCR products, but we only systematically analysed the shortest fragment, as the other 2 fragments were not visible on agarose gel. Also the common deletion could not be detected by the nature of our PCR-assay. In previous reports mtDNA rearrangements have been observed in over $50 \%$ of 
the oocytes analysed, especially in those at the germinal vesicle stage (Chen et al., 1995; Brenner et al., 1998; Barritt et al., 1999; Hsieh et al., 2002). Differences between these studies and ours were the number of PCR cycles [at least 65 (Chen et al., 1995; Brenner et al., 1998; Barritt et al., 1999) compared to our first round of 30 cycles] and the size of the mtDNA fragment tested, which could explain why we did not detect these rearrangements in the mtDNA. In general the mutation levels of the point mutations are low and mutations can be lost during further cell divisions. This is also the case for the heteroplasmy level of the de novo rearrangements, which was about $0.1 \%$ of the mtDNA (Chen et al., 1995). Low-level mutations can, however, ultimately have phenotypic consequences as they can get fixed in some occasions by random genetic drift. This has been observed in rapidly dividing colonic crypt cells (Taylor et al., 2003) and cancer cells (Carew and Huang, 2002). This means that a low level of a mtDNA mutation in the oocyte may accumulate during life in specific tissues (like cytochrome $b$ mutations in muscle (Andreu et al., 1999). A deterioration of the OXPHOS system during life due to this accumulation may be a key factor in many agerelated diseases (Cottrell and Turnbull, 2000; Wei and Lee, 2002).

The bottleneck preserves a homoplasmic mtDNA content early during oocyte formation. The lowest number of mitochondria $(<10)$ is found in the early primordial germ cells (PGCs) of a three weeks old embryo (Jansen and de Boer, 1998), allowing most individuals to start with an entirely homoplasmic "clean" mtDNA (Cummins, 1998; Cummins, 2001). Because this process is taking place early the chance to preserve age-related mutations in the early oocyte is small. Based on our data this system works very well. The bottleneck is calculated to be between 1 and $30 \mathrm{mtDNA}$ molecules (Bendall et al., 1996; Poulton et al., 1998), indicating that a mtDNA mutation leaking through with replication being proportional would lead to a heteroplasmy percentage between $3.5 \%$ and $100 \%$. Two homoplasmic differences were detected between two oocytes of a single woman. A single mtDNA molecule as segregating unit can explain this, although we can not be sure as we could not analyse the maternal mtDNA. It does however indicate that the segregation can happen very fast, as has been shown for Holstein cattle (Koehler et al., 1991) and pathogenic mutations in humans (De Coo et al., 1996; Degoul et al., 1997). Five of our mutations had a heteroplasmy percentage of about $15 \%$ to $50 \%$ and these mutations could have been leaking through the bottleneck or originated very early during oocyte development. At that stage the amount of mitochondria and mtDNA molecules in the oocyte is low, usually only one mtDNA molecule per mitochondrion (Michaels et al., 1982; Chen et al., 1995) and, if a mutation occurs, it affects a higher proportion of the mtDNA molecules. Since none of the mutations was observed in other oocytes of the same woman this indicates that the mutations probably originated early during oocyte development although the number of analyzed oocytes in total and per woman is still rather small. The levels of other mutations were very low (below $5 \%$ ) and are, therefore, thought to have occurred de novo after the bottleneck and the earliest developmental stages of the oocyte and after migration of the primordial germ cells (PGC) to the ovary. If the mutated mtDNA does not specifically increase, then they must have occurred before the embryo reached the fetal stages because by then the number of mitochondria in the 
oocyte is $>1000$ and mutations would not be detected anymore as single heteroplasmic peaks by DHPLC analysis.

Seven oocytes carried one or more point mutations in the mtDNA. Five of these contained only a single heteroplasmic mutation, whereas one oocyte contained two and the last one four heteroplasmic mutations. In case an oocyte carries more than one mutation the levels are generally low and can for this reason be considered as early embryonic, somatic mutations. Because of these small numbers, it is unclear if some oocytes are more susceptible for mutational events than others or that it is just a chance event. Several reasons can be considered for the existence of multiple mtDNA mutations in one oocyte. The first is possible environmental damage by, for example ROS, radiation or chemical substances. Another aspect that could play a role is defects in genes associated with mtDNA replication and repair. Recently it was shown that the mtDNA in mice can be subject to several forms of DNA repair (Larsen et al., 2005). If this is also the case in human cells problems arising in one of these repair mechanisms could also influence the occurrence of mutations in oocytes. It is known from human patients and mice studies that a dysfunctional polymerase gamma leads to deletions and point mutations in the mtDNA (Trifunovic et al., 2004). However, if there were genetic problcms in the mtDNA repair mechanism one would expect to observe this susceptibility in more oocytes from the same woman, although this may be not that obvious as repair may depend on oocyte and embryo quality and this may differ in the same cohort.

From our study it can be concluded that the mtDNA bottleneck is in general an effective mechanism in preserving a homoplasmic state of the mtDNA. However, we observed 14 mutations in 8 oocytes (total 26), 10 of which were present in the coding part of the mtDNA. The distribution of these mutations appears to be random and as four of these mutations have substantial heteroplasmy levels (ranging form 15\% to 50\%), we hypothesize that these mutations, presumably occurring very early during oocyte development, may contribute to de novo mtDNA disease, which is a frequent cause of OXPHOS disease in children (Thorburn, 2004).

\section{References}

Andreu AL, Hanna MG, Reichmann H, Bruno C, Penn AS, Tanji K, Pallotti F, Iwata S, Bonilla E, Lach $B$, et al. (1999) Exercise intolerance due to mutations in the cytochrome $b$ gene of mitochondrial DNA. N Engl J Med 341,1037-1044.

Barritt JA, Brenner CA, Cohen J and Matt DW (1999) Mitochondrial DNA rearrangements in human oocytes and embryos. Mol Hum Reprod 5,927-933.

Bendall KE, Macaulay VA, Baker JR and Sykes BC (1996) Heteroplasmic point mutations in the human mtDNA control region. Am J Hum Genet 59,1276-1287.

Biggin A, Henke R, Bennetts B, Thorburn DR and Christodoulou J (2005) Mutation screening of the mitochondrial genome using denaturing high-performance liquid chromatography. Mol Genet Metab 84,61-74. Brandon MC, Lott MT, Nguyen KC, Spolim S, Navathe SB, Baldi P and Wallace DC (2005) MITOMAP: a human mitochondrial genome database--2004 update. Nucleic Acids Res 33 Database Issue, D61 1-613.

Brenner CA, Wolny YM, Barritt JA, Matt DW, Munne S and Cohen J (1998) Mitochondrial DNA deletion in human oocytes and embryos. Mol Hum Reprod 4,887-892. 
Carew JS and Huang P (2002) Mitochondrial defects in cancer. Mol Cancer 1,9.

Chen X, Prosser R, Simonetti S, Sadlock J, Jagiello G and Schon EA (1995) Rearranged mitochondrial genomes are present in human oocytes. Am J Hum Genet 57,239-247.

Chinnery PF, Brown DT, Andrews RM, Singh-Kler R, Riordan-Eva P, Lindley J, Applegarth DA, Turnbull DM and Howell N (2001) The mitochondrial ND6 gene is a hot spot for mutations that cause Leber's hereditary optic neuropathy. Brain 124,209-218.

Chinnery PF, Howell N, Andrews RM and Turnbull DM (1999) Mitochondrial DNA analysis: polymorphisms and pathogenicity. J Med Genet 36,505-510.

Chinnery PF, Howell N, Lightowlers RN and Turnbull DM (1997) Molecular pathology of MELAS and MERRF. The relationship between mutation load and clinical phenotypes. Brain 120 ( Pt 10),1713-1721.

Chinnery PF and Turnbull DM (2001) Epidemiology and treatment of mitochondrial disorders. Am J Med Genet 106,94-101.

Clayton DA (2000) Transcription and replication of mitochondrial DNA. Hum Reprod I5 Suppl 2,1117.

Conley YP, Brockway H, Beatty M and Kerr ME (2003) Qualitative and quantitative detection of mitochondrial heteroplasmy in cerebrospinal fluid using denaturing high-performance liquid chromatography. Brain Res Brain Res Protoc 12,99-103.

Cormio A, Milella F, Vecchiet J, Felzani G, Gadaleta MN and Cantatore P (2005) Mitochondrial DNA mutations in RRF of healthy subjects of different age. Neurobiol Aging 26,655-664.

Cottrell DA and Turnbull DM (2000) Mitochondria and ageing. Curr Opin Clin Nutr Metab Care 3,473478.

Cummins J (1998) Mitochondrial DNA in mammalian reproduction. Rev Reprod 3,172-182.

Cummins JM (2001) Mitochondria: potential roles in embryogenesis and nucleocytoplasmic transfer. Hum Reprod Update 7,217-228.

De Coo IF, Smeets HJ, Gabreels FJ, Arts N and van Oost BA (1996) Isolated case of mental retardation and ataxia due to a de novo mitochondrial T8993G mutation. Am J Hum Genet 58,636-638.

Degoul F, Francois D, Diry M, Ponsot G, Desguerre I, Heron B, Marsac C and Moutard ML (1997) A near homoplasmic T8993G mtDNA mutation in a patient with atypic Leigh syndrome not present in the mother's tissues. J Inherit Metab Dis 20,49-53.

Fernandez-Silva P, Enriquez JA and Montoya J (2003) Replication and transcription of mammalian mitochondrial DNA. Exp Physiol 88,41-56.

Herrnstadt C, Elson JL, Fahy E, Preston G, Turnbull DM, Anderson C, Ghosh SS, Olefsky JM, Beal MF, Davis RE, et al. (2002) Reduced-median-network analysis of complete mitochondrial DNA coding-region sequences for the major African, Asian, and European haplogroups. Am J Hum Genet 70,1152-1171.

Horai S, Kondo R, Nakagawa-Hattori Y, Hayashi S, Sonoda S and Tajima K (1993) Peopling of the Americas, founded by four major lineages of mitochondrial DNA. Mol Biol Evol 10,23-47.

Howell N, Halvorson S, Kubacka I, McCullough DA, Bindoff LA and Turnbull DM (1992)

Mitochondrial gene segregation in mammals: is the bottleneck always narrow? Hum Genet 90,117-120.

Hsieh RH, Tsai NM, Au HK, Chang SJ, Wei YH and Tzeng CR (2002) Multiple rearrangements of mitochondrial DNA in unfertilized human oocytes. Fertil Steril 77,1012-1017.

Jacobs LJ, de Coo IF, Nijland JG, Galjaard RJ, Los FJ, Schoonderwoerd K, Niermeijer MF, Geraedts JP, Scholte HR and Smeets HJ (2005) Transmission and prenatal diagnosis of the T9176C mitochondrial DNA mutation. Mol Hum Reprod.

Jakupciak JP, Wang W, Markowitz ME, Ally D, Coble M, Srivastava S, Maitra A, Barker PE, Sidransky D and O'Connell CD (2005) Mitochondrial DNA as a cancer biomarker. J Mol Diagn 7,258-267. Jansen RP and de Boer K (1998) The bottleneck: mitochondrial imperatives in oogenesis and ovarian follicular fate. Mol Cell Endocrinol 145,81-88.

Keefe DL, Niven-Fairchild T, Powell S and Buradagunta S (1995) Mitochondrial deoxyribonucleic acid deletions in oocytes and reproductive aging in women. Fertil Steril 64,577-583. 
Koehler CM, Lindberg GL, Brown DR, Beitz DC, Freeman AE, Mayfield JE and Myers AM (1991) Replacement of bovine mitochondrial DNA by a sequence variant within one generation. Genetics 129,247-255.

Kuchino Y, Mori F, Kasai H, Inoue H, Iwai S, Miura K, Ohtsuka E and Nishimura S (1987) Misreading of DNA templates containing 8-hydroxydeoxyguanosine at the modified base and at adjacent residues. Nature 327,77-79.

Larsen NB, Rasmussen M and Rasmussen LJ (2005) Nuclear and mitochondrial DNA repair: similar pathways? Mitochondrion 5,89-108.

Lee HC, Yin PH, Lin JC, Wu CC, Chen CY, Wu CW, Chi CW, Tam TN and Wei YH (2005) Mitochondrial Genome Instability and mtDNA Depletion in Human Cancers. Ann N Y Acad Sci 1042, 109-122.

Licvre A, Chapusot C, Bouvier AM, Zinzindohoue F, Piard F, Roignot P, Arnould L, Beaune P, Faivre $\mathrm{J}$ and Laurent-Puig $\mathrm{P}$ (2005) Clinical value of mitochondrial mutations in colorectal cancer. J Clin Oncol 23,3517-3525.

Liu MR, Pan KF, Li ZF, Wang Y, Deng DJ, Zhang L and Lu YY (2002) Rapid screening mitochondrial DNA mutation by using denaturing high- performance liquid chromatography. World J Gastroenterol 8,426-430.

Lutz S, Weisser HJ, Heizmann J and Pollak S (2000) Mitochondrial heteroplasmy among maternally related individuals. Int J Legal Med 113,155-161.

Maassen JA, Biberoglu S, t Hart LM, Bakker E and de Knijff P (2002) A case of a de novo A3243G mutation in mitochondrial DNA in a patient with diabetes and deafness. Arch Physiol Biochem 110,186-188.

Maitra A, Cohen Y, Gillespie SE, Mambo E, Fukushima N, Hoquc MO, Shah N, Goggins M, Califano J, Sidransky D, et al. (2004) The Human MitoChip: a high-throughput sequencing microarray for mitochondrial mutation detection. Genome Res 14,812-819.

Marzuki S, Noer AS, Lertrit P, Thyagarajan D, Kapsa R, Utthanaphol P and Byrne E (1991) Normal variants of human mitochondrial DNA and translation products: the building of a reference data base. Hum Genet 88,139-145.

Michaels GS, Hauswirth WW and Laipis PJ (1982) Mitochondrial DNA copy number in bovine oocytes and somatic cells. Dev Biol 94,246-251.

Poulton J (1995) Transmission of mtDNA: cracks in the bottleneck. Am J Hum Genet 57,224-226.

Poulton J, Macaulay V and Marchington DR (1998) Mitochondrial genetics '98 is the bottleneck cracked? Am J Hum Genet 62,752-757.

Povalko N, Zakharova E, Rudenskaia G, Akita Y, Hirata K, Toyojiro M and Koga Y (2005) A new sequence variant in mitochondrial DNA associated with high penetrance of Russian Leber hereditary optic neuropathy. Mitochondrion 5,194-199.

Reynier P, Chretien MF, Savagner F, Larcher G, Rohmer V, Barriere P and Malthiery Y (1998) Long PCR analysis of human gamete mtDNA suggests defective mitochondrial maintenance in spermatozoa and supports the bottleneck theory for oocytes. Biochem Biophys Res Commun 252,373-377.

Samuels DC, Boys RJ, Henderson DA and Chinnery PF (2003) A compositional segmentation of the human mitochondrial genome is related to heterogeneities in the guanine mutation rate. Nucleic Acids Res 31,6043-6052.

Tanaka M and Ozawa T (1994) Strand asymmetry in human mitochondrial DNA mutations. Genomics 22,327-335.

Taylor RW, Barron MJ, Borthwick GM, Gospel A, Chinnery PF, Samuels DC, Taylor GA, Plusa SM, Needham SJ, Greaves LC, et al. (2003) Mitochondrial DNA mutations in human colonic crypt stem cells. J Clin Invest $112,1351-1360$ $27,349-362$

Thorburn DR (2004) Mitochondrial disorders: prevalence, myths and advances. J Inherit Metab Dis

Thorburn DR and Dahl HH (2001) Mitochondrial disorders: genetics, counseling, prenatal diagnosis and reproductive options. Am J Med Genet 106,102-114.

Tikhomirov E and Baranov A (2005) MITOMAP mtDNA Sequence Data. 
Trifunovic A, Wredenberg A, Falkenberg M, Spelbrink JN, Rovio AT, Bruder CE, Bohlooly YM, Gidlof S, Oldfors A, Wibom R, et al. (2004) Premature ageing in mice expressing defective mitochondrial DNA polymerase. Nature 429,417-423.

van Den Bosch BJ, de Coo RF, Scholte HR, Nijland JG, van Den Bogaard R, de Visser M, de DieSmulders CE and Smeets HJ (2000) Mutation analysis of the entire mitochondrial genome using denaturing high performance liquid chromatography. Nucleic Acids Res 28,E89.

van Eijsden RG, Gerards M, Eijssen LM, Hendrickx AT, Jongbloed RJ, Wokke JH, Hintzen RQ, Rubio-Gozalbo ME, De Coo IF, Briem E, et al. (2006) Chip-based mtDNA mutation screening enables fast and reliable genetic diagnosis of OXPHOS patients. Genet Med 8,620-627.

Wei YH and Lee HC (2002) Oxidative stress, mitochondrial DNA mutation, and impairment of antioxidant enzymes in aging. Exp Biol Med (Maywood) 227,671-682.

White SL, Collins VR, Wolfe R, Cleary MA, Shanske S, DiMauro S, Dahl HH and Thorburn DR (1999) Genetic counseling and prenatal diagnosis for the mitochondrial DNA mutations at nucleotide 8993. Am $J$ Hum Genet 65,474-482.

Zhou L, Chomyn A, Attardi G and Miller CA (1997) Myoclonic epilepsy and ragged red fibers (MERRF) syndrome: selective vulnerability of CNS neurons does not correlate with the level of mitochondrial tRNAlys mutation in individual neuronal isolates. J Neurosci 17,7746-7753. 
General discussion 
Diseases due to defects of oxidative phosphorylation (OXPHOS), mitochondrial diseases, affect approximately 1 in 8,000 of the general population making them the most common inherited metabolic diseases (Chinnery, 2004). OXPHOS diseases are an important cause of morbidity and mortality and in general OXPHOS disorders cannot be cured. Many treatment modalities have been proposed but efficacy has been limited. Patients can be counselled as guidance for their future and can be informed about the transmission. Clinical monitoring and interventions, such as cardiac pacing, surgical correction of ptosis, cataract surgery and mechanical aids, can prevent known complications of mitochondrial disease. Antioxidants may be beneficial to patients as free radicals produced by the repiratory chain are considered important in pathogenesis of mitochondrial disorders. Coenzyme $Q$ works as an electron transporter and free radical scavenger and has been reported to be beneficial in KSS and MELAS (Dimauro et al., 2004). Standard doses of vitamin C, E, K, riboflavin, thiamine, succinate, nicotinamide have been used to bypass blocks in respiratory chain (Dimauro et al., 2004). A substantial part of OXPHOS disease are due to heteroplasmic defects in the mtDNA, which has the additional problem that clinical expression can be extremely heterogeneous and prognosis unpredictable, partly due to variation in mutation load between tissues. Therapeutic strategies are being developed either directed at replacing the defective gene or at reducing mutation heteroplasmy levels. Furthermore, the transmission of these mutations can be highly unpredictable and common options for the prevention of transmission of inherited disease, like PND or PGD, are not applicable to the majority of mtDNA caused disease. This discussion will concentrate on strategies for treating mtDNA based disease, for example. by modulating the mutation load, and on options to prevent the transmission of the mtDNA caused disease, which were the central themes of this thesis.

\section{Therapeutic approaches of mtDNA mutations}

The increasing number of patients and disorders, in which OXPHOS defects are fundamental and the severity of the clinical symptoms involved stress the need for the development of new therapeutic interventions. A broad variety of strategies are being considered and tested.

\section{Allotopic expression of mtDNA encoded proteins}

A possible strategy to restore the function of a defective mtDNA encoded protein is the allotopic expression of mitochondrial genes by the introduction of a wild-type mitochondrial gene in the nucleus and adding a targeting signal for the introduction of the protein in the mitochondria. This approach was successful in yeast (Law et al., 1988; Law et al., 1990), but replication in mammalian cells turned out to be difficult. Critical factors are the transformation of the mitochondrial genetic code to the nuclear genetic code and the translocation and assembly of mitochondrial proteins translated in the cytosol, fused to an Nterminus targeting signal. Also, the delivery and prolongation of the production of the protein has to be optimised (Oca-Cossio et al., 2003). An alternative is the delivery of a selfreplicating plasmid into the mitochondria in the form of DQAsomes (liposome-like cationic 
vesicles). DQAsomes can bind and transport DNA to the mitochondria to selectively release this DNA in the mitochondria, when the DNA is coupled to a Mitochondrial Leader Sequence (MLS) peptide. Initial data on this technique are successful although it is still unknown if mitochondrial genes delivered to the mitochondria using DQAsomes are expressed in the cells. Alternatively, DNA can be transported in the form of plasmids or oligonucleotides (D'Souza et al., 2005).

\section{Reduction of the mutation load}

An alternative strategy is the reduction of the heteroplasmy level of mtDNA mutations. Heteroplasmy is the key factor in the manifestation of mtDNA caused disease. Even if it is not the only factor involved, it is evident that strategies to reduce the mutation load will be beneficial. Techniques are being developed to prevent the replication of mutated mtDNA. Tanaka and co-workers introduced gene constructs with the mitochondrial targeting sequence and restriction endonuclease activity for the m.8993 $>\mathrm{G}$ mutation (Tanaka et al., 2002). The endonuclease Smal cuts mtDNA moleculcs containing the m.8993T $>\mathrm{G}$ mutation which leads to a selective destruction of the mutated molecules. This strategy has been shown to be effective in cybrids and even in vivo in hamsters, when targeted against cytochrome $\mathrm{c}$ and causing a reduction in cytochrome $c$ activity (Tanaka et al., 2002). This technique is now being explored in heteroplasmic mice and is effective in vivo as well as in cell lincs (BayonaBafaluy et al., 2005). A major disadvantage is that this approach is only applicable to those mutations with new and unique restriction sites. Another option to reduce the heteroplasmy levels in cells is the selective inhibition of the replication of mutated mtDNA molecules. A promising approach is the use of peptide nucleic acid (PNA) oligomers. PNAs are nucleic acid analogues that selectively bind complementary DNA or RNA inhibiting replication and translation. Studies have shown that PNAs can be targeted to the mitochondria. However no reduction of replication has been observed so far (Muratovska et al., 2001; Taylor et al., 2001).

An alternative approach is not directed at the molecules containing the mtDNA mutation, but at specifically inducing the replication of the normal mtDNA molecule (Smith et al., 2004). Segregation studies imply the existence of factors coded by nuclear genes which probably promote the replication of normal mtDNA over mutated mtDNA, but none of these factors has yet been characterised (Dunbar et al., 1995; Jenuth et al., 1997; Battersby et al., 2003). The identification of genetic factors that modify the heteroplasmy levels would be of key importance. Experiments in mice have revealed tissue specific factors that influence the mtDNA type present (Jenuth et al., 1996; Jenuth et al., 1997). Observation on other (Mita et al., 1998; Ozawa et al., 1998; Saitoh et al., 1999; Silvestri et al., 2000; He et al., 2002; Gigarel et al., 2005) and our own patients (chapter 5) also imply that genetic or environmental factors exist in humans that influence the mutant load. The identification of these factors, could provide the basis for a therapeutic strategy for OXPHOS disease caused by mtDNA mutations. This would also be of importance for genetic counselling in case these genetic factors might influence the chance of having affected offspring. 


\section{Prevention of the transmission of mtDNA caused OXPHOS disease}

Several methods have been applied to prevent the transmission of inherited OXPHOS disease. Two of these techniques, PND and PGD have also been developed for OXPHOS disease due to mtDNA mutations. Although this is technically feasible, interpretation remains problematic; this raises ethical issues (chapter 2 and 4). So far PND for mtDNA mutations has been performed several times (Harding et al., 1992; White et al., 1999; Leshinsky-Silver et al., 2003; Chou et al., 2004; Jacobs et al., 2005; Bouchet et al., 2006), with reliable results resulting in ongoing pregnancies with low or no detectable mutation load and in a few cases in pregnancy terminations, because of high mutation loads. Only one case has yet been described where PGD was used to prevent the transmission of the m.8993T $>\mathrm{G}$ mutation (Steffann et al., 2006). As PND or PGD may not be sufficiently reliable for most mtDNA mutations, new approaches need to be developed which can be applied in a more gencral manner.

\section{Strategies under development: cytoplasmic and nuclear transfer}

Techniques like cytoplasmic transfer (CT) and nuclear transfer (NT) are potentially promising to prevent transmission of mtDNA mutations but are still at the developmental stage of technical feasibility. The use of animal models harbouring disease causing mtDNA mutations (Larsson et al., 1998; Inoue et al., 2000; Sligh et al., 2000; Nakada et al., 2001; Biousse et al., 2002) will allow in vivo testing and provide the knowledge to determine the feasibility for the human situation.

\section{Cytoplasmic transfer (CT)}

CT is an adaptation from the ICSI technique ((Cohen et al., 1997; Cohen et al., 1998), where donor cytoplasm is injected into the oocytes. This technique has been tested on women experiencing repeated embryonic development failure, which was thought to be caused by a reduced ATP and mtDNA level in their oocytes (Van Blerkom et al., 1995; Van Blerkom et al., 2001). Although this was not supposed to be due to an mtDNA defect, CT could theoretically be extended to prevent the transmission of mtDNA disease by diluting the mtDNA level to below the critical threshold for disease by the transfer of healthy mtDNA (Kagawa and Hayashi, 1997). From earlier tests it appeared that CT is associated with a relatively high number of chromosomal abnormalities and birth defects (Barritt et al., 2001), It still needs to be experimentally determined whether it is possible to introduce the required, large amount of cytoplasm in the oocyte or to replace a substantial amount of the oocyte's cytoplasm by cytoplasm containing healthy mitochondria. According to experiments in mice, due to restrictions in volume no more than approximately $30 \%$ heteroplasmy could be achieved using CT. This might be insufficient to recondition the oocytes in case of mtDNA mutations (Thorburn and Dahl, 2001). Alternatively, purified mitochondria from oocytes could be used. Experiments on pig oocytes have proven that oocytes can be supplemented with pure populations of mitochondria leading to more reproductive competent cells (El Shourbagy et al., 2006). 


\section{Nuclear Transfer (NT)}

Nuclear transfer (NT) involves the injection of a donor nucleus from an oocyte or early embryonic cell into an enucleated recipient oocyte. This technique is an adaptation from nuclear transfer techniques that are being used for reproductive cloning (Roberts, 1999). Because it is still unclear whether the differentiation process can be fully reversed the use of an undifferentiated nucleus (like the nucleus of an oocyte) would make nuclear transfer more safely applicable. A disadvantage of the use of oocytes as nuclear donors is the lack of a nuclear membrane, which makes the risk of chromosomal loss during transfer significant. This problem could be overcome by the transfer of the clearly visible germinal vesicle but the limited developmental possibility of this premature stage of the oocytes makes this method less feasible. Furthermore problems may occur with respect to the compatibility between recipient oocyte and donor nucleus, the reaction of the nucleus and recipient oocyte as a consequence of the transfer, the disruption of the cytoskeleton because of the transfer and the defects (like placental oedema and respiratory problems) seen in animal offspring after using this technique (Cibelli et al., 2002). Also, the manipulations should not interfere with the fertilization of the oocyte. A better option would be the use of the male and female pronuclei for transfer. These are distinct structures in the fertilised embryo that could be transferred into an enucleated oocyte. This latter technique has been proven useful in reducing the mutant load in mice offspring (Sato et al., 2005). Although in these mice, because of the presence of mutant mtDNA in the karyoplast, the mutant load in offspring was found to be higher than the expected mutant load on basis of the amount of mutated mtDNA in the karyoplast of the nuclear donor cell. This might mean that differences in mtDNA replication efficiency exist and that the karyoplast mtDNA is more frequently replicated. It was also a concern if the nucleus could be freed completely from possibly mutated mitochondria, especially as these perinuclear mitochondria might have a replicative advantage over mitochondria further from the nucleus (Shadel and Clayton, 1997). Recent studies using mouse oocytes demonstrated that karyoplast mitochondria are homogeneously distributed throughout the entire cytoplasm before the oocyte has completed its maturation (Fulka, 2004).

To experimentally validate NT and CT appropriate animal models are needed, but only few natural models exist (for example there is a mouse model with mtDNA caused hearing loss (Johnson et al., 2001)). Over the last decade a number of mouse models have been developed for OXPHOS disease, both for nuclear and mtDNA mutations. Only 2 mouse models with mtDNA mutations exist, the CAP-resistant $\left(\mathrm{CAP}^{\mathrm{R}}\right)$ mouse with the m.2433T $>C$ mutation in the 16SrRNA and the mtDNA deletion mice with a 4.696 bp deletion (Sligh et al., 2000; Wallace, 2001). Disease symptoms were related to human OXPHOS disease, caused by comparable mutations. Both transgenic animal lines demonstrated transmission of the mutated mtDNA to successive generations and can be used to study the inheritance and segregation of pathogenic mtDNA mutations. The $C A P^{R}$ mice transmitted the heteroplasmic mtDNA mutation to some of there progeny in homoplasmic or heteroplasmic state but most animals died either in utero or within the first day after birth, one animal survived 11 days (Sligh et 
$a l ., 2000)$. The mtDNA deletion mice transmitted the rearranged mtDNA through three successive generations with a tendency to increasing heteroplasmy percentage to a maximum of $90 \%$ in muscle of some animals, most likely due to the replication advantage of the smaller mtDNA molecule (Inoue et al., 2000). By using these animal models newly developed techniques to prevent transmission of mtDNA disease can be studied to determine whether they can be successful. An example is the study with respect to the efficiency of NT in these animal models with a deletion in the mtDNA (Sato et al., 2005). The estimated heteroplasmy percentage after transfer was $2 \%$. However after measuring the heteroplasmy percentages in offspring the results were significantly higher then expected (heteroplasmy percentages were $6-21 \%$ ) and heteroplasmy percentages increased with the age of the micc. In the end the heteroplasmy percentages in transplanted mice were much lower than in the non-transplanted controls and no significant symptoms related to the deleted mtDNA were observed in the transplanted mice. So this study shows that these models can be used to study the safety and effect of these innovative treatment options. Furthermore they can be used to compare the efficacy of different technical approaches.

\section{The transmission and segregation of mtDNA mutations in conclusion}

The transmission and segregation of mtDNA mutations are complex and not readily understood or manipulated to treat or prevent the transmission of mtDNA caused disease. Not only the type of mtDNA mutation has an important role, but also the genetic background and most likely lifestyle of the person or family carrying this mutation. These factors influence the distribution pattern among tissues and in time and the transmission of disease to the offspring. This complexity also implies that there are several points were interventions might be possible and effective as a preventive or therapeutic approach. Some of these strategies will be directed at mtDNA replication to reduce the mutation load in cells, others can be used in reproductive options to prevent disease, like the application of PGD or NT to prevent the transmission of the mtDNA mutation. Whatever option is considered, it should be technically safe, ethically evaluated and effective, as it is important to realise that the ultimate goal is still to improve the life of people who are dealing with serious illness whether they experience it themselves or with someone they care for.

\section{References}

Barritt JA, Brenner CA, Malter HE and Cohen J (2001) Mitochondria in human offspring derived from ooplasmic transplantation. Hum Reprod 16,513-516.

Battersby BJ, Loredo-Osti JC and Shoubridge EA (2003) Nuclear genetic control of mitochondrial DNA segregation. Nat Genet 33,183-186.

Bayona-Bafaluy MP, Blits B, Battersby BJ, Shoubridge EA and Moraes CT (2005) Rapid directional shift of mitochondrial DNA heteroplasmy in animal tissues by a mitochondrially targeted restriction endonuclease. Proc Natl Acad Sci U S A 102,14392-14397.

Biousse V, Pardue MT, Wallace DC and Newman NJ (2002) The eyes of mito-mouse: mouse models of mitochondrial disease. J Neuroophthalmol 22,279-285. 
Bouchet C, Steffann J, Corcos J, Monnot S, Paquis V, Rotig A, Lebon S, Levy P, Royer G, Giurgea I, et al. (2006) Prenatal diagnosis of myopathy, encephalopathy, lactic acidosis, and stroke-like syndrome: contribution to understanding mitochondrial DNA segregation during human embryofetal development. J Med Genet 43,788-792.

Chinnery PF (2004) New approaches to the treatment of mitochondrial disorders. Reprod Biomed Online 8,16-23.

Chou YJ, Ou CY, Hsu TY, Liou CW, Lee CF, Tso DJ and Wei YHI (2004) Prenatal diagnosis of a fetus harboring an intermediate load of the A3243G mtDNA mutation in a maternal carrier diagnosed with MELAS syndrome. Prenat Diagn 24,367-370.

Cibelli JB, Campbell KH, Seidel GE, West MD and Lanza RP (2002) The health profile of cloned animals. Nat Biotechnol 20,13-14.

Cohen J, Scott R, Alikani M, Schimmel T, Munne S, Levron J, Wu L, Brenner C, Wamer C and Willadsen S (1998) Ooplasmic transfer in mature human oocytes. Mol Hum Reprod 4,269-280.

Cohen J, Scott R, Schimmel T, Levron J and Willadsen S (1997) Birth of infant after transfer of anucleate donor oocyte cytoplasm into recipient eggs. Lancet 350,186-187.

Dimauro S, Mancuso M and Naini A (2004) Mitochondrial encephalomyopathies: therapeutic approach. Ann N Y Acad Sci 1011,232-245.

D'Souza GG, Boddapati SV and Weissig V (2005) Mitochondrial leader sequence--plasmid DNA conjugates delivered into mammalian cells by DQAsomes co-localize with mitochondria. Mitochondrion 5,352358.

Dunbar DR, Moonie PA, Jacobs HT and Holt IJ (1995) Different cellular backgrounds confer a marked advantage to either mutant or wild-type mitochondrial genomes. Proc Natl Acad Sci U S A 92,6562-6566.

El Shourbagy SH, Spikings EC, Freitas M and St John JC (2006) Mitochondria directly influence fertilisation outcome in the pig. Reproduction 131,233-245.

Fulka H (2004) Distribution of mitochondria in reconstructed mouse oocytes. Reproduction 127,195200.

Gigarel N, Ray PF, Burlet P, Frydman N, Royer G, Lebon S, Bonnefont JP, Frydman R, Munnich A and Steffann J (2005) Single cell quantification of the 8993T>G NARP mitochondrial DNA mutation by fluorescent PCR. Mol Genet Metab 84,289-292.

Harding AE, Holt IJ, Sweeney MG, Brockington M and Davis MB (1992) Prenatal diagnosis of mitochondrial DNA8993 T----G discase. Am J Hum Genet 50,629-633.

He L, Chinnery PF, Durham SE, Blakely EL, Wardell TM, Borthwick GM, Taylor RW and Turnbull DM (2002) Detection and quantification of mitochondrial DNA deletions in individual cells by real-time PCR. Nucleic Acids Res 30,e68.

Inoue $\mathrm{K}$, Nakada K, Ogura A, Isobe K, Goto Y, Nonaka I and Hayashi JI (2000) Generation of mice with mitochondrial dysfunction by introducing mouse mtDNA carrying a deletion into zygotes. Nat Genet 26,176-181.

Jacobs LJ, de Coo IF, Nijland JG, Galjaard RJ, Los FJ, Schoonderwoerd K, Niermeijer MF, Geraedts JP, Scholte HR and Smeets HJ (2005) Transmission and prenatal diagnosis of the T9176C mitochondrial DNA mutation. Mol Hum Reprod.

Jenuth JP, Peterson AC, Fu K and Shoubridge EA (1996) Random genetic drift in the female germline explains the rapid segregation of mammalian mitochondrial DNA. Nat Genet 14,146-151.

Jenuth JP, Peterson AC and Shoubridge EA (1997) Tissue-specific selection for different mtDNA genotypes in heteroplasmic mice. Nat Genet 16,93-95.

Johnson KR, Zheng QY, Bykhovskaya Y, Spirina O and Fischel-Ghodsian N (2001) A nuclearmitochondrial DNA interaction affecting hearing impairment in mice. Nat Genet 27,191-194.

Kagawa Y and Hayashi JI (1997) Gene therapy of mitochondrial diseases using human cytoplasts. Gene Ther 4,6-10. 
Larsson NG, Wang J, Wilhelmsson H, Oldfors A, Rustin P, Lewandoski M, Barsh GS and Clayton DA (1998) Mitochondrial transcription factor $A$ is necessary for mtDNA maintenance and embryogenesis in mice. Nat Genet 18,231-236.

Law RH, Devenish RJ and Nagley P (1990) Assembly of imported subunit 8 into the ATP synthase complex of isolated yeast mitochondria. Eur J Biochem 188,421-429.

Law RH, Farrell LB, Nero D, Devenish RJ and Nagley P (1988) Studies on the import into mitochondria of yeast ATP synthase subunits 8 and 9 encoded by artificial nuclear genes. FEBS Lett 236,501505.

Leshinsky-Silver E, Perach M, Basilevsky E, Hershkovitz E, Yanoov-Sharav M, Lerman-Sagie T and Lev D (2003) Prenatal exclusion of Leigh syndrome due to T8993C mutation in the mitochondrial DNA. Prenat Diagn 23,31-33.

Mita S, Tokunaga M, Uyama E, Kumamoto T, Uekawa K and Uchino M (1998) Single muscle fiber analysis of myoclonus epilepsy with ragged-red fibers. Muscle Nerve 21,490-497.

Muratovska A, Lightowlers RN, Taylor RW, Tumbull DM, Smith RA, Wilce JA, Martin SW and Murphy MP (2001) Targeting peptide nucleic acid (PNA) oligomers to mitochondria within cells by conjugation to lipophilic cations: implications for mitochondrial DNA replication, expression and disease. Nucleic Acids Res $29,1852-1863$.

Nakada K, Inoue K and Hayashi JI (2001) Mito-mice: animal models for mitochondrial DNA-based diseases. Semin Cell Dev Biol 12,459-465.

Oca-Cossio J, Kenyon L, Hao H and Moraes CT (2003) Limitations of allotopic expression of mitochondrial genes in mammalian cells. Genetics 165,707-720.

Ozawa M, Nonaka I and Goto Y (1998) Single muscle fiber analysis in patients with 3243 mutation in mitochondrial DNA: comparison with the phenotype and the proportion of mutant genome. J Neurol Sci $159,170-175$.

Roberts RM (1999) Prevention of human mitochondrial (mtDNA) disease by nucleus transplantation into an enucleated donor oocyte. Am J Med Genet 87,265-266.

Saitoh S, Momoi MY, Yamagata T, Nakauchi H, Nihei K and Fujii M (1999) Single-cell analysis of mitochondrial DNA in patients and a carrier of the tRNA(Leu)(UUR) gene mutation. J Inherit Metab Dis $22,608-614$.

Sato A, Kono T, Nakada K, Ishikawa K, Inoue S, Yonekawa H and Hayashi J (2005) Gene therapy for progeny of mito-mice carrying pathogenic mtDNA by nuclear transplantation. Proc Natl Acad Sci U S A 102,16765-16770.

Shadel GS and Clayton DA (1997) Mitochondrial DNA maintenance in vertebrates. Annu Rev Biochem $66,409-435$.

Silvestri G, Rana M, Odoardi F, Modoni A, Paris E, Papacci M, Tonali P and Servidei S (2000) Singlefiber PCR in MELAS(3243) patients: correlations between intratissue distribution and phenotypic expression of the mtDNA(A3243G) genotype. Am J Med Genet 94,201-206.

Sligh JE, Levy SE, Waymire KG, Allard P, Dillehay DL, Nusinowitz S, Heckenlively JR, MacGregor GR and Wallace DC (2000) Maternal germ-line transmission of mutant mtDNAs from embryonic stem cellderived chimeric mice. Proc Natl Acad Sci U S A 97,14461-14466.

Smith PM, Ross GF, Taylor RW, Turnbull DM and Lightowlers RN (2004) Strategies for treating disorders of the mitochondrial genome. Biochim Biophys Acta 1659,232-239.

Steffann J, Frydman N, Gigarel N, Burlet P, Ray PF, Fanchin R, Feyereisen E, Kerbrat V, Tachdjian G, Bonnefont JP, et al. (2006) Analysis of mtDNA variant segregation during early human embryonic development: a tool for successful NARP preimplantation diagnosis. J Med Genet 43,244-247.

Tanaka M, Borgeld HJ, Zhang J, Muramatsu S, Gong JS, Yoneda M, Maruyama W, Naoi M, Ibi T, Sahashi $\mathrm{K}$, et al. (2002) Gene therapy for mitochondrial disease by delivering restriction endonuclease SmaI into mitochondria. J Biomed Sci 9,534-541.

Taylor RW, Wardell TM, Smith PM, Muratovska A, Murphy MP, Turnbull DM and Lightowlers RN (2001) An antigenomic strategy for treating heteroplasmic mtDNA disorders. Adv Drug Deliv Rev 49,121-125. 
Thorburn DR and Dahl HH (2001) Mitochondrial disorders: genetics, counseling, prenatal diagnosis and reproductive options. Am J Med Genet 106,102-114.

Van Blerkom J, Davis P and Alexander S (2001) A microscopic and biochemical study of fragmentation phenotypes in stage-appropriate human embryos. Hum Reprod 16,719-729.

Van Blerkom J, Davis PW and Lee J (1995) ATP content of human oocytes and developmental potential and outcome after in-vitro fertilization and embryo transfer. Hum Reprod 10,415-424.

Wallace DC (2001) Mouse models for mitochondrial disease. Am J Med Genet 106,71-93.

White SL, Shanske S, Biros I, Warwick L, Dahl HM, Thorburn DR and Di Mauro S (1999) Two cases of prenatal analysis for the pathogenic $T$ to $G$ substitution at nucleotide 8993 in mitochondrial DNA. Prenat Diagn 19,1165-1168. 
Summary

Samenvatting

Dankwoord

Curriculum Vitae

Publications and Abstracts 


\section{Summary}

Mitochondrial encephalomyopathies are disorders associated with abnormalities of the terminal component of mitochondrial energy metabolism, i.e. oxidative phosphorylation (OXPHOS). Recent epidemiological studies have shown that $\sim 1$ in 8000 of the general population have an OXPHOS disorder. OXPHOS related diseases therefore cause significant morbidity and mortality. OXPHOS disease can be due to mutations in mitochondrial DNA (mtDNA) or nuclear DNA genes. The main topic of this thesis is to define the somatic segregation and familial transmission and, as well, the origin of heteroplasmic mutations in the mtDNA. This is related to their clinical expression and possible modifying factors. The aims were:

- to develop reliable tools that can predict and/or prevent the transmission of mtDNA mutations, like prenatal diagnosis or preimplantation genetic diagnosis;

- to identify factors that influence the severity and nature of the phenotypic manifestations or distribution of the mtDNA load, in order to predict the effect of transmission of mtDNA mutations more accurately;

- to determine the presence and impact of de novo mtDNA mutations in oocytes.

These aims have been accomplished by studying patients characteristics coupled to the load of the mtDNA mutations and their transmission as well as by analysing mtDNA mutations in the more unique state of the single cell. For the latter studies mtDNA mutations have been studied in lymphocytes, fibroblasts and oocytes.

Chapter 2 is an introduction to the transmission of OXPHOS disease and methods to prevent this. The expression and segregation of mtDNA mutations is different from nuclear gene defects and the most prominent characteristics of the mtDNA genes and mutations are highlighted. Diseases caused by nuclear gene mutations show a normal Mendelian inheritance pattern and often have more constant clinical manifestations as compared to diseases caused by mtDNA mutations. The heteroplasmic nature of many pathogenic mtDNA mutations is an important feature for disease manifestation, although homoplasmic mutations are known as well. In case of heteroplasmic mtDNA mutations disease usually becomes manifest when the mutation exceeds a tissue-specific threshold. This threshold can vary between tissues and between patients and an exact correlation between mutation load and phenotypic expression is often lacking. The transmission of mtDNA mutations is regarded to be exclusively maternal, although few possible paternal exceptions have been described. The extreme variability in mutation load between siblings, which can already be observed between embryos, is caused by a bottleneck of a limited number of segregating units during early oocyte development. Given the prevalence and severity of OXPHOS diseases and the lack of adequate therapy, existing and new methods for the prevention of transmission of OXPHOS disorders, like prenatal diagnosis (PND), preimplantation genetic diagnosis (PGD), cytoplasmic transfer (CT) and nuclear transfer (NT), are technically and ethically evaluated. 
Chapter 3 gives a detailed comparison of the genetic defects and clinical outcome in 2 patients with Pearson syndrome, an often fatal multisystem disease associated with mitochondrial DNA rearrangements, to identify factors, which might be involved in and can predict the severity of the disorder. These rearrangements, which are most frequently deletions, are most likely the result of loop formations between repeat sequences in the mtDNA during mtDNA replication in the developing oocyte. A comparison is made between the presence of deletion dimers (a combination of two deleted fragments) and duplications (a combination of a normal and a deleted fragment) and the outcome of the disease. It is hypothesized that duplications might have a beneficial effect on disease severity. Because of the often de novo character of rearrangement the transmission risk is much lower than for the mtDNA point mutations.

Chapter 4 describes a family with three affected children with Leigh syndrome, a progressive neurodegenerative disorder. The disease was diagnosed by clinical features, lactic acidosis and a decrease of complex $\mathrm{V}$ activity. Mutation analysis revealed the m.9176T $>\mathrm{C}$ mutation in the mtDNA ATPase 6 gene. Because of the pregnancy of a maternal relative of the proband the possibility of prenatal diagnosis (PND), and for a future pregnancy also preimplantation genetic diagnosis (PGD), was evaluated. The main problem was the lack of data on genotype-phenotype correlations for the m.9176 $>\mathrm{C}$ mutation and on the variation of the mutation percentage in tissues and in time. Additional data were collected from different maternal relatives for different tissues. Eventually, prenatal diagnosis was offered, with understanding by the couple that there could be considerable uncertainty in the interpretation of the results. Prenatal diagnosis was carried out twice on cultured and uncultured chorion villi and amniotic fluid cells to evaluate tissue and time related effects on the mutation percentage. The fetal mutation percentage turned out to be within a grey area, just below the assumed threshold of expression (90\%) and above the arbitrary safe percentage of $60 \%$. The parents decided to continue the pregnancy and a healthy child was born at term after a normal pregnancy. It can be concluded that the challenge for PND in case of mtDNA mutations is not the technique, but the interpretation of the result.

To get a better insight in the distribution of mtDNA mutations among single cells and the potential use for counselling carriers with respect to recurrence risks, the m.9176T $>\mathrm{C}$ mutation at the single cell level was studied (chapter 5). The mutation load was determined in single lymphocytes and fibroblasts of several relatives, patients and carriers from the family with the m.9176 $>\mathrm{C}$ mutation. The results revealed a skewed distribution pattern of the mutation in both lymphocytes and fibroblasts of three carriers with moderate mutation levels, although the pattern seems more deviant in fibroblasts. In contrast the distribution pattern in lymphocytes and fibroblast of the two patients with very high mutation levels $(90 \%)$ is close to a normal Gaussian distribution pattern. In one of the carriers an extremely skewed pattern could be observed in fibroblasts going either to $0 \%$ and $100 \%$ mutation load. Although heteroplasmy is known to migrate to homoplasmy of either the mutation or the wild type by 
cell division, our data show that this differs between cell types and individuals and can occur in oocytes more rapidly than expected. This could imply that (genetic) factors exist that influence the distribution pattern and if the same factors would influence the mutation load in oocytes this may help predicting the recurrence risk. The carrier with the extremely skewed distribution has three children with very high mutation loads and severe disease symptoms, which fits with our hypotheses. More single cell studies in larger families are required to determine the predictive power of distribution patterns in single cells for the mutation load in offspring. The differences in distribution might also reveal yet unknown and possibly genetic mechanisms involved in the segregation of mtDNA mutations, which could open up the possibility to manipulate variations in heteroplasmy levels.

As a large part of patients with OXPHOS defects carry de novo mutations in the mtDNA the load of mutations and polymorphisms in the mitochondrial DNA (mtDNA) of healthy human oocytes, was determined, as these mutations might have originated in the oocyte (chapter 6). Two sensitive and accurate analytical systems to identify these mutations and polymorphisms were used. The mtDNA of 26 oocytes has been screened completely for heteroplasmic mutations using DHPLC analysis. Ten different heteroplasmic mutations, of which one was located in the D-loop and two were observed twice, were detected in seven oocytes with mutation loads ranging from less than $5 \%$ to $50 \%$. Furthermore, the mtDNA (with exception of the D-loop region) of four oocytes of a single woman has been screened using a resequencing CHIP (Affymetrix MitoChip ${ }^{(B)}$ ), but no differences between the four oocytes were detected. It is concluded that heteroplasmic mtDNA mutations are common in oocytes and that depending on the position and mutation load they might increase the risk on developing OXPHOS disease early or later in life.

Finally, in the general discussion (chapter 7) the current strategies to improve the quality of life of patients or to prevent the transmission of mtDNA disease are discussed. Since no cure is known at the moment for mitochondrial diseases, only palliative therapies are applied. A number of therapeutic approaches are under development either to complement the genetic defect (for example by allotopic expression of mtDNA encoded proteins) or to reduce the mutation load of mtDNA mutations (for example by selective inhibition of the replication of mutant mtDNA or the stimulation of replication of normal mtDNA), which potentially can alleviate disease manifestations. Furthermore, possible approaches to prevent the transmission of mtDNA mutations, in case PND and PGD is not reliable, are being discussed. Techniques like nuclear transfer (NT) and cytoplasmic transfer (CT) are under development and are currently tested in animal models. Whatever option is considered, it should be technically safe, ethically evaluated and effective, as it is important to realise that the ultimate goal is still to improve the life of people who are dealing with serious illness whether they experience it themselves or with someone they care for. 


\section{Samenvatting}

Mitochondriële Encephalomyopathieën zijn aandoeningen geassocieerd met deficiënties in het laatste deel van het mitochondriale energiemetabolisme, de zogenaamde oxidatieve fosforylering (OXPHOS). Recent epidemiologisch onderzoek heeft aangetoond dat ongeveer 1 op de 8000 mensen in de algemene populatie een OXPHOS-aandoening heeft. Daarom leiden OXPHOS-gerelateerde aandoeningen tot significante morbiditeit en mortaliteit. OXPHOS- aandoeningen kunnen worden veroorzaakt door mutaties in het mitochondriale DNA (mtDNA) of in nucleaire genen. Het voornaamste thema van dit proefschrift is het onderzoek naar enerzijds de somatische segregatie en familiaire transmissie en anderzijds de oorsprong van heteroplasmische mutaties in het mtDNA. Deze worden onderzocht in relatie tot de klinische expressie en mogelijk modificerende factoren. Onze doelen zijn:

-het ontwikkelen van betrouwbare methodes voor het voorspellen en/of het voorkomen van de transmissie van mtDNA-mutaties, zoals prenatale diagnostiek (PND) en preïmplantatie genetische diagnostiek (PGD);

-het identificeren van factoren die ernst en fenotype of het mtDNA-mutatiepercentage beïnvloeden, om het effect van de overerving van mtDNA mutaties beter te kunnen voorspellen; -het bepalen van de aanwezigheid en impact van de novo mtDNA-mutaties in eicellen.

Deze doelen zijn bereikt door het bestuderen van kenmerkende patiëntgegevens in samenhang met mtDNA-mutatiepercentage en -overerving en door het bestuderen van de mtDNA-mutaties in de meer unieke situatie van de individuele cel. De mtDNA-mutaties bestudeerd in individuele lymfocyten, fibroblasten en eicellen.

In het inleidende hoofdstuk 2 van dit proefschrift wordt ingegaan op de transmissie van OXPHOS-aandoeningen en methoden om overdracht te voorkomen. De expressie en segregatie van mtDNA-mutaties is afwijkend van die van nucleaire gendefecten en de meest karakteristieke kenmerken van de mitochondriale genen en mutaties worden belicht. Aandoeningen veroorzaakt door nucleaire genmutaties vertonen een normaal mendeliaans overervingspatroon en hebben vaak een meer constante klinische manifestatie dan aandoeningen veroorzaakt door mtDNA-mutaties. De heteroplasmische aard van veel pathogene mtDNA mutaties is een belangrijk kenmerk bij de manifestatie van de aandoening, alhoewel homoplasmische aandoeningen ook bestaan. In het geval van heteroplasmische mtDNA-mutaties worden de aandoeningen pas manifest als het mutatiepercentage een bepaalde weefsel specifieke drempelwaarde overschrijdt. Deze drempelwaarde kan variëren tussen weefsels en patiënten en het is daarom vaak niet mogelijk een exacte correlatie tussen het mutatiepercentage en het fenotypisch tot uiting komen van de aandoening te bepalen.

Overerving van mtDNA-mutaties gaat bijna uitsluitend via de moederlijke lijn. Er zijn slechts enkele gevallen beschreven van overerving via de vaderlijke lijn. De (zeer) grote variaties in mutatiepercentage tussen broers en zussen, die al bestaat in de embryonale fase, wordt veroorzaakt door een genetische "flessenhals" (bottleneck) tijdens de vroege 
eicelontwikkeling, waardoor slechts een beperkt aantal segregerende units de uiteindelijke samenstelling van het mtDNA in de eicel bepalen. Vanwege het ontbreken van een adequate therapie voor OXPHOS-aandoeningen wordt technisch en ethisch onderzocht of met bestaande en nieuwe methoden de transmissie van deze aandoeningen kan worden voorkomen. Potentiële benaderingen zijn prenataal onderzoek (PND), preïmplantatie genetische diagnostiek (PGD), cytoplasma transfer (CT) en kern transplantatie (NT).

In hoofdstuk 3 wordt het genetisch defect en de klinische gevolgen hiervan bij twce patiënten met Pearson-syndroom beschreven. Dit is een vaak fataal verlopende multisysteemaandoening die geassocieerd is met mtDNA-herschikkingen (o.a. deleties en duplicaties). Het doel was om factoren te identificeren die mogelijk betrokken zijn bij en de ernst kunnen voorspellen van de klinische manifestatie. Deze herschikkingen, voornamelijk deleties, zijn waarschijnlijk het gevolg van onjuiste paring tussen repeterende DNAsequenties tijdens de mtDNA-replicatie in de zich ontwikkelende eicel. Een vergelijking wordt gemaakt tussen de aanwezigheid van deletiedimeren (een combinatie van twee gedeleteerde fragmenten) en duplicaties (een combinatie van een normaal en een gedeleteerd fragment) en de ernst van de aandoening. Duplicaties lijken een voordelig effect op de ernst van de ziekte te hebben. Door het voornamelijk de novo karakter van herschikkingen is de kans op transmissie vele malen kleiner dan voor mtDNA-puntmutaties.

Hoofdstuk 4 beschrijft een familie met drie kinderen met Leigh-syndroom, een progressieve neurodegeneratieve aandoening. De ziekte is gediagnosticeerd op grond van klinische kenmerken, lactaat acidose en een verlaging in de complex V-activiteit. De m.9176T $>C$ mutatie in het ATPase6 gen van het mtDNA is ontdekt met mutatie-analyse. Omdat een maternaal famielid zwanger was, is de mogelijkheid van prenataal onderzoek, en voor eventuele volgende zwangerschappen preïmplantatie genetische diagnostiek, verder geëvalueerd. Het voornaamste probleem hierbij was het gebrek aan data m.b.t. de genotypefenotype correlatie voor de m.9176 $>\mathrm{C}$ mutatie en de variatie van het mutatie-percentage in verschillend weefsels en in de tijd. Van een aantal maternale familieleden zijn aanvullende gegevens verzameld uit meerdere weefsels. Uiteindelijk is prenataal onderzoek aangeboden waarbij het paar bekend was met de bestaande onzekerheden ten aanzien van de interpretatie van de resultaten. Prenataal onderzoek is twee maal verricht op gekweekte en ongekweekte vlokken en vruchtwatercellen om weefsel- en tijds-gerelateerde effecten op het mutatiepercentage te kunnen evalueren. Het foetale mutatie-percentage was lager dan de mogelijke drempelwaarde van $90 \%$, waarboven Leigh syndroom manifest wordt, maar hoger dan het enigszins arbitrair bepaalde veilige percentage van $60 \%$. De ouders hebben besloten de zwangerschap te continueren en na een normale zwangerschap en zwangerschapstermijn is een gezond kindje geboren. Er kan geconcludeerd worden dat het probleem bij prenataal onderzoek van mtDNA-mutaties niet de techniek is, maar de interpretatie van de resultaten. 
Om een beter inzicht te krijgen in de verdeling van mtDNA-mutaties tussen enkele cellen en het belang hiervan bij de counseling van dragers ten aanzien van het risico van herhaling, is de m.9176T $>\mathrm{C}$ mutatie op het individuele cel-niveau bestudeerd (hoofdstuk 5). Het mutatiepercentage is bepaald in individuele lymfocyten en fibroblasten van verschillende familieleden, patiënten en dragers, met de m.9176T $>C$ mutatie. Onze resultaten tonen een van een normaal afwijkende verdeling in lymfocyten en fibroblasten van drie dragers met een matig mutatieniveau. Het patroon lijkt sterker afwijkend in de fibroblasten. Daarentegen lijkt het verdelingspatroon in lymfocyten en fibroblasten van de twee patiënten met zeer hoge mutatieniveaus $(90 \%)$ erg op een normaal Gaussiaans verdelingspatroon. In één van de dragers wordt een extreem afwijkend patroon gevonden in de fibroblasten, waarbij percentages vooral richting $0 \%$ en $100 \%$ gaan. Alhoewel het bekend is dat heteroplasmie migrcert naar homoplasmie van òf de mutatie òf het wild-type, tijdens celdeling, tonen onze gegevens aan dat dit verschilt tussen celtype en individuen en in eicellen sneller kan gebeuren dan verwacht. Dit zou kunnen betekenen dat er (genetische) factoren bestaan die het verdelingspatroon beïnvloeden, Als dezelfde factoren de mutatiebelasting in eicellen beïnvloeden, kan dit van belang zijn bij het bepalen van het herhalingsrisico. De drager met de extreem afwijkende verdeling heeft drie kinderen met erg hoge mutatic-niveaus en ernstige ziektesymptomen, wat past bij onze hypothese. Mecrdere onderzoeken op het niveau van de individuele cel zijn nodig in grote families om de voorspellende waarde van het verdelingspatroon in individuele cellen voor het mutatieniveau bij nakomelingen te bepalen. De verdelingsverschillen kunnen mogelijk ook nog onbekende, mogelijk genetische, mechanismen onthullen die betrokken zijn bij de segregatie van mtDNA-mutaties. Dit kan ingangen opleveren om het heteroplasmieniveau te beïnvloeden.

Omdat een groot deel van de patiënten met OXPHOS-aandoeningen een de novomutatie in het mtDNA dragen en deze mutaties waarschijnlijk zijn ontstaan in de eicellen, zijn gezonde eicellen onderzocht op de aanwezigheid van heteroplasmische varianten in het mtDNA (hoofdstuk 6). Hiervoor werd gebruik gemaakt van twee gevoelige en nauwkeurige analysemethoden om varianten op te sporen. Het mtDNA van 26 eicellen is volledig gescreend op heteroplasmische varianten m.b.v. DHPLC-analyse. Tien verschillende heteroplasmische varianten, waarvan er één is gelokaliseerd in de D-loop en twee tweemaal zijn gevonden, zijn gedetecteerd in zeven eicellen waarbij het percentage varieerde van minder dan 5\% tot 50\%. Verder is het mtDNA (met uitzondering van de D-loop) van vier eicellen verkregen van één donor gescreend door gebruik te maken van een resequencing CHIP (Affymetrix MitoChip ${ }^{\circledR}$ ), maar er zijn geen verschillen tussen de vier eicellen gedetecteerd. Er kan geconcludeerd worden dat heteroplasmische varianten in het mtDNA gangbaar zijn in eicellen en dat afhankelijk van de locatie in het mtDNA en het percentage dit het risico op een OXPHOS-aandoening in een vroeg of later levensstadium kan verhogen.

Uiteindelijk worden in de algemene discussie (hoofdstuk 7) de huidige strategieën bediscussieerd die worden gebruikt ter verbetering van de levenskwaliteit van patiënten of om 
transmissie van mtDNA-aandoeningen te voorkomen. Omdat momenteel genezing niet mogelijk is bij mitochondriale aandoeningen, worden alleen palliaticve therapieën toegepast. Er zijn een aantal nieuwe therapeutische benaderingen in ontwikkeling die of het genetische defect aanvullen (bijvoorbeeld door de allotopische expressie van mtDNA gecodeerde eiwitten), of de mutatiebelasting van de mtDNA-mutatie verminderen (bijvoorbeeld door de selectieve remming van de replicatie van het gemuteerde mtDNA of de stimulatie van de replicatie van het normaal mtDNA). Deze therapieën kunnen mogelijk op termijn de ziekteverschijnselen verminderen. Verder worden er nog mogelijke benaderingen bediscussieerd, indien PND en PGD niet betrouwbaar kunnen worden uitgevoerd. Technicken zoals kerntransplantatie (NT) en cytoplasma-overdracht (CT), zijn in ontwikkeling en worden momenteel getest op dieren. Welke optie ook in beschouwing wordt genomen, wat belangrijk is, is dat nieuwe methoden met name uit technisch oogpunt veilig zijn, ethisch geëvalueerd en effectief. Het is van groot belang zich te blijven realiseren dat het uitcindelijke doel het verbeteren van de levenskwaliteit van mensen is, die te maken hebben met een ernstige $\mathrm{c}$ aandoening, of ze deze nu zelf dragen of dat deze anwezig is bij iemand voor wie ze zorgen. 


\section{Dankwoord}

Eindelijk is het dan na 9 jaar zover en kan ik het dankwoord schrijven voor mijn proefschrift. Wat cen heerlijk gevoel. Het waren 9 jaren met zo nu en dan bittere tranen, maar vooral ook met veel leuke momenten. Toen ik 9 jaar geleden aan mijn promoticonderzoek begon, was dit met de intentie on voor paren die geen gezonde kinderen konden krijgen of warbij de kans op gezonde kinderen klein was, een mogelijkheid te creëren het geluk van een gezond kind te mogen ervaren. Zelf heb ik dit geluk inmiddels twee keer mogen ervaren. Dit is echt iets overweldigends waar ik dagelijks veel van geniet. Het idee dat wellicht door het onderzoek zoals beschreven in dit proefschrift, ook anderen dit mogen ervaren is erg prettig. Echter onderzoek zoals dit brengt ook kantekeningen met zich mee welke ik via deze weg met jullie wil delen. We moeten ons blijven afvragen hoever we gaan in het onderzoek en er voor zorgen dat het respect voor het menselijk leven hierin niet verloren gaat. Er mag niet nonchalant met het leven worden omgesprongen.

Maar nu mijn echte dankwoord. Ik wil graag beginnen met de mensen die er al die AlO jaren. maar ook de jaren daarvoor, voor me waren in leuke, maar vooral ook in moeilijke tijden. Pap en man jullie hebben me altijd gesteund bij elke beslissing die ik heb genomen en staan altijd voor me klaar. Bij jullie kan ik altijd terecht met elk probleem, maar ook voor een leuke vakantie (lekker drie weken naar Spanje en daar een super tijd hebben), een keertje shoppen (om bij te komen van alle stress) en natuurlijk om heerlijk te eten. Pap wat dat betreft ben je echt een super leraar voor me geweest. Via deze weg wil ik jullie bedanken voor alles wat jullie voor me hebben gedaan. Zonder jullie steun en motivatie zou ik nu nog niet klaar zijn. Ik houd ontzettend veel van jullie en voel dat dit wederzijds is.

Ook wil ik graag mijn zusje bedanken voor de leuke dingen dic we gingen doen als ik er weer even doorheen zat en dat motiveerde me dan weer om door te gaan. Tatjana bedankt voor alle leuke dingen die we samen hebben gedaan. En natuurlijk niet te vergeten Lianne en Connor. Jullie zijn mijn twee schatjes en door jullie is het altijd leuk weer thuis te komen en dan compleet omver geknuffeld te worden. Ook zorgen jullie dat mama zich zo nu en dan even goed kan ontspannen wat ook weer nodig is om het hoofd helder te houden.

Ook mijn familie en vrienden wil ik bedanken voor alle steun en interesse die ze hebben getoond en nog steeds hebben. Marije bedankt voor alle lange telefoongesprekken welke we hebben gehad, waarbij ik dan weer even mijn hart kon luchten.

Verder zijn er natuurlijk nog heel veel meer mensen die ik graag wil bedanken en ik ga er ook vast een parar vergeten. Alvast mijn excuses daarvoor. Graag wil ik Joep bedanken, omdat je altijd tijd voor me makte om even te luisteren als er iets was en voor de adviezen die je me regelmatig hebt gegeven. Bert wil ik bedanken voor alles wat je me in deze periode hebt geleerd. Rene, bedankt dat je altijd tijd makte om mijn stukken na te kijken en ik zal nooit vergeten dat je me, op het eerste congres waar ik helemaal alleen naar toe gekomen was, aan iedereen die je tegenkwam ging voorstellen. 
Ik ben mijn AIO periode gestart na een stage op de IVF afdeling van het AZM. De mensen van deze afdeling wil ik gralag bedanken voor hun steun en interesse gedurende de bele periode. John, Lucie, Marijke, Marij, Chantal, Rosy, Edith en Josien bedankt voor de leuke tijd die ik bij jullie heb gehad. Jos, jij was tijdens mijn stage mijn begeleider, maar ook tijdens mij AIO periode heb ik veel steun aan je gehad en kon ik altijd bij je terecht voor vragen en adviezen. Behalve natuurlijk tijdens de carnavalsperiode, want dan had je een betere tijdsbesteding. Marion, je hebt stapels cellen voor me verzameld en geanalyseerd, maar dat niet alleen, ik kon ook bij je blijven slapen als ik een keertje lekker met de groep mee op stap wilde gaan. Ook bij jou kon ik altijd terecht met vragen en problemen, bedankt voor de fijne tijd.

$\mathrm{Na}$ die stagetijd ben ik begonnen als AIO. Toen ik begon was ik helemaal alleen, dus ik was erg blij dat jij erbij kwam Katinka. Daarna is de groep flink uitgebreid met meerdere AIO's en analisten. Mijn mede AIO's wil ik bedanken voor alle steun en het plezier dat we samen hebben gehad. Bianca het was erg gezellig om samen naar Rolduc te gaan met een extra dikke pyjama cn warme sokken, want we waren zo bang dat het er heel koud zou zijn. We hebben daar heel wat gelachen. Lars we hebben wat geMSN'd en heel wat spelletjes tetrisc gespeeld en dat terwijl we nog geen twee meter van clkaar afzaten. Rudy je was altijd te vinden voor een geintje, maar was er ook als ik ergens hulp voor nodig had. Zonder jou had ik heel wat minder mooie plaatjes in mijn artikelen gehad.

Ook de overige leden van de afdeling populatie genetica, waar ik ook mijn plekje had, wil ik bedanken voor alle leuke momenten die ik daar en tijdens uitstapjes heb gehad: Miranda en Blanche (jullic waren echt fijne studenten en ik vond het erg leuk jullie begelcider te zijn). Roselie, Torik, Aimee, Rosy (bij jou kon ik altijd terecht als ik even een dipje had en mijn verhaal kwijt wilde), Saskia, Ton, Ellen, Mike (super zoals je PCR's en Arrays voor me hebt gedaan en zoals je ons bent komen halen nadat we verdwaald waren met de GPS tocht), Frank, Patrick, Erika, Rob (bedankt voor alle sequentics die je voor me hebt gedraaid). Ook de mensen van de afdeling klinische genetica (DNA diagnostiek), waar ik eigenlijk toe behoorde wil ik hier bedanken; Lars, Dimitri en Demis bedankt voor alle jullie hulp net de DHPLC. Zonder die hulp had het allemaal nog langer geduurd. Crool, Patricia, Diane, Wil, Judith, Jeroen, Alexandra, Sabine, Rien, Kees, JosH en Arthur ook jullic bedankt.

Ook mijn huidige collega's in Breda zou ik willen bedanken. Ik vond het erg leuk om bij jullie te komen werken en doe dat nog steeds met heel veel plezicr. Jan en George heel erg bedankt voor jullie respect en vertrouwen. Mijn directe collega's Marcel, Jean-Paul, Rachel, Ole, Robert en Francisca bedankt voor de interesse en de leuke tijd, die hopelijk nog een tijdje mag duren. Ook de mensen op het lab heel erg bedankt, Theo ik vond het erg fijn dat ik bij je terecht kon toen ik net daar kwam werken en nu nog met alle vragen die ik heb. Bonny en Wendy, de gesprekken met jullie zijn erg prettig en zorgen zeker voor een beetje ontspanning. Abdel heel erg bedankt voor alle leuke gesprekken en dat je ondanks het onderwerp me toch 
probeerde te motiveren om door te gaan. Ook alle andere collega's bedankt voor alle leuke gesprekken en motiverende woorden.

Verder wil ik graag mijn beide paranimfen bedanken, maar ecrst jullie vrouwen. Angelique en Maud bedankt voor jullie interesse en steun en natuurlijk ook heel fijn dat ik jullie mannen een dagje mag lenen. Cristian je bent er altijd voor me geweest vanaf het moment dat ik ben geboren. Toen we klein waren was het goed als we samen waren (Tan en Jen bij elkaar), maar ook nu nog sta je voor me klaar als het nodig is en kan ik altijd op je steun en goede raad rekenen. Ik ben heel erg blij dat je op deze belangrijke dag achter me staat. Robert, ik heb je het afgelopen jaar steeds beter leren kennen. Je hebt me in dat jaar constant gesteund en was er voor me op de moeilijke momenten. Het is mede aan jouw motivatie te danken dat ik door ben gegaan met schrijven op de momenten dat ik het echt niet meer zag zitten. Ik vind het echt super dat je op deze belangrijke dag achter me wilt staan ook al sta je niet volledig achter het onderwerp. Jongens ik houd van jullie!!. 


\section{Curriculum Vitae}

Lorraine Johanna Arnolda Maria Jacobs werd geboren op 26 mei 1975 te Bakel alwaar ze ook is opgegroeid en de lagere school heeft bezocht. Van 1987 to 1993 doorliep zij het voortgezet wetenschappelijk onderwijs (VWO) aan het Dr. Knippenberg college te Helmond. Alvorens aan haar opleiding Gezonheidswetenschappen aan de Universiteit van Maastricht te beginnen, heeft zij een jaar geneeskunde gestudeert aan de Universiteit van Antwerpen. Tijdens haar opleiding Gezondheidswetenscahppen groeide de interesse in de genetica en heeft zij gekozen voor de afstudeer richting van de Biologische Gezondheidkunde welke in 1998 is afgerond met een genetische stage op een combinatie van de afdelingen Klinische Genetica en IVF van het academisch ziekenhuis van Maastricht. Aangezien het onderzoek haar erg goed beviel is zij na het behalen van haar doctoraal examen begonnen als assistent in opleiding (AIO) op de afdeling Genetica en Celbiologie, aan de faculteit der Genecskunde van de Unversiteit Maastricht. Het doel van haar onderzoek was Ontwikkeling van Pre-implantatie diagnostiek voor neuromusculaire aandoeningen veroorzaakt door mutaties in het mitochondriaal DNA. Gedurende deze periode als AIO heeft zij verschillende cursussen en trainingen gevolgd en certificaten behaald. Sinds 1 Februari 2006 is zij werkzaam als Study director voor Eurofins Medinet B.V.. 


\title{
Publications
}

Dreesen JC, Jacobs LJ, Bras M, Herbergs J, Dumoulin JC, Geraedts JP, Evers JL, Smeets HJ. Multiplex PCR of polymorphic markers flanking the CFTR gene; a general approach for preimplantation genetic diagnosis of cystic fibrosis. Mol Hum Reprod. 2000 May;6(5):391-6.

L. J. A. M. Jacobs, R. Jongbloed, F. Wijburg, J. Nijland, I. F. M. de Coo, H. J. M. Smeets. Pearson syndrome and the role of deletion dimers and duplications in the mtDNA. J. Inherit. Metab. Dis. 27 (2004) 47-55.

L.J.A.M. Jacobs, et al. Prenatal Transmission and prenatal diagnosis of the T9176C mitochondrial DNA mutation. Mol Hum Reprod. 2005 Mar;11(3):223-228.

LJAM Jacobs, G de Wert, JPM Geraedts, IFM de Coo, HJM Smeets. The transmission of OXPHOS disease and methods to prevent this (review). Hum Reprod Update. 2006 MarApr;12(2):119-36.

LJAM Jacobs, M Drusedau, IFM de Coo, P.J. Lindsey, HJM Smeets. Skewed heteroplasmy levels in single fibroblasts and lymphocytes of carriers of the Leigh syndrome m.9176T $>\mathrm{C}$ mutation. In prepcration

L.J.A.M. Jacobs, et al. mtDNA point mutations are present at various levels of heteroplasmy in human oocytes. Mol Hum Reprod. 2007 Mar;13(3):149-54.

\author{
Abstracts \\ Euromit 41999 \\ Mutation analysis of the entire mitochondrial DNA using Denaturing High Performance \\ Liquid Chromatography (DHPLC). L.J.A.M. Jacobs, B.J.C. van den Bosch, J.G. Nijland, \\ I.F.M. de Coo, H.R. Scholte, J.P.M. Geraedts, H.J.M. Smeets. (poster presentation) \\ NAV 2000 \\ Prenatal and Preimplantation Genetic Diagnosis (PGD) for carriers of mitochondrial DNA \\ (mtDNA) mutations. L.J.A.M. Jacobs, J.G. Nijland, I.F.M. de Coo, H.R. Scholte, J.P.M. \\ Geraedts, H.J.M. Smeets. (poster presentation).
}

Euromit 52001

Heteroplasmic and homoplasmic variants in the mtDNA of oocytes. Jacobs L.J.A.M., Bosch van den B.J.C., Nijland J.G., Dumoulin J.C.M., Smeets H.J.M. (poster presentation). 
Rolduc 2001

Detection of mtDNA variants in oocytes using DHPLC and the development of PGD protocols to prevent the transmission of pathogenic mtDNA mutations. Jacobs L.J.A.M., Bosch van den B.J.C., Nijland J.G., Dumoulin J.C.M., Galjaard R.J.H., Scholte H.R., Busch H.F.M., De Die C.E.M., De Coo I.F.M., Geraedts J.P.M., Smeets H.J.M. (oral presentation).

Miteuro plenary meeting 2003

How to prevent transmission of mtDNA mutations? L.J.A.M. Jacobs, J.G. Nijland, I.F.M. de Coo, H.R. Scholte, J.P.M. Geraedts, H.J.M. Smeets. (poster presentation). 